Aus der Klinik für Gastroenterologie und Gastrointestinale Onkologie

(Prof. Dr. med. V. Ellenrieder)

der Medizinischen Fakultät der Universität Göttingen

\title{
Evaluation von Ramucirumab und FOLFIRI bezüglich Wirksamkeit und Sicherheit in der palliativen Therapie des Magenkarzinoms
}

\author{
INAUGURAL-DISSERTATION \\ zur Erlangung des Doktorgrades \\ der Medizinischen Fakultät der \\ Georg-August-Universität zu Göttingen
}

vorgelegt von

Anna Katharina Grünewald

aus

Aachen

Göttingen 2020 
Dekan:

Betreuungsausschuss

Betreuer:

Ko-Betreuer:

Prüfungskommission

Referent:

Ko-Referent/in:

Drittreferent/in:

Datum der mündlichen Prüfung:
Prof. Dr. med. W. Brück

PD Dr. med. A. König

Prof. Dr. med. J. Gaedcke

PD Dr. med. A. König

Prof. Dr. med. J. Gaedcke

Prof. Dr. med. G. Wulf

30. November 2021 
Hiermit erkläre ich, die Dissertation mit dem Titel „Evaluation von Ramucirumab und FOLFIRI bezüglich Wirksamkeit und Sicherheit in der palliativen Therapie des Magenkarzinoms" eigenständig angefertigt und keine anderen als die von mir angegebenen Quellen und Hilfsmittel verwendet zu haben.

Göttingen, den 


\section{Inhaltsverzeichnis}

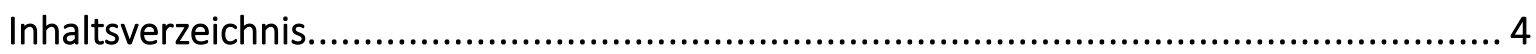

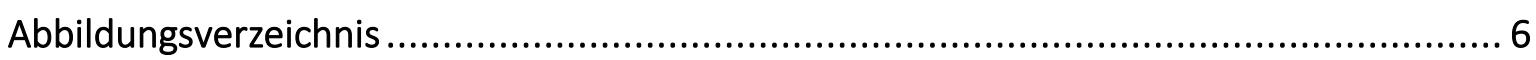

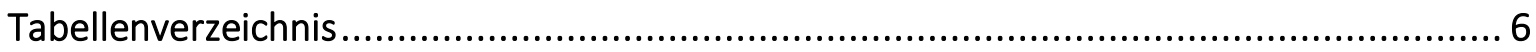

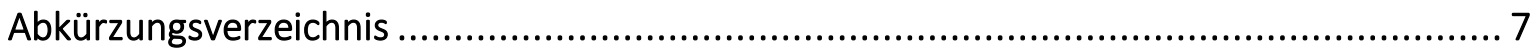

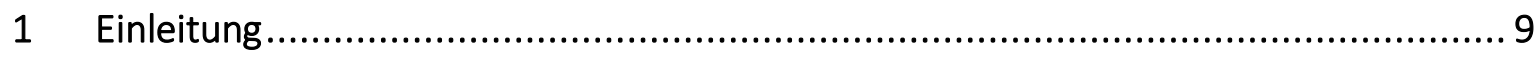

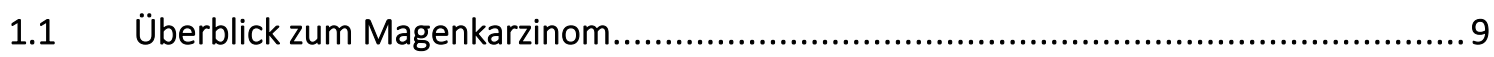

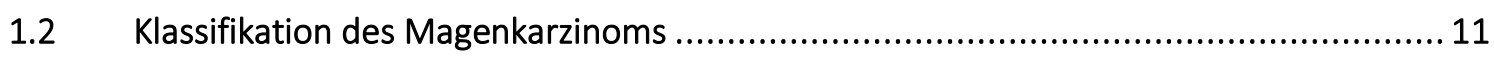

1.3 Kurative und palliative Behandlungsansätze..................................................... 12

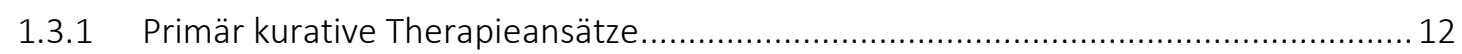

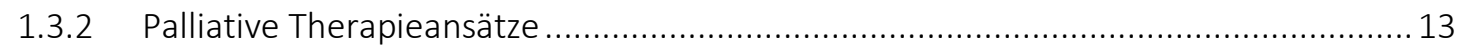

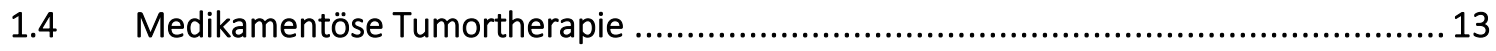

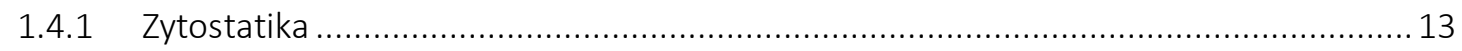

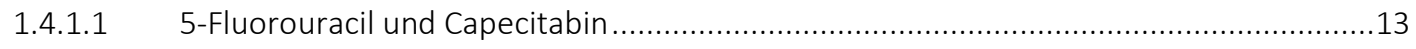

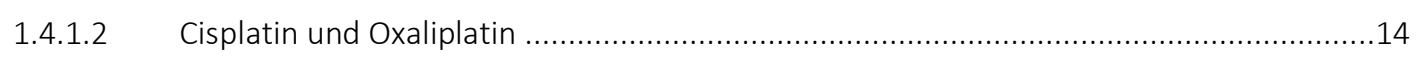

1.4.1.3 Docetaxel und Paclitaxel ...................................................................................................

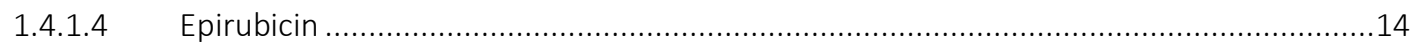

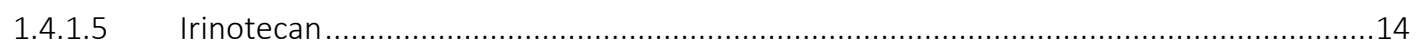

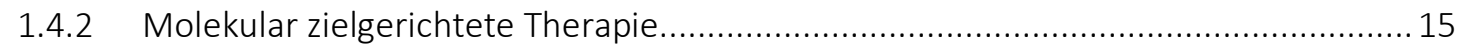

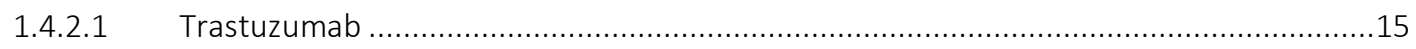

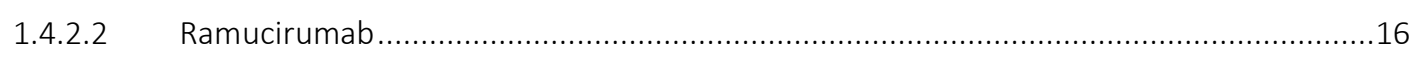

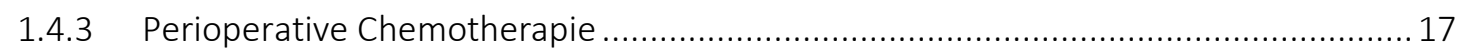

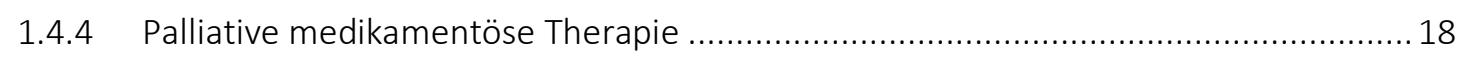

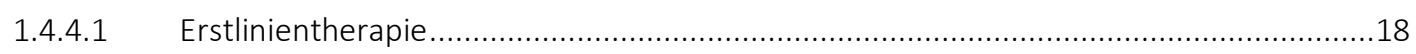

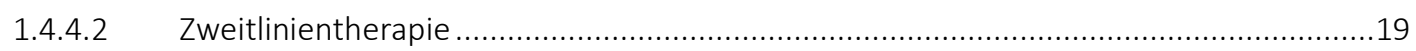

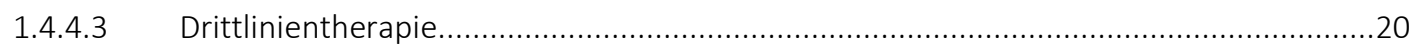

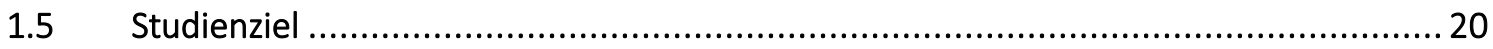

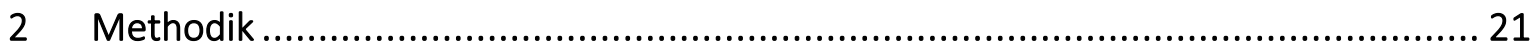

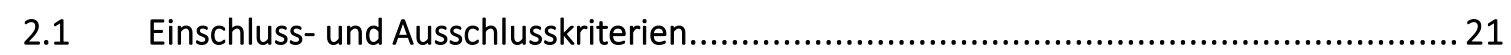

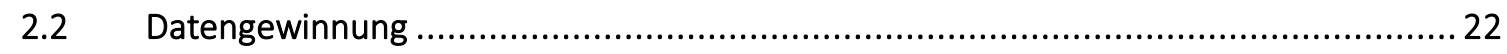

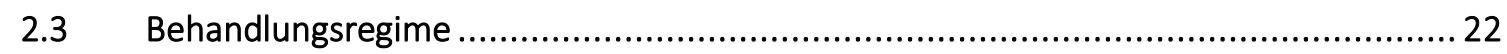

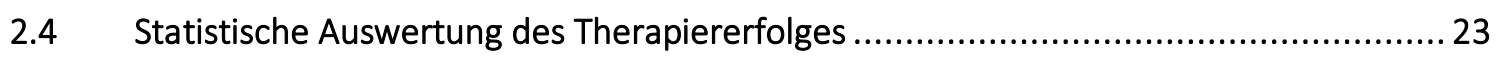

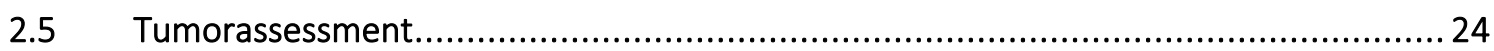




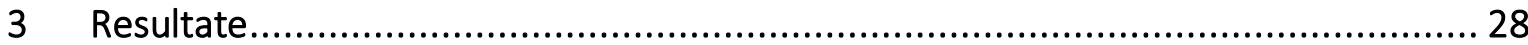

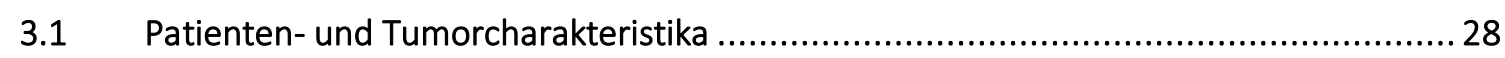

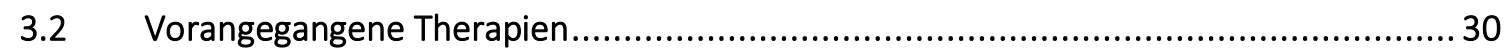

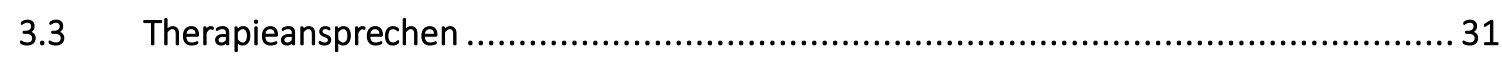

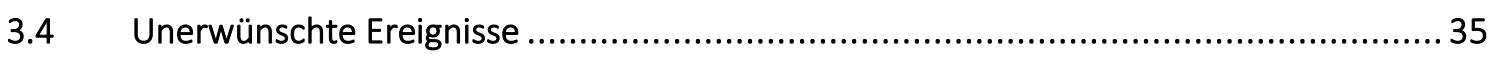

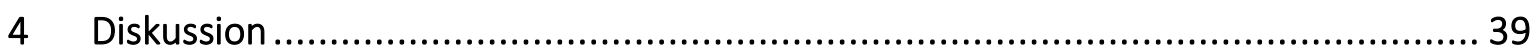

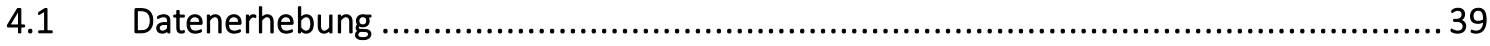

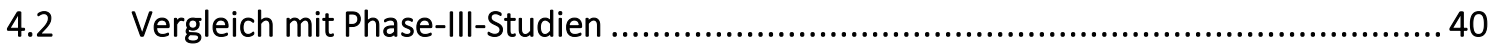

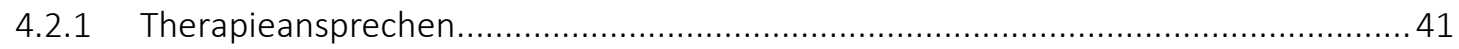

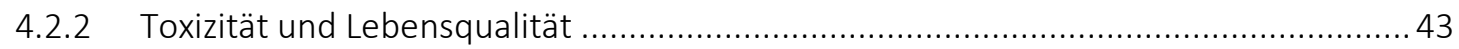

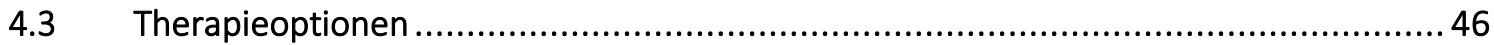

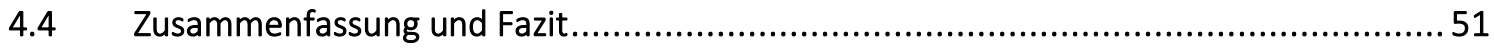

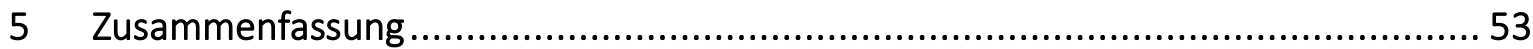

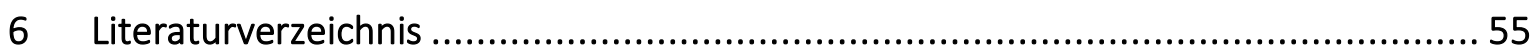




\section{Abbildungsverzeichnis}

Abbildung 1: Algorithmus zur Primärtherapie in Abhängigkeit des Tumorstadiums 12

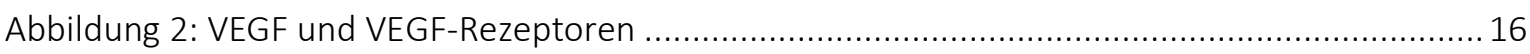

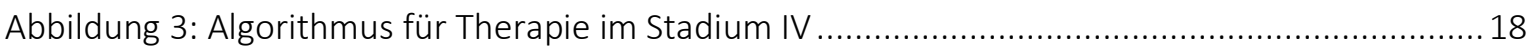

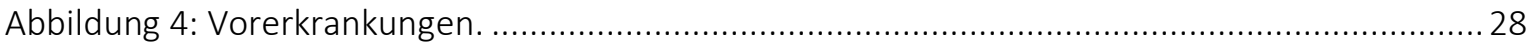

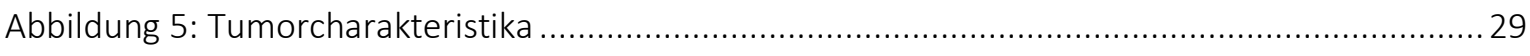

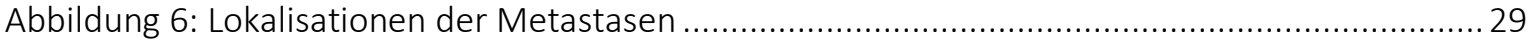

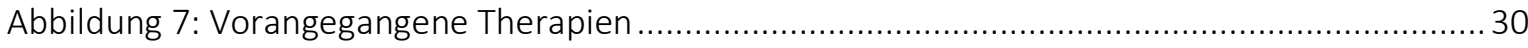

Abbildung 8: Diagnose bis Therapie und Therapiedauer in Monaten............................................. 31

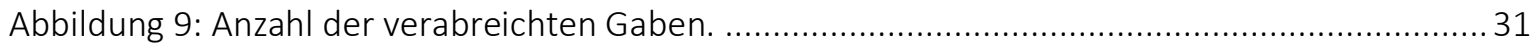

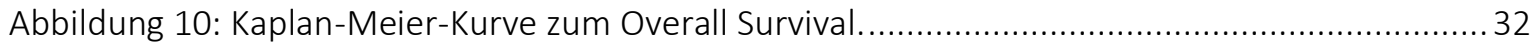

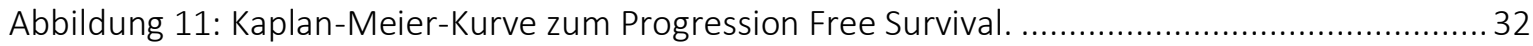

Abbildung 12: Therapieansprechen nach drei Monaten bei Nachweis von Siegelringzellen ............. 33

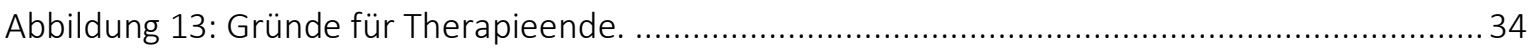

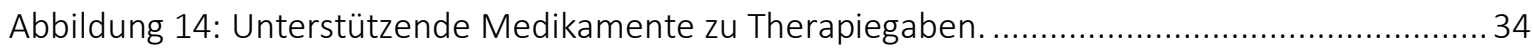

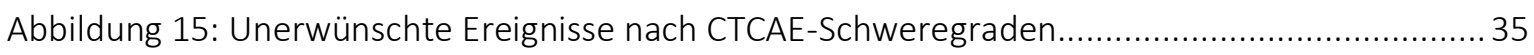

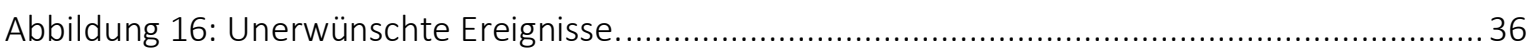

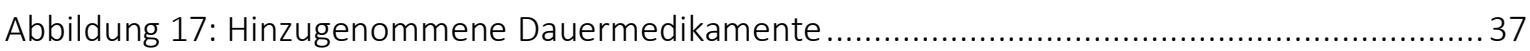

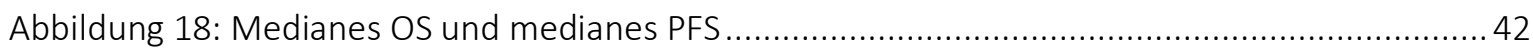

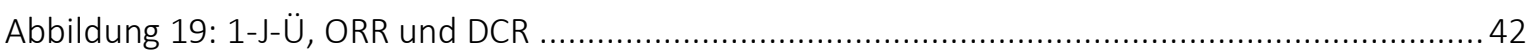

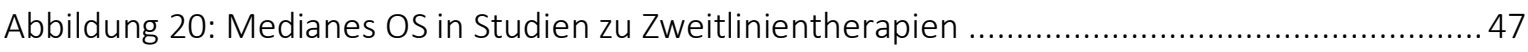

\section{Tabellenverzeichnis}

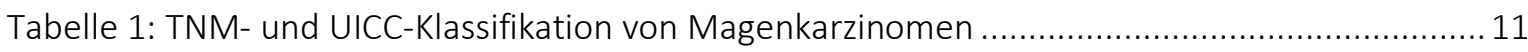

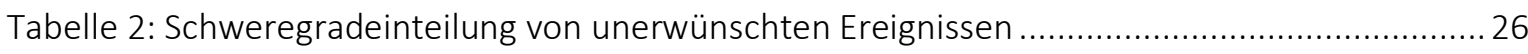

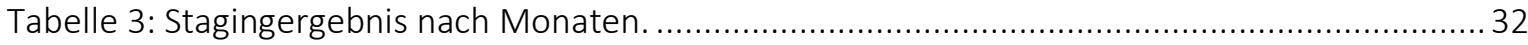




\section{Abkürzungsverzeichnis}

\begin{tabular}{|c|c|}
\hline $5-\mathrm{FU}$ & Fluorouracil \\
\hline 5-HT3 & Serotoninrezeptor Subtyp \\
\hline AEG & Adenokarzinome des ösophagogastralen Überganges \\
\hline AP & Alkalische Phosphatase \\
\hline AST & Aspartate Aminotransaminase \\
\hline ATL & Aufgaben des täglichen Lebens \\
\hline BSC & Best Supportive Care \\
\hline CR & Complete Remission \\
\hline CT & Computertomographie \\
\hline CTCAE & Common Terminology Criteria for Adverse Events \\
\hline CTLA-4 & Cytotoxic T-Lymphocyte-Associated Protein 4 \\
\hline DCF & Docetaxel, Cisplatin, Fluorouracil \\
\hline DCR & Disease Control Rate \\
\hline ECF & Epirubicin, Cisplatin, Fluorouracil \\
\hline ECOG & Eastern Cooperative Oncology Group \\
\hline ECX & Epirubicin, Cisplatin, Capecitabin \\
\hline$E G F(R)$ & Epidermal Growth Factor (Receptor) \\
\hline EOX & Epirubicin, Oxaliplatin, Capecitabin \\
\hline EudraCT & European Union Drug Regulating Authorities Clinical Trials \\
\hline$F G F(R)$ & Fibroblast Growth Factor (Receptor) \\
\hline $\mathrm{FISH}$ & Fluorescence In Situ Hybridization \\
\hline $\mathrm{FLO}(\mathrm{T})$ & Fluorouracil, Folsäure, Oxaliplatin (Docetaxel) \\
\hline FOLFIRI & Fluorouracil, Folsäure, Irinotecan \\
\hline FOLFOX & Fluorouracil, Folsäure, Oxaliplatin \\
\hline HER2 & Human Epidermal Growth Factor Receptor 2 \\
\hline $\mathrm{IHC}$ & Immunohistochemistry \\
\hline i. v. & intravenös \\
\hline n. a. & not available \\
\hline NW & Normwert \\
\hline ORR & Objective Response Rate \\
\hline OS & Overall Survival \\
\hline PD & Progessive Disease \\
\hline PD-1 & Programmed Cell Death Protein 1 \\
\hline PD-L1 & Programmed Death-Ligand 1 \\
\hline
\end{tabular}


PFS

PR

RECIST

$\mathrm{RR}$

SD

TDM-1

USA

VEGF(R)

yGT
Progression Free Survival

Partial Response

Response Evaluation Criteria in Solid Tumors

Blutdruck nach der Riva-Rocci-Methode

Stable Disease

Trastuzumab Emtansin

United States of America

Vascular Endothelial Growth Factor (Receptor)

Gamma-Glutamyl Transferase 


\section{Einleitung}

\section{1 Überblick zum Magenkarzinom}

Das Magenkarzinom ist weltweit die fünfthäufigste maligne Neoplasie und die dritthäufigste krebsbedingte Todesursache. Die Inzidenz und Mortalität des Magenkarzinoms variieren stark innerhalb der ethnischen Gruppen und in verschiedenen Teilen der Welt, mit der größten Fallzahl in Ostasien (Torre et al. 2015). Während die Häufigkeit von Magenkarzinomen im Gesamten zurückgegangen ist, nimmt die Häufigkeit von Adenokarzinomen des ösophagogastralen Überganges zu (Pennathur et al. 2013). In Deutschland ist das Magenkarzinom die fünfthäufigste krebsbedingte Todesursache bei Männern und die sechsthäufigste Ursache bei Frauen. Mit einer Fünf-JahresÜberlebensrate von nur 33 Prozent (männlich) und 31 Prozent (weiblich) bleibt die Prognose von Magenkarzinomen schlecht und ist Gegenstand umfangreicher Forschung, insbesondere zu Therapieoptionen (Robert Koch-Institut 2017). Das Magenkarzinom ist definiert als jede maligne Neoplasie, die aus einem Bereich zwischen dem ösophagogastralen Übergang und dem Pylorus stammt. Je nach Herkunftsgewebe können die Tumore aufgrund ihrer histologischen Eigenschaften als Adeno-, Adenosquamus-, Plattenepithel- und undifferenzierte Karzinome klassifiziert werden. Das Siegelringzellkarzinom ist ein Subtyp des Adenokarzinoms des Magens. Das Klassifikationssystem von Laurén unterscheidet zwischen einer intestinalen und einer diffusen Form des Magenkrebses, welche zwei unterschiedliche klinische und epidemiologische Entitäten bilden (Laurén 1965). Während der gut differenzierte intestinale Typ drüsenähnliche tubuläre Formationen bildet, die kohäsive neoplastische Zellen enthalten, infiltriert der wenig differenzierte diffuse Typ typischerweise die Magenwand multifokal und bildet häufig keine klar begrenzte Tumorformation. Der intestinale Typ weist meinst eine bessere Prognose auf und tritt vor allem in höherem Lebensalter und bei Männern auf, während der diffuse Typ häufiger bei jüngeren Menschen und Frauen ist (Corso et al. 2012). Magenatrophie und intestinale Metaplasie bilden präkanzeröse Läsionen, die durch Helicobacter-pylori-Infektionen und andere Umweltfaktoren wie Ernährung und Fettleibigkeit begünstigt werden. Der diffuse Typ wird seltener von einer intestinalen Metaplasie begleitet, sondern zeigt eine erbliche Komponente und ist häufig mit einer genetischen Disposition assoziiert. Karzinome mit sowohl intestinalen als auch diffusen 
Komponenten wurden ebenfalls identifiziert und gelten als gemischte Typen. Eine Reihe von endogenen und exogenen Faktoren wie beispielsweise eine Helicobacter-pyloriInfektion, ein Ulcus ventriculi, eine nitrat- sowie salzreiche Diät, Alkoholismus, genetische Faktoren und sozioökonomischer Status wurden als risikosteigernde Faktoren in der Entstehung von Magenkarzinomen identifiziert (Nagini 2012).

Adenokarzinome des ösophagogastralen Überganges (AEG-Karzinome) werden nach Siewert in Abhängigkeit vom Abstand zwischen Tumorzentrum und Z-Linie klassifiziert (Spechler 2013). An der Z-Linie zeigt sich ein histologischer Epithelübergang vom ösophagealen Plattenepithel zum gastralen Zylinderepithel. Siewert-Typ-I-Tumore manifestieren sich oral der Z-Linie, Typ-II- und III-Tumore aboral des Epithelüberganges. AEG-Karzinome sind mit einer Reihe von anderen Risikofaktoren assoziiert, unter anderem mit dem Barrett-Ösophagus. Hierunter versteht man metaplastische Veränderungen aufgrund der chronischen gastroösophagealen Reflux-Krankheit, eine Erkrankung prädominant bei adipösen Patienten. Im Folgenden werden unter dem Begriff Magenkarzinom sowohl Karzinome des Magens als auch Adenokarzinome des ösophagogastralen Überganges zusammengefasst.

Die Heterogenität der Magenkarzinome zeigt sich auch in der variablen molekularen Pathogenese. Die Überexpression des humanen epidermalen Wachstumsfaktorrezeptors-2 (HER2) ist häufiger beim proximalen Magenkarzinom, ähnlich die vermehrte Expression des epidermalen Wachstumsfaktorrezeptors (EGFR) und die c-Met-Amplifikation (Schulte et al. 2015). Distale nicht-diffuse Tumore sind häufig mit einer chronischen Helicobacterpylori-Infektion verbunden. Dieser Subtyp exprimiert vermehrt den vaskulären endothelialen Wachstumsfaktor (VEGF). Weitere molekulare Aberrationen, einschließlich des fibroblastischen Wachstumsfaktorrezeptor-2(FGFR2)-Signalwegs und des Phosphoinositid3-Kinase-Akt-Säugetierziels von Rapamycin (PI3K/Akt/mTOR), wurden beschrieben (Schulte et al. 2015). Diese multiplen molekularen Veränderungen können als potenzielle Ziele für spezifische biomolekulare Behandlungen angesehen werden. In neuen Studien wird daher das Magenkarzinom in vier molekulare Subtypen nach Untersuchung von Genom, Transkriptom, Epigenom und Proteom eingeteilt (The Cancer Genome Atlas Research Network 2014). Die Unterteilung in chromosomal instabil, Epstein-Barr-Virus-assoziiert, Mikrosatelliten-instabil und genomisch stabil führte zur Entwicklung neuer klinischer 
Studien zur Untersuchung von spezifischen zielgerichteten Therapien für Patienten mit Magenkarzinomen der verschiedenen molekularen Subgruppen.

\subsection{Klassifikation des Magenkarzinoms}

Die Stadieneinteilung erfolgt unter Berücksichtigung der Ausdehnung des Primärtumors und der Metastasierung basierend auf den UICC-TNM-Kriterien (Tabelle 1). In Europa wird seit Beginn des Jahres 2017 die 8. Edition verwendet (Brierley et al. 2017).

Tabelle 1: TNM- und UICC-Klassifikation von Magenkarzinomen. Basierend auf (Brierley et al. 2017).

$\begin{array}{ll}\text { TNM- } & \text { Tumor } \\ \text { Klassifikation } & \\ \text { T } & \text { Primärtumor } \\ \text { Tis } & \begin{array}{l}\text { Carcinoma in situ: Intraepithelialer Tumor } \\ \text { ohne Invasion der Lamina propria }\end{array} \\ \text { T1 } & \text { Oberflächlich infiltrierender Tumor } \\ \text { T1a } & \text { Tumor infiltriert Lamina propria oder Muscularis } \\ & \text { Mucosae } \\ \text { T1b } & \text { Tumor infiltriert Submucosa } \\ \text { T2 } & \text { Tumor infiltriert Muscularis propria } \\ \text { T3 } & \text { Tumor infiltriert Subserosa } \\ & \text { ohne Invasion des viszeralen Peritoneums } \\ \text { T4a } & \text { Tumor perforiert Subserosa (viszerales } \\ \text { T4b } & \text { Peritoneum) } \\ \text { N } & \text { Tumor infiltriert benachbarte Strukturen } \\ \text { N0 } & \text { Regionale Lymphknoten } \\ \text { N1 } & \text { Keine regionalen Lymphknotenmetastasen } \\ \text { N2 } & \text { Metastase in 1 - 2 Lymphknoten } \\ \text { N3a } & \text { Metastasen in 3 - 6 Lymphnoten } \\ \text { N3b } & \text { Metastasen in 7 - 15 Lymphknoten } \\ \text { M } & \text { Metastasen in 16 oder mehr Lymphknoten } \\ \text { M0 } & \text { Fernmetastasen } \\ \text { M1 } & \text { Keine Fernmetastasen } \\ & \text { Fernmetastasen oder positive peritoneale } \\ & \text { Zytologie } \\ \end{array}$

\begin{tabular}{|c|c|c|c|}
\hline UICC-Stadium & Primärtumor & Lymphknoten & Fernmetastasen \\
\hline 0 & Tis & NO & MO \\
\hline \multirow[t]{2}{*}{ IA } & T1a & NO & MO \\
\hline & $\mathrm{T} 1 \mathrm{~b}$ & NO & MO \\
\hline \multirow[t]{2}{*}{ IB } & $\mathrm{T} 2$ & NO & MO \\
\hline & $\mathrm{T} 1$ & N1 & MO \\
\hline \multirow[t]{3}{*}{$\| A$} & T3 & NO & MO \\
\hline & $\mathrm{T} 2$ & N1 & MO \\
\hline & T1 & N2 & MO \\
\hline \multirow[t]{4}{*}{ IIB } & T4a & NO & Mo \\
\hline & T3 & N1 & MO \\
\hline & $\mathrm{T} 2$ & N2 & Mo \\
\hline & $\mathrm{T} 1$ & N3 & MO \\
\hline \multirow[t]{3}{*}{ IIIA } & T4a & N1 & MO \\
\hline & T3 & N2 & MO \\
\hline & $\mathrm{T} 2$ & N3 & MO \\
\hline \multirow[t]{3}{*}{ IIIB } & $\mathrm{T} 4 \mathrm{~b}$ & No/1 & MO \\
\hline & $\mathrm{T} 4 \mathrm{a}$ & N2 & MO \\
\hline & T3 & N3 & MO \\
\hline \multirow[t]{2}{*}{ IIIC } & $\mathrm{T} 4 \mathrm{~b}$ & $\mathrm{~N} 2 / 3$ & Mo \\
\hline & T4a & N3 & MO \\
\hline IV & jedes $T$ & jedes N & M1 \\
\hline
\end{tabular}

Magenfrühkarzinome zeigen sich klinisch in der Regel symptomlos oder mit unspezifischen Beschwerden, sodass häufig erst nach der Infiltration der Tunica muscularis propria und mit dem Auftreten der typischen Trias von Eisenmangelanämie, Gewichtsverlust und Abneigung gegen Fleisch die Diagnose in einem fortgeschrittenen Stadium gestellt wird (Nagini 2012). Das Magenkarzinom metastasiert sowohl lymphogen als auch hämatogen mit Ansiedelungen in Leber, Lunge, Skelettsystem und Gehirn. Weiterhin können durch Infiltration von Nachbarstrukturen unter anderem Ösophagus, Colon transversum, Pankreas und das Peritoneum mitbefallen werden. 


\subsection{Kurative und palliative Behandlungsansätze}

\subsubsection{Primär kurative Therapieansätze}

In der aktuellen S3-Leitlinie zur Therapie des Magenkarzinoms werden im Rahmen der kurativen Ansätze in Abhängigkeit von Erkrankungsstadium, Tumorlokalisation und histologischen Typus eine endoskopische (Sub-)Mukosaresektion oder eine (sub-)totale Gastrektomie mit Lymphadenektomie empfohlen (Abbildung 1) (Leitlinie Magenkarzinom 2012). Das Ziel ist eine vollständige Entfernung des Karzinoms und den regionären Lymphknoten mit tumorfreien Resektionsrändern im Sinne einer RO-Resektion. In der Regel werden in einer interdisziplinären Tumorkonferenz die Therapieoptionen evaluiert. Aktuell kann bei einem Adenokarzinom der Kategorie UT2 und sollte/soll bei UT3 und resektablem UT4a Tumoren laut aktueller S3-Leitlinie eine perioperative Chemotherapie durchgeführt werden. Diese wird präoperativ begonnen und postoperativ fortgesetzt. Bei Adenokarzinomen des ösophagogastralen Überganges der gleichen Kategorien wird zudem in der Leitlinie eine neoadjuvante Radiochemotherapie mit dem gleichen Empfehlungsgrad in Betracht gezogen.

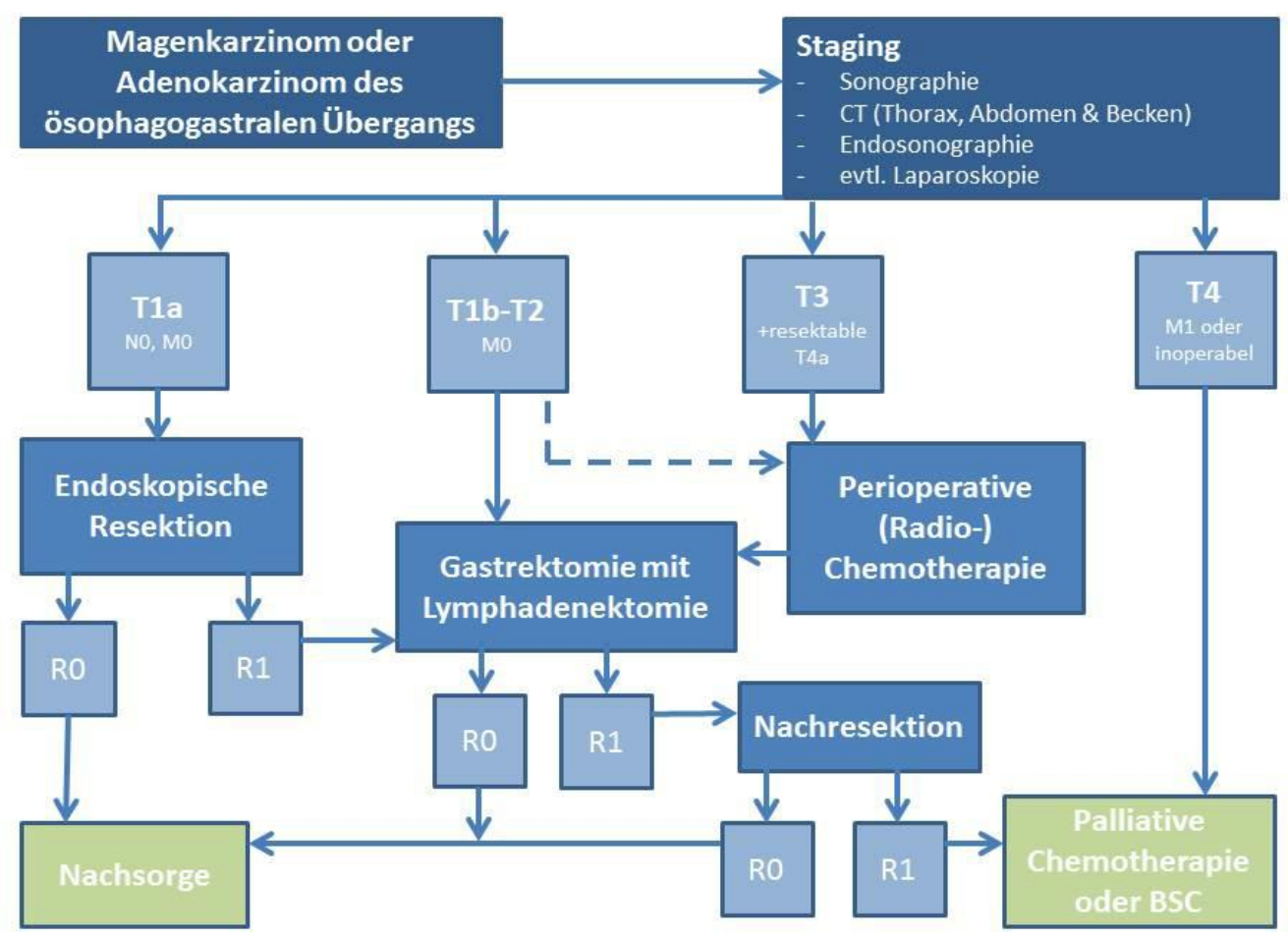

Abbildung 1: Algorithmus zur Primärtherapie in Abhängigkeit des Tumorstadiums. T, N und M nach TNM-Klassifikation des Magenkarzinoms. R0: Resektionsrand tumorfrei, R1: Resektionsrand nicht tumorfrei. Basierend auf (Leitlinie Magenkarzinom 2012). 


\subsubsection{Palliative Therapieansätze}

Bei Patienten mit fortgeschrittenem Magenkarzinom im klinischen Stadium IV, sowie bei Patienten mit inoperablen Tumoren, können verschiedene palliative Therapieoptionen diskutiert werden. Es konnte gezeigt werden, dass eine palliativ intendierte systemische Therapie die Überlebenszeit im Vergleich zu ausschließlich unterstützenden Maßnahmen (Best Supportive Care, BSC) verlängert (Wagner et al. 2010). Eine Gastrektomie oder Metastasenresektion sollte im fortgeschrittenen Stadium bei unzureichender Evidenz gemäß der aktuellen S3-Leitlinie nur in Ausnahmefällen wie nicht kontrollierbare Blutung oder Perforation durchgeführt werden (Leitlinie Magenkarzinom 2012). In erster Linie kommen zur symptomatischen Therapie beispielsweise eine Stentimplantation oder palliative Bestrahlung in Frage.

\subsection{Medikamentöse Tumortherapie}

\subsubsection{Zytostatika}

In der medikamentösen Tumortherapie des Magenkarzinoms werden die im Folgenden aufgeführten Zytostatika verwendet. Die einzelnen Wirkstoffe werden häufig in verschiedenen Chemotherapieregimen kombiniert. Die genannten unerwünschten Ereignisse und schweren Nebenwirkungen, welche gemäß der Common Terminology Criteria for Adverse Events (CTCAE) den Graden drei oder vier zugeordnet wurden, traten bei mehr als fünf Prozent der Patienten in den jeweiligen Zulassungsstudien auf.

\subsubsection{5-Fluorouracil und Capecitabin}

In vielen medikamentösen (Kombinations-)Therapien des Magenkarzinoms wird ein Fluoropyrimidin verwendet. Die verwendeten Wirkstoffe 5-Fluorouracil (5-FU) und Capecitabin gehören zu der Klasse der Pyrimidinanaloga und wirken aufgrund der strukturellen Ähnlichkeit zu den Pyrimidinbasen und über die Hemmung der Pyrimidinbiosynthese zytostatisch (Schütte und Barth 2010). Durch die Kombination mit Folinsäure wird die Wirksamkeit gesteigert. Capecitabin wird als orales Fluoropyrimidin im Körper zu 5-FU verstoffwechselt. Schwere Nebenwirkungen bei einer Therapie mit 5-FU sind Diarrhoe und Stomatitis und mit Capecitabin Diarrhoe und Hand-Fuß-Syndrom (Sakamoto et al. 2006; Kang et al. 2009). 


\subsubsection{Cisplatin und Oxaliplatin}

Zu den wirksamsten Einzelsubstanzen zählen Platinderivate, die in Kombination sowohl in der perioperativen als auch in der palliativen Therapie eingesetzt werden. Platin-haltige Substanzen führen zu Quervernetzungen zwischen den DNA-Strängen und wirken folglich durch eine verminderte DNA-Replikationsrate zytostatisch (Schütte und Barth 2010). Übelkeit und Erbrechen, Diarrhoe, Mukositis, Elektrotytverschiebungen, sowie Nephrotoxizität, Polyneuropathie, Ototoxizität und Hämatotoxizität zählen zu den schweren Nebenwirkungen, wobei insbesondere Cisplatin mehr Übelkeit, Erbrechen und renale Toxizität, Oxaliplatin hingegen mehr Neuropathien hervorruft (Al-Batran et al. 2008).

\subsubsection{Docetaxel und Paclitaxel}

Docetaxel und Paclitaxel zählen zu den Taxanen, welche über eine Stabilisierung der Mikrotubuli und konsekutiver Hemmung des Abbaus des Spindelapparates die Mitose verhindern (Schütte und Barth 2010). Docetaxel ist ein wirksamer Partner in Kombination mit Fluoropyrimidinen und Platinderivaten in der medikamentösen Therapie. In der palliativen Zweitlinientherapie wird Paclitaxel als Monotherapie verwendet. Als spezifische schwere Nebenwirkungen werden Infektionen, Nagelveränderungen, sowie Stomatitis und Diarrhoe für beide Medikamente aufgeführt. Weiterhin treten zum Teil irreversible Polyneuropathien auf (Kang et al. 2012; Hironaka et al. 2013).

\subsubsection{Epirubicin}

Epirubicin ist ein Vertreter der Anthrazykline, welche ihre Wirkung über die Hemmung der Topoisomerase-II entfalten (Schütte und Barth 2010). Mukositis sowie Neutrozytopenie, Thrombozytopenie und Anämie im Rahmen einer hämatologischen Toxizität zählen zu den schweren Nebenwirkungen. Eine irreversible linksventrikuläre Herzinsuffizienz aufgrund von Kardiomyopathie oder Rhythmusstörungen wird als seltene kritische Komplikation beschrieben (Plosker und Faulds 1993).

\subsubsection{Irinotecan}

Irinotecan zählt zu den Topoisomerase-I-Inhibitoren und kann einerseits in Kombination, aber auch als Monotherapie angewendet werden. Während der DNA-Replikation spaltet die Topoisomerase-I einen der beiden DNA-Stränge und durch Inhibition des Enzymes kommt es zu sekundären DNA-Läsionen welche bis hin zum Zelltod führen können (Schütte und Barth 2010). Irinotecan ist ein Prodrug, welches nach Verabreichung hauptsächlich in 
der Leber zu seinem aktiven Metaboliten SN38 verstoffwechselt wird. Sowohl Diarrhoe, Übelkeit und Erbrechen als auch Neutropenie und neutropenisches Fieber sind schwere Nebenwirkungen (Thuss-Patience et al. 2011). Die gastrointestinalen Beschwerden sowie Hypotonien und Bradykardien können durch ein Irinotecan-induziertes cholinerges Syndrom verursacht werden.

\subsubsection{Molekular zielgerichtete Therapie}

Spezifische biomolekulare Behandlungen mit zielgerichteten Therapien hängen von der Anwesenheit von potentiellen Zielen im Sinne von molekularen Veränderungen der Tumorzellen ab. In Deutschland sind bisher die Antikörper Trastuzumab und Ramucirumab zur Therapie des fortgeschrittenen Magenkarzinoms zugelassen. Weitere zielgerichtete Therapien werden zurzeit in Studien untersucht.

\subsubsection{Trastuzumab}

Der humane epidermale Wachstumsfaktorrezeptor-2 (HER2) ist ein transmembraner Tyrosinkinaserezeptor, der zur Familie der epidermalen Wachstumsfaktorrezeptoren (EGFR) gehört. Eine Aktivierung des HER2-Rezeptors führt letztendlich über eine Signalkaskade zur Regulierung von Zellwachstum, Differenzierung und Überleben (Hsieh und Moasser 2007).

Ein positiver HER2-Rezeptorstatus liegt bei sechs bis 34 Prozent der Patienten mit Magenkarzinom vor, abhängig von histologischem Subtyp und Primärtumorlokalisation. Sowohl Tumore vom intestinalen Typ weisen gegenüber dem diffusen Typ vermehrt einen positiven Rezeptorstatus auf, als auch Karzinome im Bereich des gastroösophagealen Überganges gegenüber anderen Lokalisationen (Gravalos und Jimeno 2008). In einer randomisierten Phase-III-Studie ToGA wurden Patienten mit fortgeschrittenen HER2positiven Karzinomen des Magens oder des ösophagogastralen Überganges mit Trastuzumab zusätzlich zur Chemotherapie behandelt (Bang et al. 2010). Die HER2Überexpression wurde definiert als Nachweis mittels Fluoreszenz-in-situ-Hybridisierung $(\mathrm{FISH}+)$ oder immunhistochemisch dreifach positiver HER2-Expression (IHC3+). In der Analyse der Subgruppen fiel auf, dass insbesondere Patienten mit $\mathrm{IHC}+$ oder $\mathrm{IHC2}+$ und FISH+ Tumoren von Trastuzumab profitierten. Für die beiden Subgruppen IHCO/FISH+ und IHC1+/FISH+ konnte kein Überlebenszeitvorteil beobachtet werden. Trastuzumab wurde als erster monoklonaler Antikörper gegen HER2-Rezeptoren für die palliative Behandlung 
von Patienten mit HER2-Überexpression oder -Genamplifikation zugelassen. Die Therapie wird in der Regel gut vertragen und es gibt selten schwere Nebenwirkungen (Bang et al. 2010).

\subsubsection{Ramucirumab}

Die Angioneogenese ist entscheidend für Tumorwachstum, Überleben und Metastasierung. Die vaskulären endothelialen Wachstumsfaktoren (VEGF) sind wichtige Regulatoren der Angiogenese und wirken auf die vaskulären endothelialen Wachstumsfaktorrezeptoren (VEGFR) (Holmes und Zachary 2005; Claesson-Welsh und Welsh 2013). Insbesondere durch die rezeptorvermittelte Signalkaskade des VEGFR-2 werden Endothelzellen zur Proliferation und Migration stimuliert, sodass sich neue Blutgefäße bilden oder aus bestehenden aussprießen (Abbildung 2). Der VEGF-Rezeptor ist in 30 bis 60 Prozent der Magenkarzinome überexprimiert und ist ein Prädiktor für eine besonders schlechte Prognose (Prins et al. 2012). Ramucirumab ist ein Vertreter der VEGF-Rezeptor2-Antikörper und hemmt durch seine Bindung an die transmembranären Rezeptortyrosinkinasen die Angiogenese (Lu et al. 2003). Bisher konnte gezeigt werden, dass in Kombination mit Paclitaxel gegenüber einer Paclitaxel-Monotherapie sowohl die progressionsfreie Überlebenszeit und die Gesamtüberlebenszeit verlängert als auch die Remissionsrate gesteigert wird (Wilke et al. 2014).
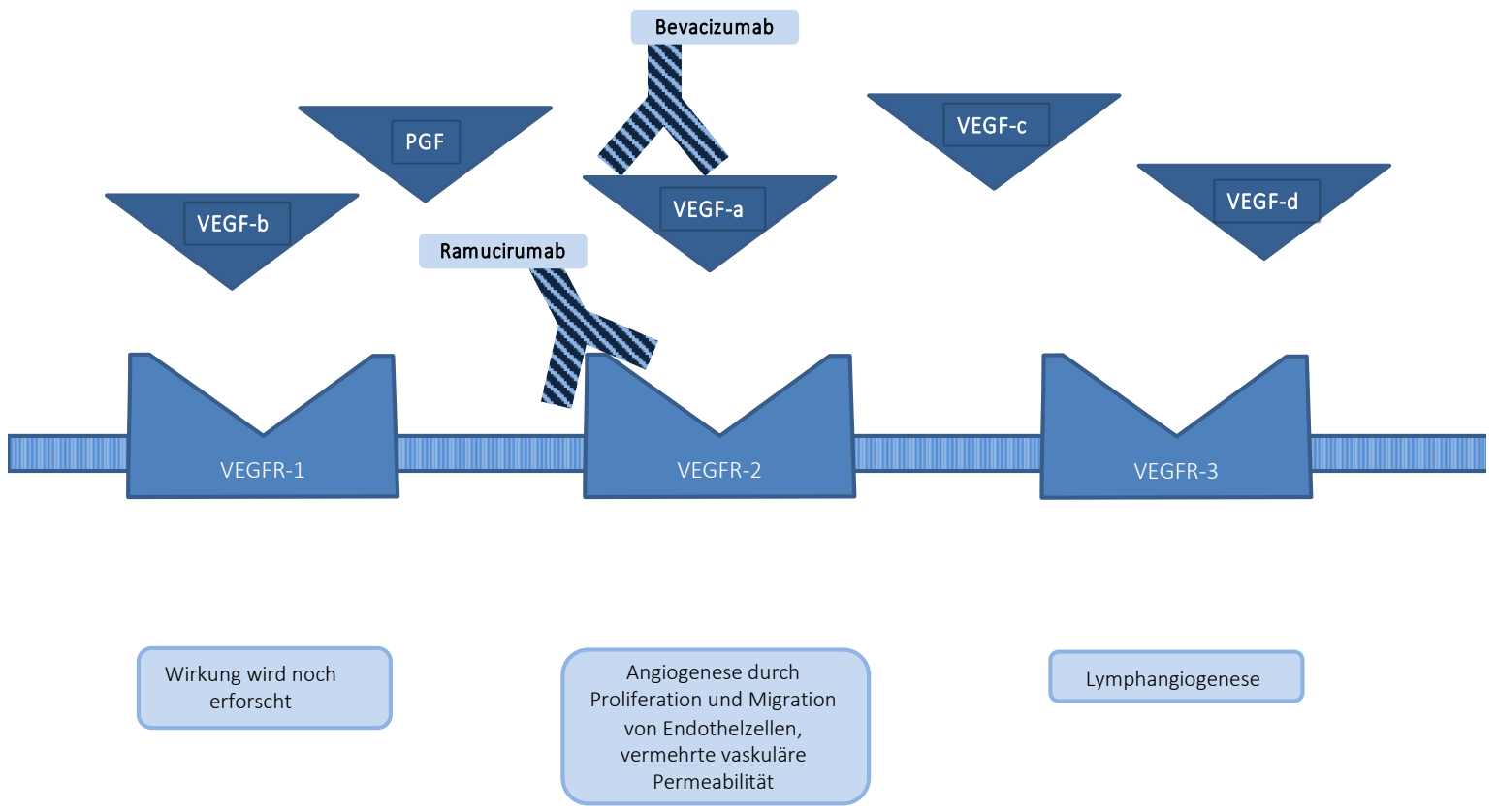

Lymphangiogenese

erforscht

Abbildung 2: VEGF und VEGF-Rezeptoren. Basierend auf (Claesson-Welsh and Welsh 2013; Holmes and Zachary 2005).

Bei Kontraindikation für eine Paclitaxeltherapie wurde für eine Monotherapie mit Ramucirumab gegenüber Placebo ebenso eine Verlängerung der progressionsfreien und 
gesamten Überlebenszeit beschrieben (Fuchs et al. 2014). Eine arterielle Hypertonie wurde als schwere Nebenwirkung in der Monotherapie, und Fatigue, Neuropathie und abdominelle Schmerzen zusätzlich in der Kombinationstherapie genannt.

\subsubsection{Perioperative Chemotherapie}

Aktuell wird in der perioperativen Chemotherapie bei Magenkarzinomen in den Stadien IB bis IIIC häufig das FLOT-Regime (5-FU, Leucovorin, Oxaliplatin, Docetaxel) verwendet, da die deutsche FLOT4-Studie im Vergleich zu ECF/X (Epirubicin, Cisplatin, 5-FU/Capecitbain) für alle untersuchten Subgruppen bei vergleichbarer postoperativer Mortalität und Letalität eine höhere histopathologische Ansprechrate, sowie eine Verbesserung des progressionsfreien Überlebens und Gesamtüberlebenszeit zeigte (Al-Batran et al. 2017b). In der derzeit gültigen S3-Leitlinie ist eine Therapie nach ECF-Schema noch der Standard, in der Zukunft ist jedoch eine Empfehlung des FLOT-Regimes mit jeweils vier prä- und postoperativen Zyklen aufgrund der FLOT4-Studie zu erwarten (Leitlinie Magenkarzinom 2012). Bei erhöhten Toxizitätsrisiken oder Kontraindikationen für Docetaxel kann beispielsweise auf ein modifiziertes FOLFOX-Schema (Folsäure, 5-FU, Oxaliplatin) zurückgegriffen werden. Die aktuelle S3-Leitlinie empfiehlt, dass bei einem Progress während der neoadjuvanten Chemotherapie diese Therapie nicht fortgesetzt und eine frühzeitige Operation durchgeführt werden sollte. Aufgrund aktuell nicht ausreichender wissenschaftlicher Evidenz wird derzeit die Integration biologisch zielgerichteter Substanzen in die perioperative Therapie nicht empfohlen. 
1.4.4 Palliative medikamentöse Therapie

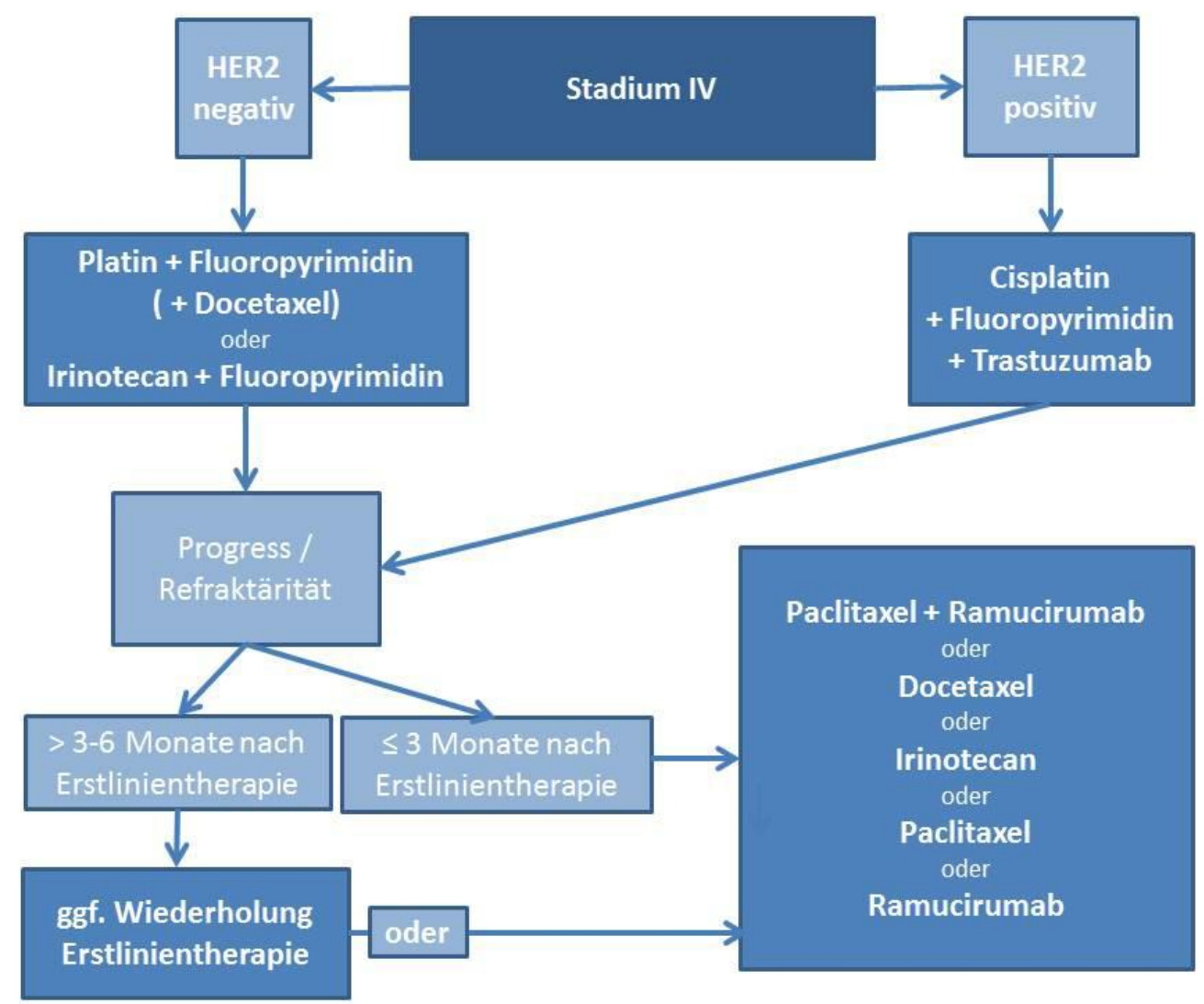

Abbildung 3: Algorithmus für Therapie im Stadium IV. Basierend auf (Leitlinie Magenkarzinom 2012).

Unter der Berücksichtigung von Allgemeinzustand und Behandlungswunsch des Patienten, sowie Komorbiditäten, HER2-Status und Toxizitätsprofil des geplanten Schemas wird eine palliativ ausgerichtete Chemotherapie ausgewählt (Abbildung 3) (Leitlinie Magenkarzinom 2012).

\subsubsection{Erstlinientherapie}

In der Leitlinie wird eine systemische Fluoropyrimidin- und Platin-haltige Kombinationstherapie als Erstlinientherapie für HER2-negative Karzinome empfohlen (Leitlinie Magenkarzinom 2012). Bezüglich der Fluoropyrimidine zeigt das orale Capecitabin bei ausreichender Nierenfunktion und guter Compliance eine dem intravenös verabreichten 5FU vergleichbare Wirksamkeit (Kang et al. 2009). Weiterhin hat Oxaliplatin gegenüber Cisplatin bei unterschiedlichen Toxizitätsprofilen eine vergleichbare Wirksamkeit, sodass die Wahl der Substanz in Abhängigkeit der Begleiterkrankungen empfohlen wird (Al-Batran et al. 2008). Laut der Leitlinie sollte eine Dreifachkombination aus Fluoropyrimidin- und Platin-haltigen Präparaten und zusätzlich Docetaxel, beispielsweise ein (modifiziertes) DCFSchema, nur Patienten in gutem Allgemeinzustand und ohne relevante Neben- 
erkrankungen angeboten werden, da mit dem signifikanten Überlebensvorteil gegenüber der Zweifachkombination auch eine erhöhte Rate an Toxizitäten einhergeht (Van Cutsem et al. 2006). An Stelle eines Platin-haltigen Präparates kann in einer 5-FU-basierten Kombinationstherapie Irinotecan (FOLFIRI) bei vergleichbarer Wirksamkeit eingesetzt werden, wenn eine Alternative zu Cisplatin oder Oxaliplatin aufgrund des Nebenwirkungsprofils sinnvoll ist (Dank et al. 2008). Für Patienten mit HER2-überexprimierenden (IHC3+ oder IHC2+ und FISH+) Tumoren besteht laut der aktuellen Leitlinie eine Indikation für die Kombination von Trastuzumab mit Cisplatin und einem Fluoropyrimidin als ErstChemotherapie (Leitlinie Magenkarzinom 2012).

\subsubsection{Zweitlinientherapie}

Als Zweitlinientherapie kann bei Patienten mit einem adäquaten Allgemeinzustand eine Monotherapie mit Irinotecan, Docetaxel oder Placitaxel in Abhängigkeit von der jeweiligen Vortherapie in Betracht gezogen werden. Für alle drei Medikamente ergab sich in Studien eine signifikante Verlängerung der Überlebenszeit im Vergleich zu BSC (Ter Veer et al. 2016). Für Ramucirumab konnte in der REGARD Studie gezeigt werden, dass der Antikörper gegenüber Placebo in der zweiten Behandlungslinie nach Platin und Fluoropyrmidin eine Überlebensverlängerung und gleichzeitig eine bessere Lebensqualität bewirkt (Fuchs et al. 2014). Weiterhin zeigte sich die Kombinationstherapie aus Paclitaxel und Ramucirumab in der RAINBOW Studie wirksamer als eine Paclitaxel-Monotherapie (Wilke et al. 2014). Zurzeit erfolgt die prospektive, multizentrische und randomisierte klinische Studie RAMIRIS, in welcher die Zweitlinientherapie von Ramucirumab in Kombination mit FOLFIRI einer Kombination mit Paclitaxel gegenübergestellt wird (Lorenzen et al. 2018). In der Zweitlinienbehandlung des fortgeschrittenen kolorektalen Karzinoms ist die Kombi-nation von FOLFIRI und Ramucirumab bereits seit Januar 2016 zugelassen, nachdem in der RAISEStudie eine signifikante Verlängerung von Progression Free Survival (PFS) und Overall Survival (OS) bei kontrollierbaren Nebenwirkungen gezeigt wurde (Tabernero et al. 2015). Im Vergleich zur FOLFIRI-Chemotherapie kam es unter der Kombination zu einer Steigerung der Nebenwirkungen, insbesondere Neutropenie und Hypertonie. Alternativ kann bei Tumorprogress nach mehr als drei Monaten nach Abschluss der Erstlinientherapie eine erneute Behandlung mit der Medikamentenkombination der Erstlinientherapie in Erwägung gezogen werden (Okines et al. 2010). 


\subsubsection{Drittlinientherapie}

In aktuellen Studien werden weitere Antikörper- und Immuntherapien evaluiert. Die deutsche S3-Leitlinie zum Magenkarzinom empfiehlt zurzeit keine Antikörpertherapie mit Cetuximab, Panitumumab oder Bevacizumab außerhalb klinischer Studien (Leitlinie Magenkarzinom 2012).

\subsection{Studienziel}

An der Universitätsmedizin Göttingen wurden Patienten mit fortgeschrittenen Adenokarzinomen des Magens oder ösophagogastralen Überganges im Rahmen eines individuellen Heilungsversuches mit der Kombination aus dem Antikörper Ramucirumab und Chemotherapie nach dem FOLFIRI-Schema behandelt. Aufgrund der erfolgreichen FLOT4-Studie werden vermehrt Patienten perioperativ nach dem Taxan-haltigen FLOTSchema behandelt. Die aktuelle S3-Leitlinie sieht für HER2-negative Karzinome im Stadium IV in erster Linie eine Chemotherapie mit einem Fluoropyrimidin- und Platin-haltigen Schema vor, wobei bei Patienten in gutem Allgemeinzustand zusätzlich Docetaxel erwogen werden kann (Leitlinie Magenkarzinom 2012). Nun gilt es, geeignete Zweitlinientherapieoptionen zu suchen. Ramucirumab ist der einzige Antikörper, welcher bisher beim fortgeschrittenen Magenkarzinom unabhängig von den molekularen Eigenschaften des Tumors in Monotherapie und in Kombination mit Paclitaxel zugelassen ist. Die Kombination von Ramucirumab mit FOLFIRI bringt, im Vergleich zur Kombination mit dem Taxan Paclitaxel, durch Irinotecan ein Medikament einer neuen Wirkstoffklasse bei Erstlinientherapie mit FLOT ein. In der retrospektiven Auswertung der Patientendaten erfolgte zur Analyse des Therapieerfolges und des Therapieansprechens die Berechnung des OS, des PFS und der 1-Jahres-Überlebenswahrscheinlichkeit, sowie der Objective Response Rate (ORR) und der Disease Control Rate (DCR). Weiterhin erfolgte zur Beurteilung der Therapiesicherheit und Toxizität die Dokumentation und Auswertung der unerwünschten Ereignisse. 


\section{Methodik}

\subsection{Einschluss- und Ausschlusskriterien}

Es wurden alle Patienten eingeschlossen, die im Zeitraum vom 01.11.2015 bis zum 01.09.2017 an der Universitätsmedizin Göttingen mindestens eine Gabe des Antikörpers Ramucirumab in Kombination mit dem Chemotherapieregime FOLFIRI erhalten haben. Die Patienten wurden entweder stationär in der Klinik für Gastroenterologie und gastrointestinale Onkologie oder in der Klinik für Allgemein- und Viszeralchirurgie behandelt, oder ambulant in der Interdisziplinären Kurzzeitonkologie. Es wurden auch Patienten berücksichtigt, bei welchen die in Göttingen begonnene Therapie in einem auswärtigen Krankenhaus oder einer onkologischen Praxis heimatnah fortgeführt wurde.

Zum Einschluss in die klinische Studie mussten die Patienten die folgenden Kriterien vor Therapiebeginn erfüllen. Primär wurde das Vorliegen eines histologisch gesicherten Magenkarzinoms oder Adenokarzinoms des ösophagogastralen Überganges (AEG II und AEG III) jeweils in fortgeschrittenem Stadium mit Fernmetastasen oder nicht resezierbarem Lokalrezidiv (Stadium IV) gefordert. Weiterhin war ein Mindestalter von 18 Jahren gefordert und der klinische Allgemeinzustand des Patienten musste für eine systemische Therapie ausreichend gut sein, welches anhand von einem ECOG von kleiner oder gleich zwei, beziehungsweise einem Karnofsky-Index von mindestens 60 Prozent, bemessen wurde. Ein weiteres Einschlusskriterium war eine ausreichende Organfunktion, insbesondere eine ausreichende Knochenmarks- und Leberfunktion. Als hämatologisches Korrelat wurde hier eine Leukozytenzahl von mindestens $1,5 \times 10^{9}$ pro Liter als Grenze gesetzt. Als Ausschlusskriterien galten eine vorliegende Hyperbilirubinämie oder Schwangerschaft.

Ausschließlich für die Analyse von unerwünschten Ereignissen und Toxizität der Kombinationstherapie wurden zusätzlich Patienten mit fortgeschrittenem kolorektalem Karzinom unter Ramucirumab- und FOLFIRI-Therapie im Zeitraum von 01.11.2015 bis zum 01.09.2017 untersucht. 


\subsection{Datengewinnung}

Aus den handschriftlichen und elektronischen Akten der eingeschlossenen Patienten, welche unter anderem Aufnahme- und Entlassdokumentationen, Arztbriefe, radiologische Befunde, Tumorboard-Anmeldungen und Beschlüsse, Laborparameter, Therapiepläne, Medikamentenpläne und Aufzeichnungen über klinische Untersuchungen umfassten, und dem Tumordokumentationssystem ONKOSTAR wurden Daten bezüglich der Patienten- und Tumorcharakteristika entnommen. Weiterhin wurden aus diesen Akten Informationen zu Vorerkrankungen und Medikation, sowie zu vorangegangenen Therapieversuchen gesammelt. Die Daten zur individuell angepassten FOLFIRI- und Ramucirumabtherapie wurden den Therapieplänen entnommen und die gewünschten und unerwünschten Wirkungen der untersuchten Kombinationstherapie aufgezeichnet. Für die Analyse der Laborwerte wurden die Ergebnisse der Blutuntersuchung vor Therapiebeginn, einen Monat nach Therapiebeginn und dann in Abständen von zwei Monaten dokumentiert. Das Körpergewicht wurde vor der ersten Gabe und im Behandlungsverlauf vor jeder zweiten Gabe erfasst.

\subsection{Behandlungsregime}

Im Rahmen der Chemotherapie nach dem FOLFIRI-Regime erhielten die Patienten 180 $\mathrm{mg} / \mathrm{m}^{2}$ Irinotecan und $400 \mathrm{mg} / \mathrm{m}^{2}$ Leucovorin intravenös appliziert. Anschließend folgte die kontinuierliche intravenöse Gabe von 5-FU in einer Dosierung von 2400 mg/m² über 24 Stunden. Der Antikörper Ramucirumab wurde gewichtsadaptiert mit 8 mg/kg intravenös im Anschluss an die Irinotecaninfusion und vor der Leucovoringabe verabreicht. Die Chemo- und Antikörpertherapie erfolgten jeweils an Tag 1 und Tag 15 eines 28-tägigen Zyklus.

Eine initiale Dosisreduktion um 25 Prozent der FOLFIRI-Chemotherapie erfolgte bei Patienten in reduziertem Allgemeinzustand oder mit verminderter Organfunktion. Für Patienten mit vorbestehender Amiodaron-Dauertherapie wurde in der Regel die Irinotecan-Dosis aufgrund medikamenteninteraktionsbedingter verminderter Verstoffwechselung und folglich deutlich erhöhtem Toxizitätsrisiko auf 50 Prozent reduziert. In Abhängigkeit von schweren Nebenwirkungen, insbesondere bei Neutrozytopenie und Thrombozytopenie oder Patienten mit reduziertem Allgemeinzustand erfolgte im Verlauf 
eine Anpassung der Zykluslänge mit Verlängerung der Zeitintervalle auf eine maximal vierwöchentliche Gabe und Reduktion der FOLFIRI-Dosis, gegebenenfalls auch der Ramucirumab-Dosis, um 25 Prozent. Bei Patienten mit Chemotherapie-induzierter Thrombozytopenie erfolgte eine Dosisreduktion bei Thrombozytenzahlen von kleiner als $100 \times 10^{9}$ pro Liter und eine Therapiepause bei Thrombozytenzahlen von kleiner als $50 \times$ $10^{9}$ pro Liter. Die Therapie wurde bei nachgewiesenem Progress, unkontrollierbaren unerwünschten Ereignissen dritten und vierten Grades (Tabelle 2), auf Patientenwunsch oder bei Tod des Patienten beendet.

Routinemäßig erhielten die Patienten vor der Chemotherapie eine prophylaktische antiemetische und anticholinerge Therapie mit $8 \mathrm{mg}$ Ondansetron und 0,5 mg Atropin. Je nach präsentierten Nebenwirkungen wurde die unterstützende Therapie an Therapietagen um Antihistaminika, Protonenpumpeninhibitoren, Dexamethason als systemisches Glukokortikoid, Vitamin B6 und Antidiarrhoika erweitert. Die jeweils verabreichten Dosierungen der Chemo- und Antikörpertherapie sowie die unterstützenden Medikamente wurden den Therapieplänen der einzelnen Patienten entnommen.

\subsection{Statistische Auswertung des Therapiererfolges}

Für die elf eingeschlossenen Patienten mit fortgeschrittenem Magenkarzinom wurde der Therapieerfolg analysiert. Zur Darstellung der Zeiträume von Diagnose bis Therapiebeginn mit FOLFIRI und Ramucirumab und der Therapiedauer wurden Box-Plot-Diagramme verwendet. Ebenso wurden die gesamte Anzahl und die Anzahl der reduzierten Gaben in diesen Darstellungen verbildlicht. Hierzu wurden aus den jeweiligen Datensätzen das Minimum, untere Quartil, Median, oberes Quartil und Maximum berechnet.

Das PFS wurde von der ersten Gabe von Ramucirumab in Kombination mit Chemotherapie nach dem FOLFIRI-Regime bis hin zum ersten Nachweis eines Tumorprogresses (auch Tod) oder dem Ende des Untersuchungszeitraumes, wenn das erstgenannte Ereignis nicht eingetreten ist, bemessen. Für das OS, gleichbedeutend mit der Gesamtüberlebenszeit, wurde das Zeitintervall von der ersten Gabe von Ramucirumab und FOLFIRI bis zum Tod oder Ende des Untersuchungszeitraumes bestimmt. Für PFS und OS wurde der Median in Monaten errechnet und beide Überlebenszeiten wurden nach dem Kaplan-MeierVerfahren analysiert. 
Mit dem Kaplan-Meier-Schätzer kann die Wahrscheinlichkeit, dass für ein Versuchsobjekt ein spezifisches Ereignis in einem definierten Zeitintervall nicht eintritt, geschätzt werden (Kaplan und Meier 1958). Er gehört in den Bereich der sogenannten parameterfreien Statistik und wird zur Auswertung von Überlebenszeiten genutzt. In einer Kaplan-MeierKurve, auch Überlebenszeitkurve genannt, können grafisch die Überlebenszeiten dargestellt werden. Mit Überlebenszeit kann nicht nur das Überleben bis zum Ereignis „Tod“, sondern jeglicher Zeitraum zu einem untersuchten Ereignis, gemeint sein. Auf der $\mathrm{x}$-Achse wird die Überlebenszeit (Zeitraum bis Eintreten des definierten Ereignisses) und auf der y-Achse wird die mit dem Kaplan-Meier-Verfahren errechnete Überlebenswahrscheinlichkeit (Wahrscheinlichkeit für Nicht-Eintreten des Ereignisses) eingetragen. Für die Analyse des PFS wurde als Ereignis „Progress" oder „Tod“ und für OS das Ereignis „Tod“ definiert. Patienten, für die das Ereignis während des untersuchten Zeitraumes nicht eintrat, wurden zensiert und auf der Kurve als Punkt dargestellt. Grund hierfür kann beispielsweise ein Überleben über das Studienende hinaus sein. In der Kaplan-Meier-Kurve wurde die 1-Jahres-Überlebenswahrscheinlichkeit abgelesen. Diese beschreibt die Wahrscheinlichkeit, dass zum Zeitpunkt von zwölf Monaten nach Therapiebeginn mit FOLFIRI und Ramucirumab das Ereignis „Tod" noch nicht eingetreten ist.

\subsection{Tumorassessment}

Zum Tumorassessment gemäß den RECIST1.1-Kriterien erfolgte nach drei Zyklen, entsprechend zwölf Wochen und sechs Gaben der Chemo- und Antikörpertherapie, eine Staging-Untersuchung mittels CT-Abdomen. Die Schnittbildgebungen wurden von einem Radiologen mit besonderem Fokus auf das Tumorassessment ausgewertet. Für die Beurteilung nach den RECIST1.1-Kriterien werden in der Ausgangsbildgebung vor Therapiebeginn Target-Läsionen (Zielläsionen) und Non-Target-Läsionen identifiziert und vermessen (Eisenhauer et al. 2009). In den Verlaufsbildgebungen unter Therapie werden die Läsionen aufgesucht und in Abhängigkeit von der Veränderung das Gesamtansprechen klassifiziert. Wenn keine Target- oder Non-Target-Läsionen mehr nachweisbar sind, spricht man von einer Complete Remission (CR). Eine Tumorreduktion um 30 Prozent im Längsdurchmesser ohne Nachweis von neuen Läsionen wird Partial Response (PR) genannt. Stable Disease (SD) beschreibt unveränderte Target-Läsionen und nicht 
progressive Non-Target-Läsionen. Jegliches Wachstum von Target-Läsionen um mindestens 20 Prozent, deutliches Wachstum von Non-Target-Läsionen oder der Nachweis von neuen Läsionen wird als Progressive Disease (PD) bezeichnet. Die ORR beschreibt den Anteil der Patienten, die gemäß der RECIST1.1-Kriterien im Rahmen des Tumorassessments eine CR oder PR zu einem gewählten Zeitpunkt zeigten. Die DCR, auch Tumor Control Rate genannt, beinhaltet im Vergleich zur ORR zusätzlich zu CR und PR auch Patienten mit einer SD. Sowohl ORR als auch DCR wurden zusätzlich als vom Zeitpunkt unabhängige Raten im Rahmen der Analyse der Best Overall Response mit den jeweils besten Tumorassessments im Studienzeitraum berechnet.

\subsection{Unerwünschte Ereignisse}

Die Daten aller Patienten, die mindestens eine Gabe der Kombinationstherapie mit FOLFIRI und Ramucirumab bei fortgeschrittenem Magenkarzinom erhalten haben, wurden, sofern vorliegend, auf Verträglichkeit und Sicherheit analysiert. Für die Untersuchung von unerwünschten Ereignissen und Toxizitäten unter FOLFIRI- und Ramucirumabtherapie wurden zusätzlich die Daten von Patienten mit fortgeschrittenem kolorektalen Karzinom unter dieser Kombinationstherapie hinzugezogen.

In regelmäßigen Abständen erfolgte die Bestimmung des Körpergewichtes und eine routinemäßige laborchemische Blutuntersuchung mit Blutbild (Hämoglobin, Thrombozyten, Leukozyten) und klinischer Chemie (Bilirubin, Kreatinin, Kalium, yGT, AST). Die verzeichneten Werte wurden gemäß der deutschen Version der Common Terminology Criteria for Adverse Events (CTCAE) Version 4.03 erfasst und mit Hilfe der entsprechenden Schweregradskala eingeteilt (CTCAE 2016). Für diese Analyse wurden zehn von elf Patienten mit fortgeschrittenem Magenkarzinom und alle vier Patienten mit fortgeschrittenem kolorektalem Karzinom einbezogen. Bei externer Fortführung der FOLFIRIund Ramucirumabtherapie nach der initialen Gabe lagen keine Verlaufswerte der Blutuntersuchungen und des Körpergewichtes vor. Die klinischen unerwünschten Ereignisse wurden den handschriftlichen und elektronischen Akten entnommen und entsprechend den Common Terminology Criteria for Adverse Events zugeordnet. Hier war bei unzureichender Dokumentation keine Einteilung in die Schweregradskala der CTCAE möglich (Tabelle 2). Für die Auswertung wurden sowohl Daten aller elf Magenkarzinom Patienten als auch aller vier Patienten mit kolorektalem Karzinom analysiert. 
Tabelle 2: Schweregradeinteilung von unerwünschten Ereignissen. Gemäß CTCAE Version 4.03 (CTCAE 2016).

\begin{tabular}{|c|c|c|c|c|c|}
\hline Kriterium & Grad 1 & Grad 2 & Grad 3 & Grad 4 & Grad 5 \\
\hline & $\begin{array}{l}\text { Gering; asymptomatisch } \\
\text { oder milde Symptome; nur } \\
\text { klinische oder diagnostische } \\
\text { Beobachtungen; } \\
\text { Intervention nicht indiziert. }\end{array}$ & $\begin{array}{l}\text { Mäßig; minimale, lokale } \\
\text { oder nicht-invasive } \\
\text { Intervention indiziert; } \\
\text { Begrenzung der } \\
\text { altersgerechten } \\
\text { instrumentellen ATL } \\
\text { (Zubereitung von } \\
\text { Mahlzeiten, Einkäufe von } \\
\text { Lebensmitteln oder } \\
\text { Kleidern, Benutzung des } \\
\text { Telefons, Umgang mit Geld, } \\
\text { etc.) }\end{array}$ & $\begin{array}{l}\text { Schwer; medizinisch } \\
\text { signifikant, nicht unmittelbar } \\
\text { lebensbedrohlich; stationäre } \\
\text { Aufnahme/Verlängerung } \\
\text { der stationären Behandlung } \\
\text { angezeigt; Begrenzung der } \\
\text { selbstversorgenden ATL } \\
\text { (Baden, An- und Ausziehen, } \\
\text { selbständig essen, } \\
\text { Toilettenbenutzung, } \\
\text { Einnahme von } \\
\text { Medikamenten etc.) }\end{array}$ & $\begin{array}{l}\text { Lebensbedrohliche } \\
\text { Auswirkungen; dringende } \\
\text { Intervention indiziert. }\end{array}$ & Tod \\
\hline $\begin{array}{l}\text { Anämie } \\
\text { (Hämoglobin) }\end{array}$ & <unterer NW - $10 \mathrm{~g} / \mathrm{dl}$ & $<10-8 \mathrm{~g} / \mathrm{dl}$ & $\begin{array}{l}<8 \mathrm{~g} / \mathrm{dl} ; \\
\text { Transfusionsindikation }\end{array}$ & lebensbedrohlich & Tod \\
\hline Leukozytopenie & <unterer NW - $3 \times 10^{9}$ | & $<3-2 \times 10^{9} \mid$ & $<2-1 \times 10^{9} \mid$ & $<1 \times 10^{9} \mid$ & - \\
\hline $\begin{array}{l}\text { Thrombozyto- } \\
\text { penie }\end{array}$ & <unterer NW - $75 \times 10^{9}$ I & $<75-50 \times 10^{9} \mid$ & $<50-25 \times 10^{9} \mid$ & $<25 \times 10^{9} \mid$ & - \\
\hline Hypokaliämie & <unterer NW - $3 \mathrm{mmol} / \mathrm{l}$ & $\begin{array}{l}\text { <unterer NW - } 3 \mathrm{mmol} / \mathrm{l} ; \\
\text { symptomatisch }\end{array}$ & $<3-2.5 \mathrm{mmol} / \mathrm{l}$ & $<2.5 \mathrm{mmol} / \mathrm{l}$ & Tod \\
\hline Hyperkaliämie & >oberer NW - $5.5 \mathrm{mmol} / \mathrm{l}$ & $>5.5-6 \mathrm{mmol} / \mathrm{l}$ & $>6-7 \mathrm{mmol} / \mathrm{l}$ & $\begin{array}{l}>7 \mathrm{mmol} / \mathrm{l} ; \\
\text { lebensbedrohlich }\end{array}$ & Tod \\
\hline $\begin{array}{l}\text { Kreatinin- } \\
\text { Erhöhung }\end{array}$ & $\begin{array}{l}\text { >oberer NW }-1.5 \\
\text { x oberer NW }\end{array}$ & $>1.5-3 \times$ oberer NW & $>3-6 \times$ oberer NW & $>6 \times$ oberer NW & - \\
\hline $\begin{array}{l}\text { Hyperbilirubin- } \\
\text { ämie }\end{array}$ & $\begin{array}{l}\text { >oberer NW }-1.5 \\
\text { x oberer NW }\end{array}$ & $>1.5-3 \times$ oberer NW & $>3-10 \times$ oberer NW & $>10 \times$ oberer NW & - \\
\hline AST-Erhöhung & $\begin{array}{l}\text { >oberer NW - } 3 \\
\text { x oberer NW }\end{array}$ & $>3-5 \times$ oberer NW & $>5-20 \times$ oberer NW & $>20 \times$ oberer NW & - \\
\hline AP-Erhöhung & $\begin{array}{l}\text { >oberer NW }-2.5 \\
\text { x oberer NW }\end{array}$ & $>2.5-5 \times$ oberer NW & $>5-20 \times$ oberer NW & $>20 \times$ oberer NW & - \\
\hline yGT-Erhöhung & $\begin{array}{l}\text { >oberer NW }-2.5 \\
\text { x oberer NW }\end{array}$ & $>2.5-5 \times$ oberer NW & $>5-20 \times$ oberer NW & $>20 \times$ oberer NW & - \\
\hline Gewichtsverlust & $5-<10 \%$ der Basislinie & $10-<20 \%$ der Basislinie & $\geq 20 \%$ der Basislinie & - & - \\
\hline $\begin{array}{l}\text { Abdominale } \\
\text { Schmerzen }\end{array}$ & Geringe Schmerzen & Mäßige Schmerzen & Starke Schmerzen & - & - \\
\hline Übelkeit & $\begin{array}{l}\text { Nahrungsaufnahme nicht } \\
\text { eingeschränkt }\end{array}$ & $\begin{array}{l}\text { Nahrungsaufnahme } \\
\text { verringert }\end{array}$ & $\begin{array}{l}\text { Unzureichende orale } \\
\text { kalorische oder flüssige } \\
\text { Aufnahme }\end{array}$ & - & - \\
\hline Erbrechen & $1-2 \times /$ Tag & $3-5 \times / \operatorname{Tag}$ & $\begin{array}{l}\geq 6 \times / \text { Tag; } \\
\text { Hospitalisierung indiziert }\end{array}$ & lebensbedrohlich & Tod \\
\hline Diarrhoe & $<4 \times /$ Tag & $4-6 \times /$ Tag & $\begin{array}{l}>6 \times / \text { Tag; } \\
\text { Hospitalisierung indiziert }\end{array}$ & lebensbedrohlich & Tod \\
\hline Obstipation & $\begin{array}{l}\text { Gelegentliche oder } \\
\text { intermittierende Symptome }\end{array}$ & $\begin{array}{l}\text { Anhaltende Symptome mit } \\
\text { regelmäßigem Gebrauch } \\
\text { von Laxativa oder Einläufen }\end{array}$ & $\begin{array}{l}\text { Obstipation mit Indikation } \\
\text { zur manuellen Entleerung }\end{array}$ & lebensbedrohlich & Tod \\
\hline Sinusbradykardie & Asymptomatisch & Symptomatisch, & $\begin{array}{l}\text { Schwere, medizinisch } \\
\text { signifikante Zeichen }\end{array}$ & lebensbedrohlich & Tod \\
\hline Hypertonie & $\begin{array}{l}\text { Prähypertonus (systolisch RR } \\
\text { 120-139 mmHg oder } \\
\text { diastolisch RR 80-89 mmHg) }\end{array}$ & $\begin{array}{l}\text { Hypertonus Stadium } 1 \\
\text { (systolisch RR }>140-159 \\
\text { mmHg oder diastolisch RR } \\
\text { 90-99 mmHg) }\end{array}$ & $\begin{array}{l}\text { Hypertonus Stadium } 2 \\
\text { (systolisch RR } 160 \text { mm Hg } \\
\text { oder diastolisch RR }>100 \\
\mathrm{mmHg} \text { ) }\end{array}$ & lebensbedrohliche & Tod \\
\hline $\begin{array}{l}\text { Blutung des } \\
\text { unteren } \\
\text { Gastrointestinal- } \\
\text { traktes }\end{array}$ & Leicht & $\begin{array}{l}\text { Mäßige Symptome; } \\
\text { Indikation zur medizinischen } \\
\text { Intervention oder } \\
\text { geringfügigen Kauterisation }\end{array}$ & $\begin{array}{l}\text { Transfusion; radiologische, } \\
\text { endoskopische oder elektive } \\
\text { operative Intervention } \\
\text { angezeigt }\end{array}$ & lebensbedrohlich & Tod \\
\hline $\begin{array}{l}\text { Wundheilungs- } \\
\text { störung }\end{array}$ & $\begin{array}{l}\text { Inzisionelle Entfernung von } \\
<=25 \% \text { der Wunde, nicht } \\
\text { tiefer als die oberflächliche } \\
\text { Faszie }\end{array}$ & $\begin{array}{l}\text { Inzisionelle Entfernung von } \\
\text { >25\% der Wunde; lokale } \\
\text { Versorgung angezeigt }\end{array}$ & $\begin{array}{l}\text { Hernie ohne Nachweis einer } \\
\text { Einklemmung; fasziale } \\
\text { Unterbrechung/ Dehiszenz; } \\
\text { primärer Wundverschluss } \\
\text { oder Revision durch } \\
\text { operative Intervention } \\
\text { angezeigt }\end{array}$ & $\begin{array}{l}\text { Hernie mit Zeichen der } \\
\text { Einklemmung; } \\
\text { Transplantation, Resektion } \\
\text { oder Amputation angezeigt }\end{array}$ & Tod \\
\hline $\begin{array}{l}\text { Periphere } \\
\text { motorische und } \\
\text { sensorische } \\
\text { Neuropathie }\end{array}$ & Asymptomatisch & Moderate Symptome & Schwere Symptome & lebensbedrohlich & Tod \\
\hline Epilepsie & $\begin{array}{l}\text { Kurzer partieller } \\
\text { Krampfanfall; kein } \\
\text { Bewusstseinsverlust }\end{array}$ & $\begin{array}{l}\text { Kurzer generalisierter } \\
\text { Krampfanfall }\end{array}$ & $\begin{array}{l}\text { Mehrfache Anfälle, } \\
\text { Indikation zur medizinischen } \\
\text { Intervention }\end{array}$ & lebensbedrohlich & Tod \\
\hline Fatigue & durch Ruhe erleichtert & durch Ruhe nicht erleichtert & $\begin{array}{l}\text { eingeschränkte } \\
\text { Selbstversorgung }\end{array}$ & - & Tod \\
\hline Pruritus & $\begin{array}{l}\text { Leicht oder lokalisiert, } \\
\text { topische Intervention } \\
\text { angezeigt }\end{array}$ & $\begin{array}{l}\text { intensiv und großflächig; } \\
\text { intermittierend; } \\
\text { Hautveränderungen durch } \\
\text { Kratzen orale Intervention } \\
\text { angezeigt }\end{array}$ & $\begin{array}{l}\text { intensiv und großflächig; } \\
\text { konstant; orale } \\
\text { Corticosteroide oder } \\
\text { immunsuppressive Therapie } \\
\text { angezeigt }\end{array}$ & - & - \\
\hline
\end{tabular}


Tabelle 3: Schweregradeinteilung von unerwünschten Ereignissen. Gemäß CTCAE Version 4.03 (CTCAE 2016).

\begin{tabular}{|l|l|l|l|l|}
\hline $\begin{array}{l}\text { Infektionen } \\
\text { allgemein }\end{array}$ & (lokale Intervention) & Orale Intervention & $\begin{array}{l}\text { i. v. Antibiotika, } \\
\text { antifungizide oder antivirale } \\
\text { Intervention indiziert; } \\
\text { Indikation zur } \\
\text { radiologischen, } \\
\text { endoskopischen oder } \\
\text { operativen Intervention }\end{array}$ & lebensbedrohlich \\
\hline Stomatitis & $\begin{array}{l}\text { Lokalisiert, lokale } \\
\text { Intervention } \\
\text { i. v. antibiotische, } \\
\text { antifungale oder antivirale } \\
\text { Intervention }\end{array}$ & lebensbedrohlich \\
\hline Husten & Leichte Symptome & $\begin{array}{l}\text { Orale Intervention } \\
\text { Indikation zur medizinischen } \\
\text { Intervention }\end{array}$ & $\begin{array}{l}\text { Schwere Symptome } \\
\text { Tod }\end{array}$ & - \\
\hline
\end{tabular}




\section{Resultate}

\subsection{Patienten- und Tumorcharakteristika}

Elf Patienten, die im Rahmen einer palliativen medikamentösen Therapie bei fortgeschrittenem Magenkarzinom oder Adenokarzinom des gastroösophagealen Überganges im Zeitraum vom 01.11.2015 bis zum 01.09.2017 mindestens eine Gabe des Antikörpers Ramucirumab in Kombination mit einer Chemotherapie nach dem FOLFIRIRegime erhielten, wurden in diese Auswertung eingeschlossen. Die acht männlichen und drei weiblichen Patienten waren zum Zeitpunkt der Diagnosestellung der Karzinomerkrankung im Durchschnitt 67 Jahre alt und präsentierten sich darüber hinaus mit diversen vorbestehenden Erkrankungen (Abbildung 4) und Dauermedikationen.

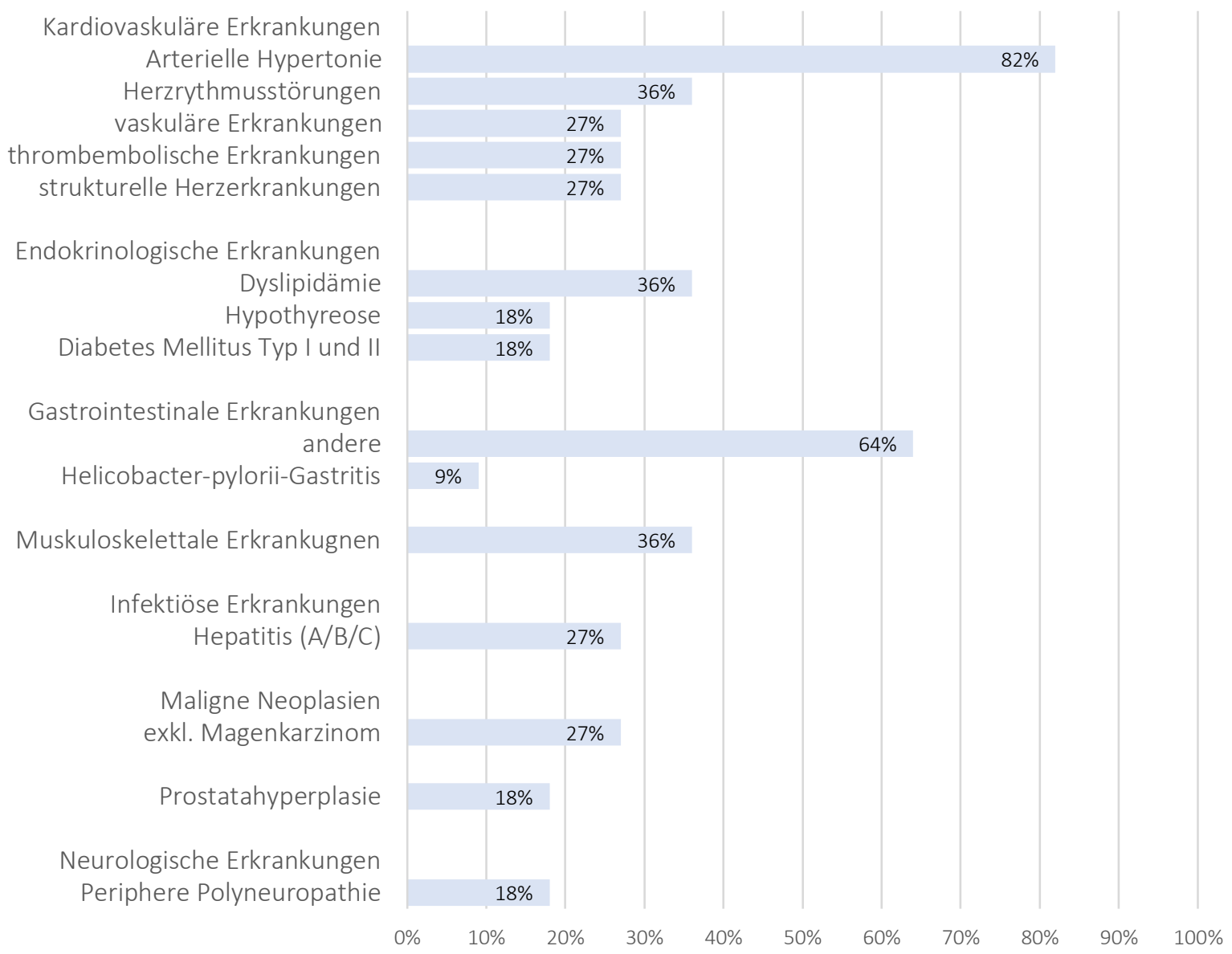

Abbildung 4: Vorerkrankungen.

Die Heterogenität der Magenkarzinome zeigte sich in den unterschiedlichen Ausprägungen der Tumorcharakteristika (Abbildung 5). Der Primärtumor befand sich bei vier Patienten im Bereich des ösophagogastralen Überganges. Jeweils zwei wurden in Korpus und Antrum 
lokalisiert, bei fünf Patienten blieb der genaue Ursprung des Magenkarzinoms unbekannt. Histologisch konnte bei allen Patienten ein Adenokarzinom nachgewiesen werden, davon wiesen 55 Prozent Siegelringzellen auf. Gemäß der Laurén-Klassifikation wurden drei dem intestinalen Typ und drei dem diffusen Typ zugeordnet. Bei den restlichen fünf ist die Laurén-Klassifikation unbekannt. Mehr als die Hälfte der Adenokarzinome waren wenig differenzierte Karzinome (G3) und alle wiesen einen HER2-negativen Rezeptorstatus auf.

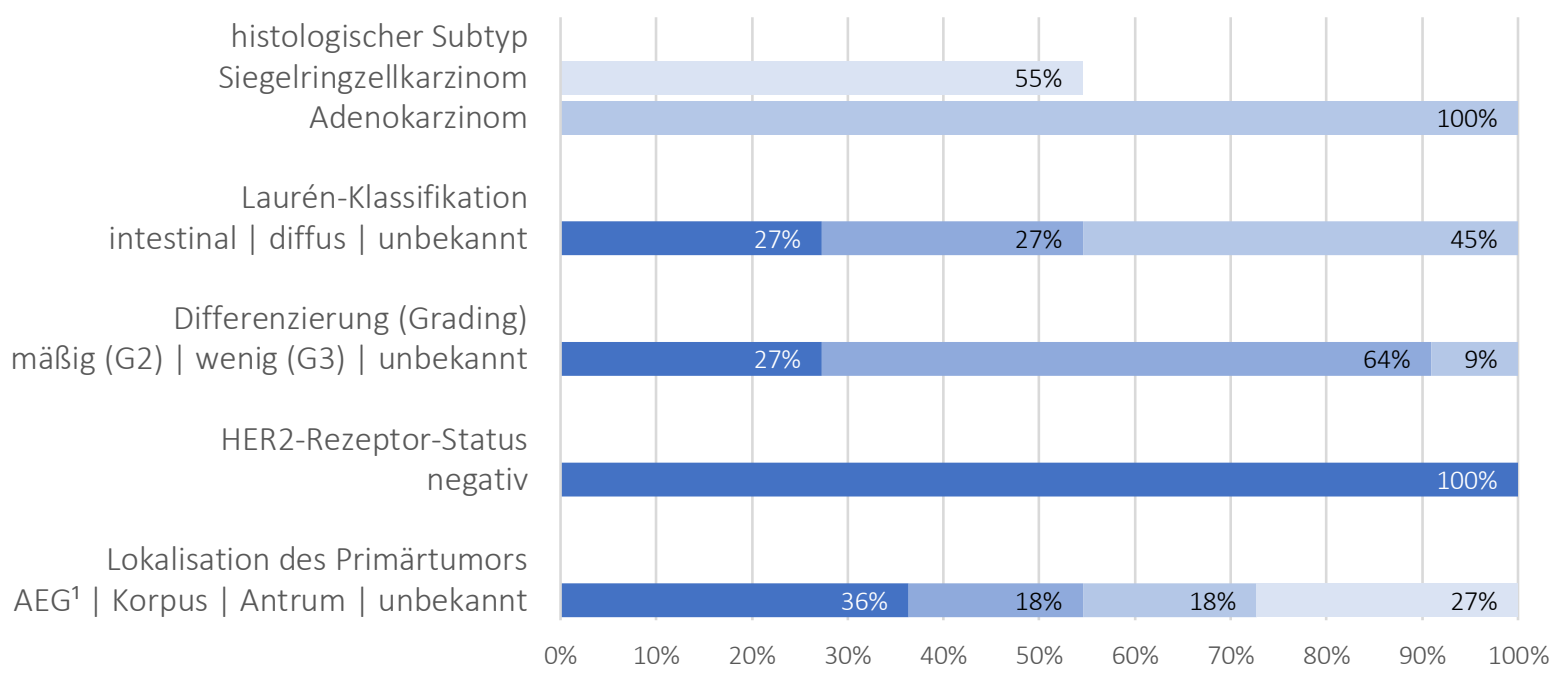

Abbildung 5: Tumorcharakteristika. ${ }^{1}$ Adenokarzinome des ösophagogastralen Überganges (AEG).

Alle Patienten befanden sich in einem fortgeschrittenen Stadium ihrer Erkrankung und wiesen Metastasen auf (Abbildung 6).

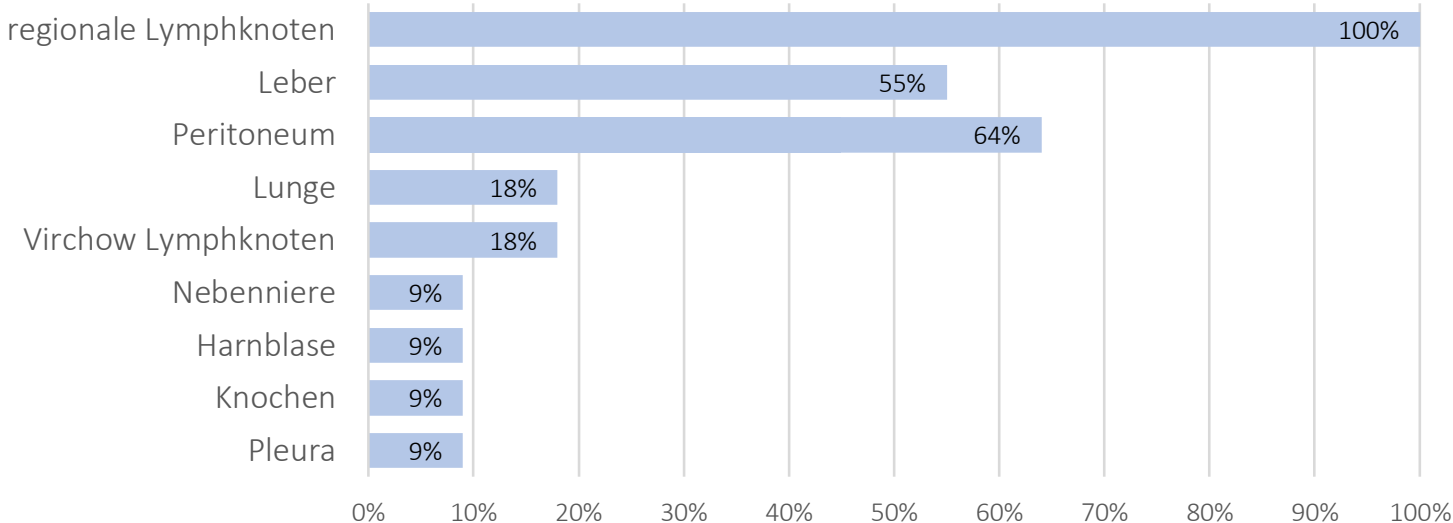

Abbildung 6: Lokalisationen der Metastasen.

Regionale Lymphknotenmetastasen zeigten sich bei 100 Prozent der Patienten und ein Befall des Virchow-Lymphknoten bei 18 Prozent der Patienten. Weiterhin zeigten sieben von elf Patienten Hinweise auf eine Peritonealkarzinose, welche in fünf Fällen histologisch bestätigt wurde. Mehr als die Hälfte der Patienten wies Leberfiliae auf. In einzelnen Fällen 
wurden zudem Metastasen in Lunge, Pleura, Knochen, Harnblase und Nebenniere nachgewiesen.

\subsection{Vorangegangene Therapien}

Die vorangegangenen Therapien variieren sowohl in der Anzahl als auch in der Art sehr stark zwischen den Patienten (Abbildung 7). In drei Fällen erfolgte nach neoadjuvanter Chemotherapie nach dem FLOT-Schema eine Gastrektomie, in einem Fall wurde die Chemotherapie postoperativ fortgeführt. In all diesen Fällen zeigte sich im Krankheitsverlauf, vor Beginn der systemischen Therapie mit Ramucirumab und FOLFIRI, ein Lokalrezidiv.

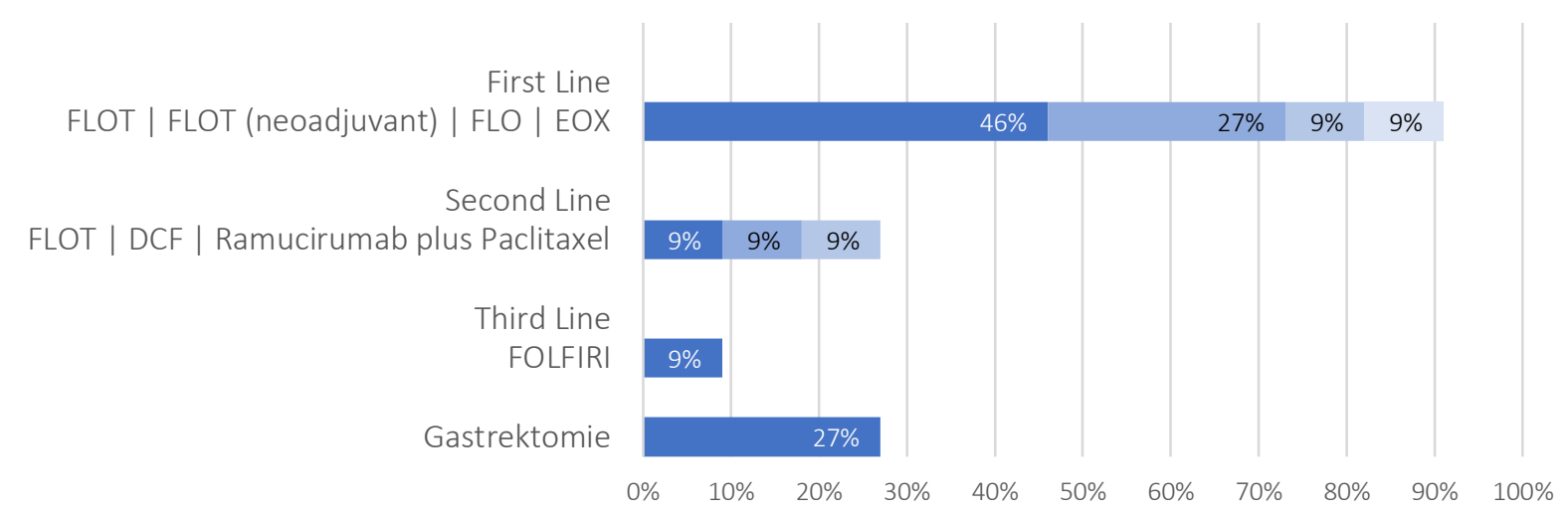

Abbildung 7: Vorangegangene Therapien.

Insgesamt erhielten zehn von elf Patienten eine Erstlinientherapie nach Diagnosestellung. Zusätzlich zu den drei Patienten, welche FLOT im Rahmen eines neoadjuvanten Therapiekonzeptes erhielten, wurden weitere fünf Patienten nach dem FLOT-Regime therapiert. Es wurden durchschnittlich zehn Zyklen appliziert. Jeweils in einem Fall erfolgte die Behandlung mit FLO beziehungsweise EOX. Drei Patienten erhielten vor Therapiebeginn mit Ramucirumab und FOLFIRI eine zweite systemische Therapie und in einem Fall erfolgte ein dritter Therapieversuch mit insgesamt 20 Zyklen FOLFIRI im Rahmen der Drittlinientherapie. Neun von zehn Patienten, die eine vorangegangene Therapie erhielten, wurden nach einem Taxan-haltigen Therapieschema behandelt. Diese vorangegangenen Therapieversuche wurden aus verschiedenen Gründen beendet. Zu diesen zählen ausgeprägte Nebenwirkungen, insbesondere Polyneuropathie und Thrombozytopenie, sowie in wenigen Fällen eine partielle Remission oder Gastrektomie mit konsekutiver Therapiepause. In einem Fall wurden ossäre Metastasen im Rahmen der palliativen symptomatischen Therapie bestrahlt. 


\subsection{Therapieansprechen}

Die systemische Therapie mit dem Antikörper Ramucirumab in Kombination mit der Chemotherapie nach dem FOLFIRI-Regime wurde bei den elf untersuchten Patienten durchschnittlich nach 18 Monaten mit einer Spanne zwischen minimal zwei und maximal 32 Monaten nach Diagnosestellung begonnen. Die Behandlung dauerte durchschnittlich fünf Monate und umfasste durchschnittlich neun Gaben (Abbildung 8; Abbildung 9).

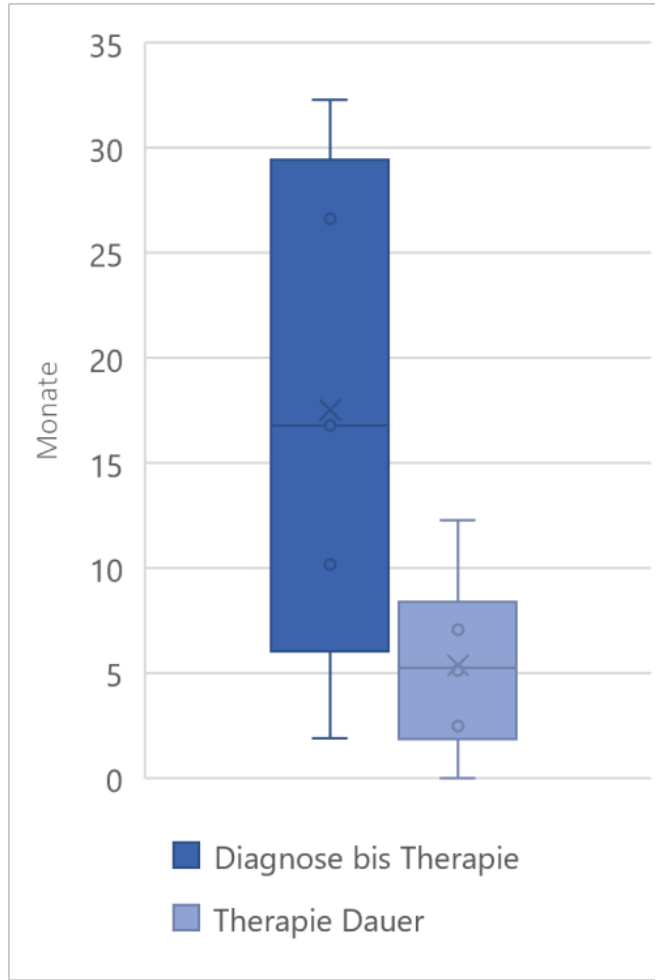

Abbildung 8: Diagnose bis Therapie und Therapiedauer in Monaten.

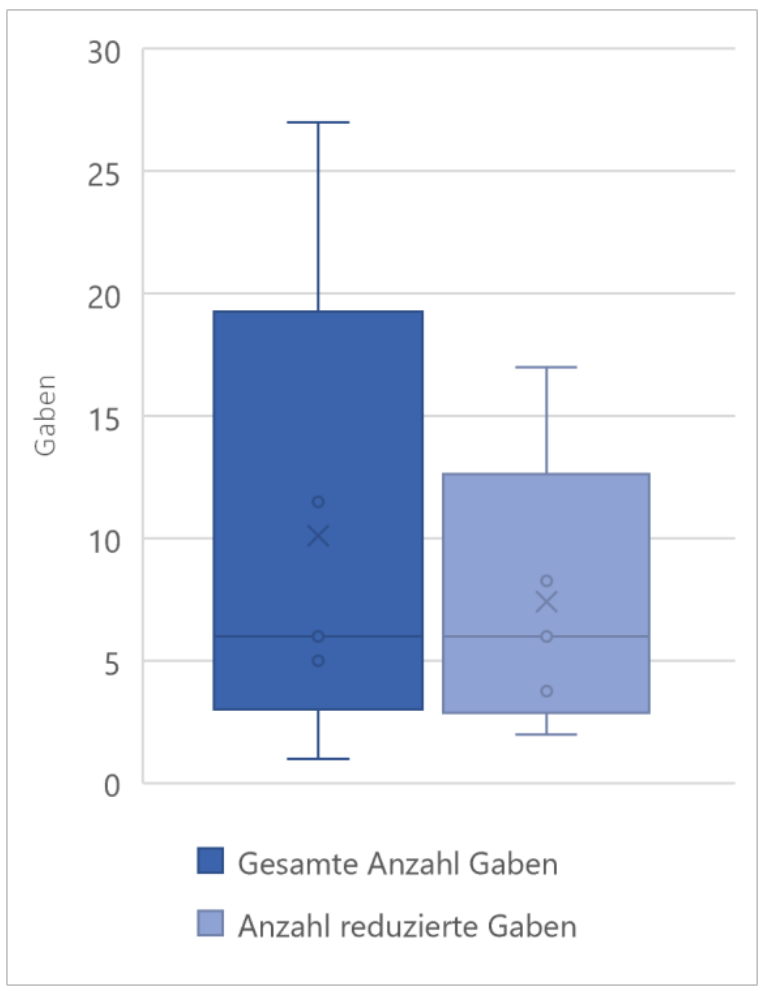

Abbildung 9: Anzahl der verabreichten Gaben gesamt und Anzahl der Gaben in reduzierter Dosierung.

Das mediane OS betrug 9,3 Monate mit einer Spanne von 0,3 bis 19,5 Monaten, wobei vier Patienten zum Endpunkt der Datensammlung noch lebten. Das mediane PFS betrug acht Monate. In den Kaplan-Meier-Kurven zum OS und PFS sind die Überlebensraten gegenüber der Zeit aufgetragen (Abbildung 10; Abbildung 11).

Die Patienten, welche zum Studienende noch lebten, werden als zensierte Fälle in der Kaplan-Meier-Kurve als Punkte dargestellt. Die 1-Jahres-Überlebenswahrscheinlichkeit nach Therapiebeginn mit FOLFIRI und Ramucirumab betrug 41 Prozent. 


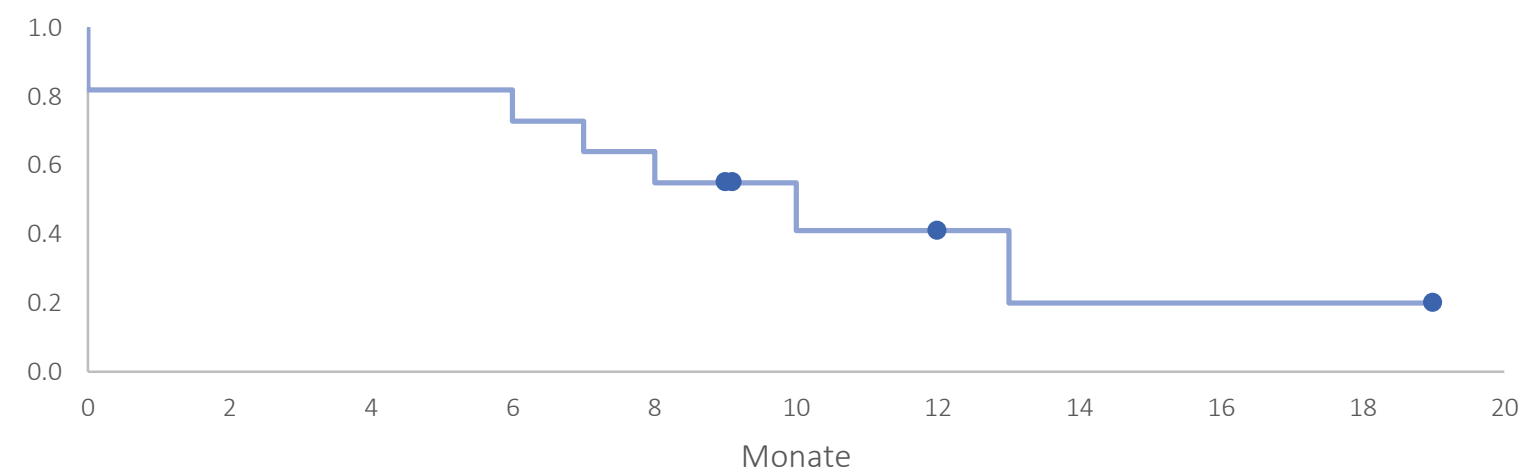

Abbildung 10: Kaplan-Meier-Kurve zum Overall Survival.

Progression Free Survival

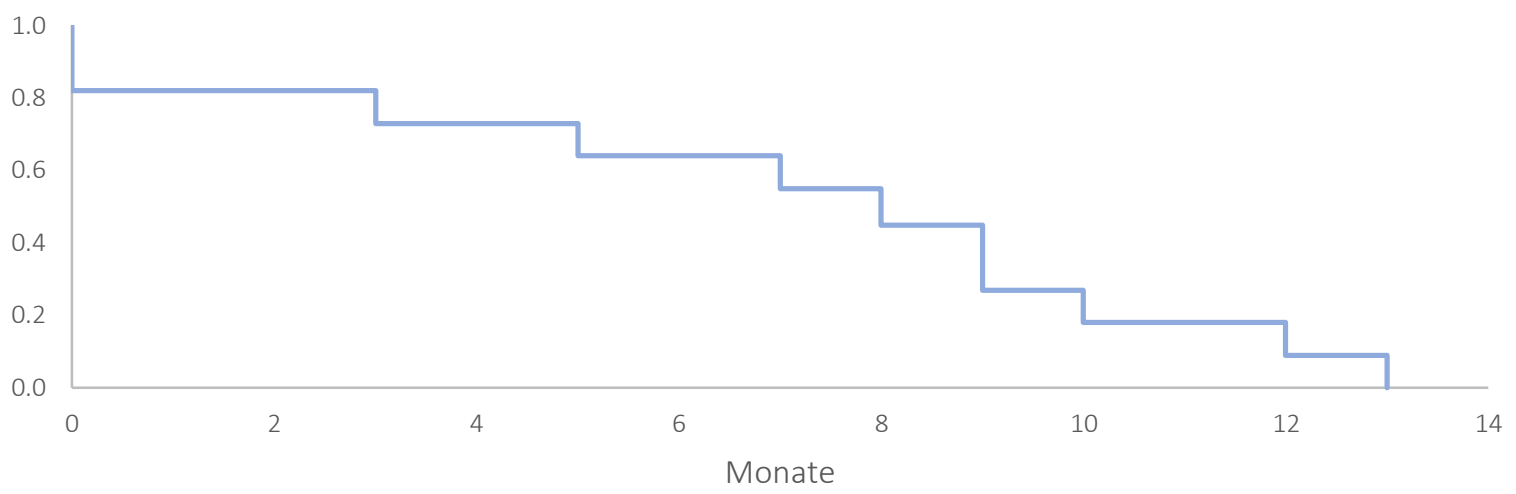

Abbildung 11: Kaplan-Meier-Kurve zum Progression Free Survival.

Nach drei Monaten Therapie mit FOLFIRI und Ramucirumab betrug die ORR bei insgesamt drei Patienten mit PR 27 Prozent und die DCR betrug 55 Prozent bei drei zusätzlichen Patienten mit SD in der Staginguntersuchung (Tabelle 3). Die Best Overall Response zeigte sich bei allen Patienten beim ersten Tumorassessment nach 3 Monaten, sodass ORR und DCR basierend auf dem besten Stagingergebnis mit 27 Prozent, respektive 55 Prozent, den Ansprechraten nach drei Monaten entsprechen.

Tabelle 4: Stagingergebnis nach Monaten.

\begin{tabular}{|l|l|l|l|l|}
\hline Pat. & $3 \mathrm{M}$ & $6 \mathrm{M}$ & $9 \mathrm{M}$ & $12 \mathrm{M}$ \\
\hline 1 & $\mathrm{SD}$ & $\mathrm{SD}$ & $\mathrm{SD}$ & $\mathrm{PD}$ \\
\hline 2 & $\mathrm{SD}$ & $\mathrm{SD}$ & $\mathrm{PD}$ & $\mathrm{PD}$ \\
\hline 3 & $\mathrm{PR}$ & $\mathrm{SD}$ & $\mathrm{PD}$ & \\
\hline 4 & $\mathrm{PR}$ & $\mathrm{PD}$ & & \\
\hline 5 & $\mathrm{PR}$ & & & \\
\hline 6 & $\mathrm{SD}$ & & & \\
\hline 7 & $\mathrm{PD}$ & & & \\
\hline 8 & $\mathrm{PD}$ & & & \\
\hline 9 & $\mathrm{PD}$ & & & \\
\hline 10 & PD & & & \\
\hline 11 & n. a. & & & \\
\hline
\end{tabular}


In der Analyse des Therapieansprechens nach 3 Monaten unter Berücksichtigung des histologischen Nachweises von Siegelringzellen zeigten im Vergleich zu nicht Siegelringzellhaltigen Magenkarzinomen weniger Patienten eine PR und mehr Patienten eine PD (Abbildung 12).

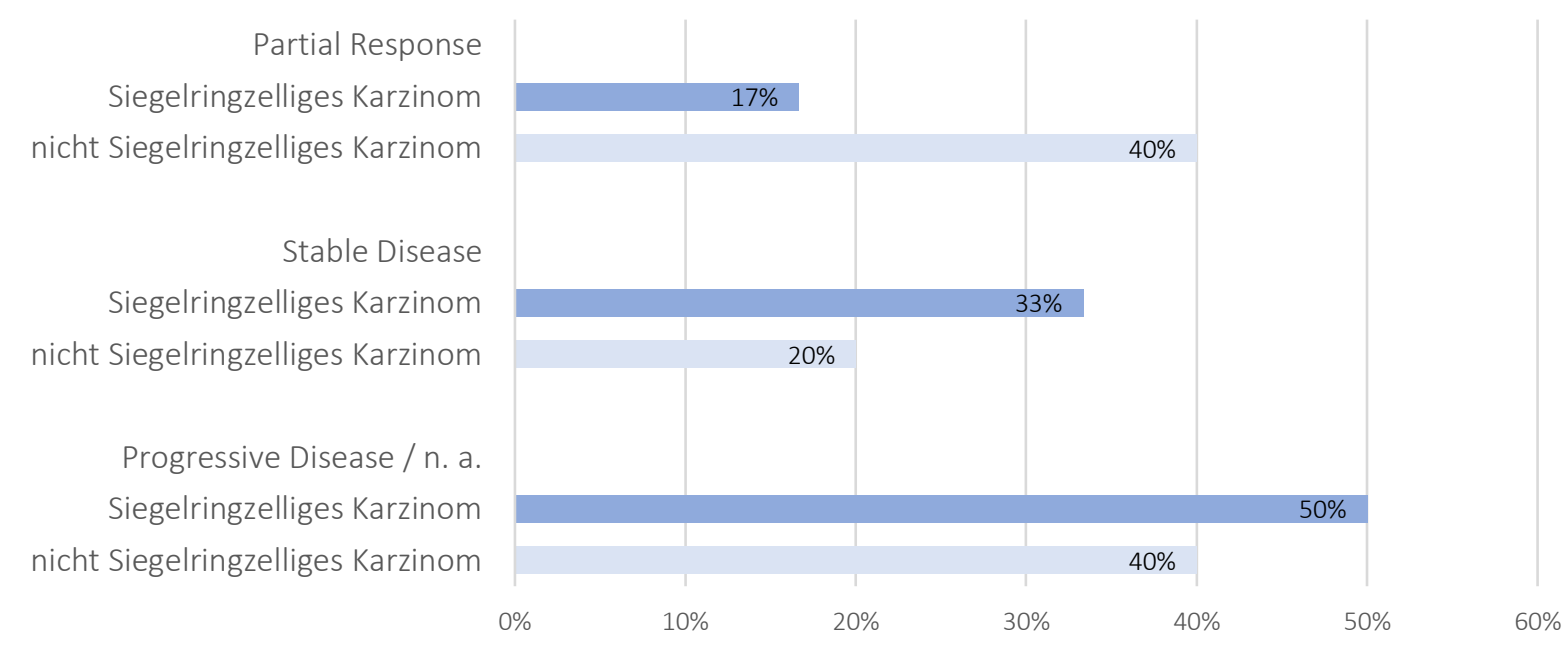

Abbildung 12: Therapieansprechen nach drei Monaten mit Bezug auf Nachweis von Siegelringzellen in der histologischen Typisierung des Magenkarzinoms.

Nach sechs Monaten nach Therapiebeginn konnte bei keinem Patienten eine PR oder CR nachgewiesen werden. Die DCR errechnete sich auf 27 Prozent, da drei Patienten in der Staginguntersuchung nach sechs Monaten eine SD zeigten.

Bei insgesamt sechs von elf Patienten erfolgte eine Dosisreduktion zu Beginn und/oder im Verlauf der Therapie. Aufgrund der gleichzeitigen Dauermedikation mit Amiodaron wurde in einem Fall während der gesamten Therapie Irinotecan in 50 prozentiger Dosis verabreicht. In einem weiteren Fall wurde bei vorbestehendem reduzierten Allgemeinzustand und Kachexie zu Therapiebeginn mit einer um 25 Prozent reduzierten FOLFIRIDosis begonnen. Bei fünf von elf Patienten mit fortgeschrittenem Magenkarzinom erfolgte im Verlauf eine Dosisreduktion von FOLFIRI auf 75 Prozent und in zwei Fällen wurde zusätzlich im Verlauf die Ramucirumab-Dosis auf 75 Prozent reduziert. Insgesamt wurden 42,4 Prozent der FOLFIRI-Gaben und 17,2 Prozent der Ramucirumab-Gaben in reduzierter Dosis verabreicht. Bei der Therapie der Patienten mit kolorektalem Karzinom erfolgte bei allen eine FOLFIRI-Dosisanpassung auf 75 Prozent oder weniger.

Es lagen diverse Gründe für eine Beendigung der Therapie mit Ramucirumab und FOLFIRI vor (Abbildung 13). In acht von elf Fällen wurde bei den Patienten mit fortgeschrittenem Magenkarzinom die Behandlung aufgrund eines Progresses beendet. Bei zwei Patienten konnte nach sechs beziehungsweise zwölf Gaben eine SD erreicht werden, sodass 
entweder eine Therapiepause oder eine palliative Gastrektomie erfolgten. In beiden Fällen kam es im weiteren Verlauf zu einem erneuten Progress. Ein Patient verstarb während der Kombinationstherapie. Insgesamt sechs Patienten erhielten nach Beendigung der systemischen Therapie mit Ramucirumab und FOLFIRI im Verlauf eine weitere palliative Therapie, wobei in zwei Fällen diese im Sinne einer Erhaltungstherapie mit entweder Ramucirumab-Monotherapie oder Ramucirumab und 5-FU plus Leucovorin zu werten ist.

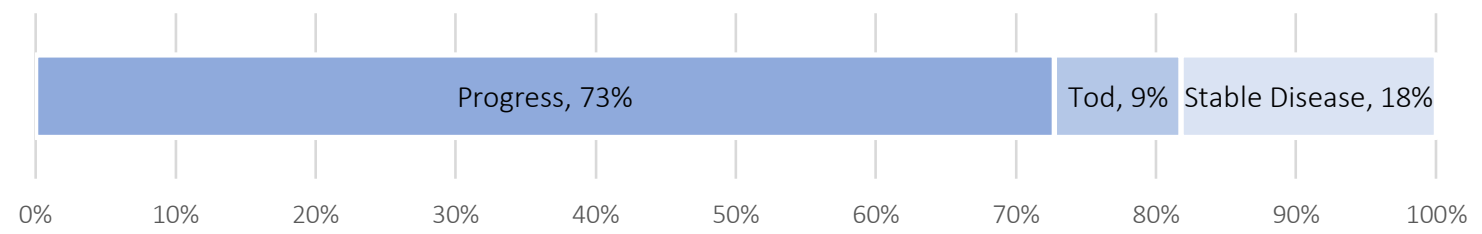

Abbildung 13: Gründe für Therapieende.

Zur Begrenzung der unerwünschten Wirkungen der Chemo- und Antikörpertherapie erhielten die Patienten im Rahmen eines individuellen Schemas gleichzeitig zur Therapiegabe unterstützende Medikamente (Abbildung 14). Im Vordergrund stand hier eine ausgeprägte antiemetische Therapie, welche in den meisten Fällen aus der Kombination verschiedener Präparate unterschiedlicher Substanzklassen bestand. Weiterhin erhielten alle Patienten zur Kontrolle cholinerger Wirkungen durch das in FOLFIRI enthaltene Irinotecan Atropin.

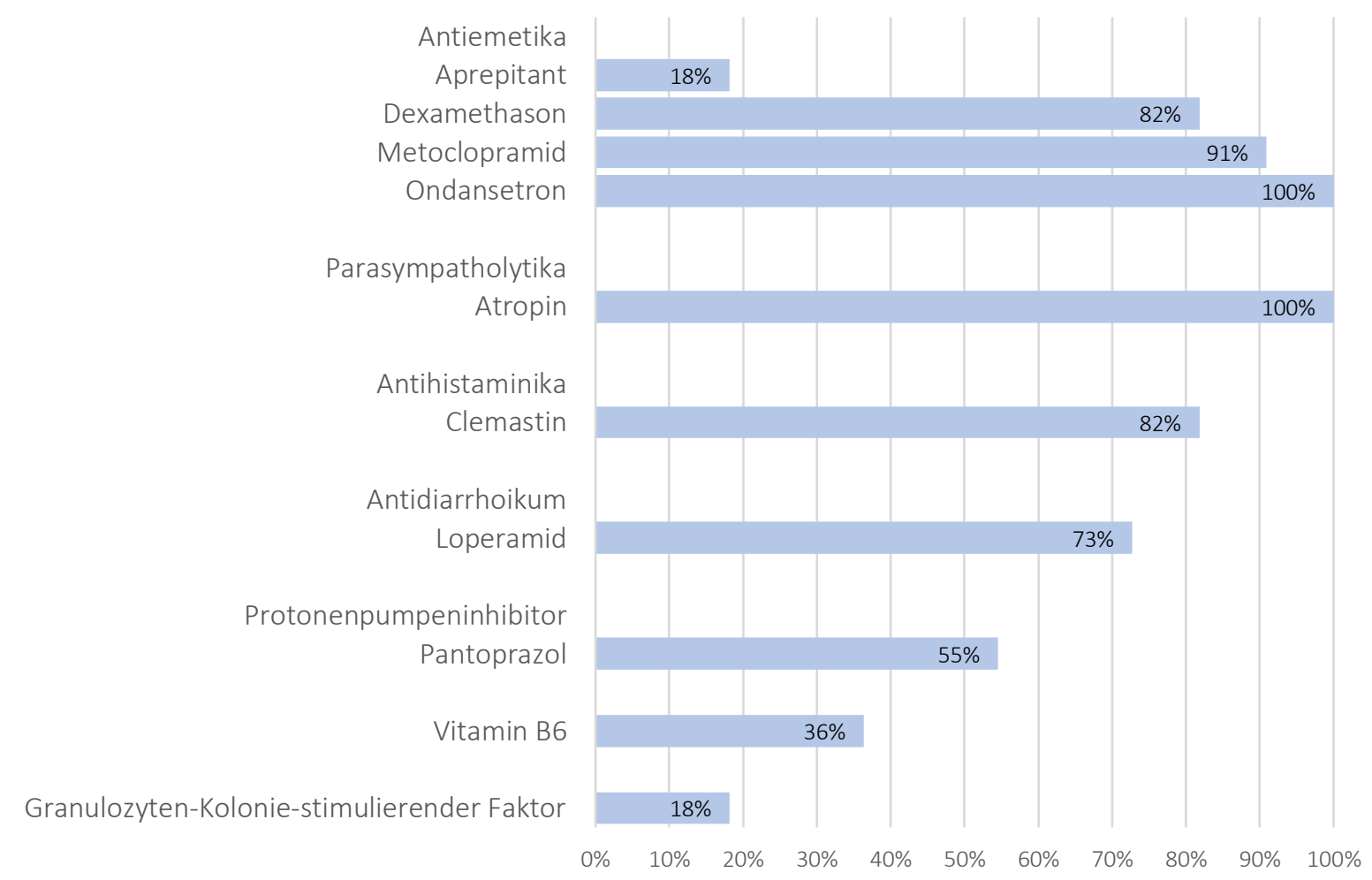




\subsection{Unerwünschte Ereignisse}

Für die Auswertung der laborchemisch gemessenen unerwünschten Ereignisse konnten zehn Patienten mit fortgeschrittenem Magenkarzinom und vier Patienten mit fortgeschrittenem kolorektalen Karzinom eingeschlossen werden. Aufgrund einer extern fortgeführten Therapie lagen in einem Fall keine Verlaufslaborwerte und Körpergewichtsmessungen vor.

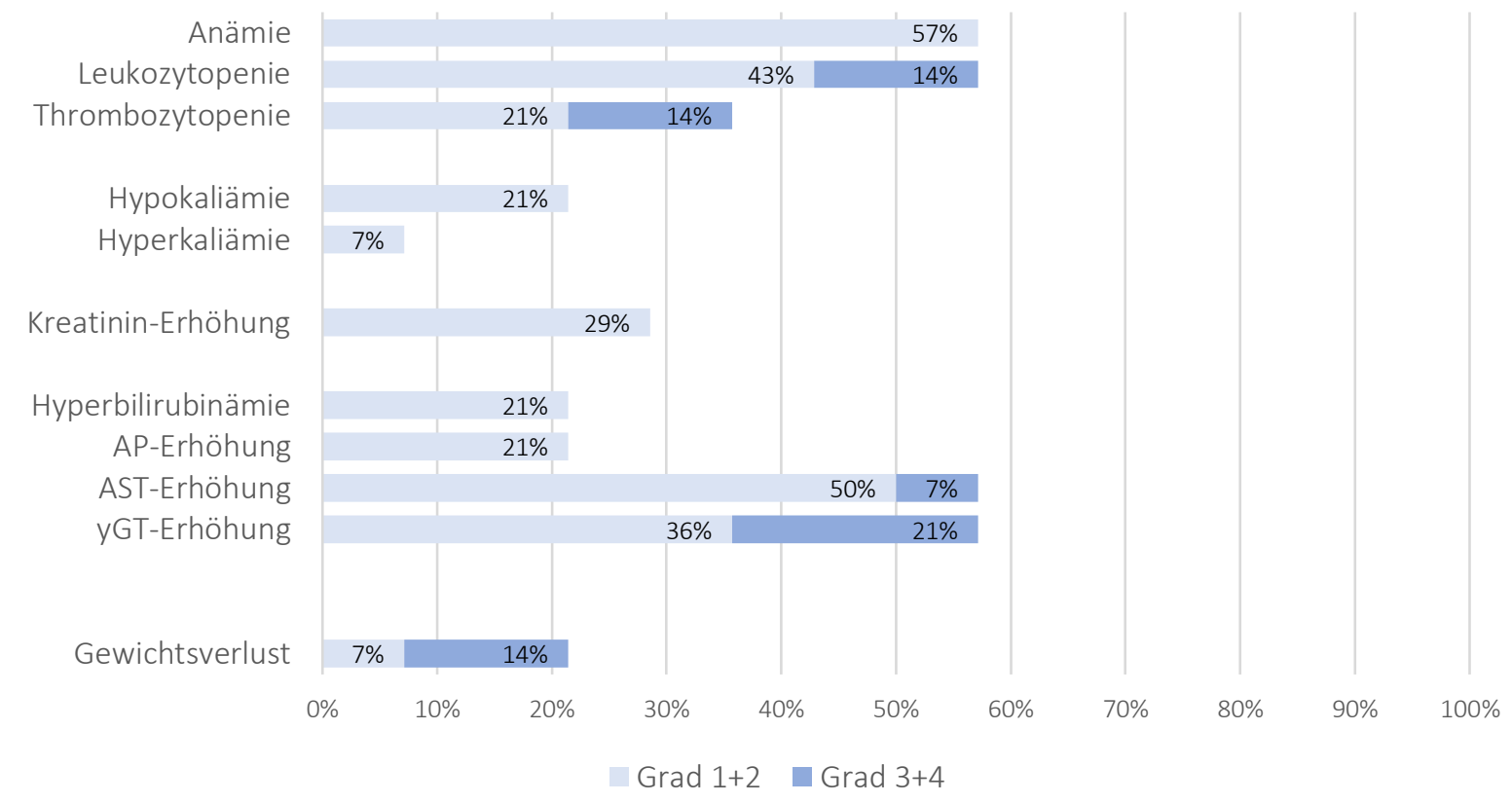

Abbildung 15: Unerwünschte Ereignisse nach CTCAE-Schweregraden.

Bei der Untersuchung der Hämatotoxizität zeigten sich gemäß den CTCAE-Kriterien unerwünschte Ereignisse Grad eins bis Grad vier (Abbildung 15). Jeweils 14 Prozent der Patienten zeigten Leukozytopenien und Thrombozytopenien dritten und vierten Grades. In der Dokumentation der leber- und cholestasespezifischen Parameter wurden dritt- und viertgradige Erhöhungen der Aspartat-Aminotransferase (AST) und Gamma-Glutamyltransferase (yGT) erfasst. Bei sieben Prozent traten höhergradige AST-Erhöhungen und bei 14 Prozent traten Erhöhungen der yGT auf. Für die leber- und cholestasespezifischen Parameter Bilirubin und alkalische Phosphatase wurden keine Erhöhungen im Sinne von dritt- oder viertgradigen unerwünschten Ereignisse verzeichnet. Als Hinweis für eine Nierenfunktionsstörung wurde der Verlauf des Kreatinins aufgezeichnet. Bei keinem Patienten stieg der Kreatinin-Wert auf mehr als den dreifachen Wert der Obergrenze, entsprechend CTCAE Grad drei oder schwerer. Ebenso wurden nur erst- oder zweitgradige Elektrolytstörungen nachgewiesen. 
Der Verlauf des Körpergewichtes war nicht nur für die Anpassung der gewichtsadaptierten Dosierung der Medikamente wichtig, sondern erlaubte auch einen vagen Rückschluss auf die Verträglichkeit der Therapie und den Allgemeinzustand des Patienten. Wobei insbesondere bei gastrointestinalen Tumormanifestationen eine genaue Differenzierung zwischen Therapie-assoziierten und erkrankungsbedingten Beschwerden bei der Nahrungsaufnahme schwierig ist. Insgesamt verloren drei der 14 Patienten im Verlauf der Therapie an Gewicht. Bei zwei Patienten war die Abnahme des Körpergewichtes drittgradig, was einem Verlust von mindestens 20 Prozent des Ausgangsgewichtes entspricht.

Zu den häufigsten und bei ungefähr der Hälfte der Patienten angegebenen klinisch präsentierten Symptomen zählten gastrointestinale Beschwerden mit Übelkeit und Erbrechen sowie abdominalen Schmerzen (Abbildung 16). Weiterhin gab zirka ein Drittel der Patienten Diarrhoen und/oder Obstipation im Verlauf der systemischen Therapie an. Ein weiteres häufiges unerwünschtes Ereignis ist Fatigue mit einem Auftreten bei 33 Prozent der Patienten.

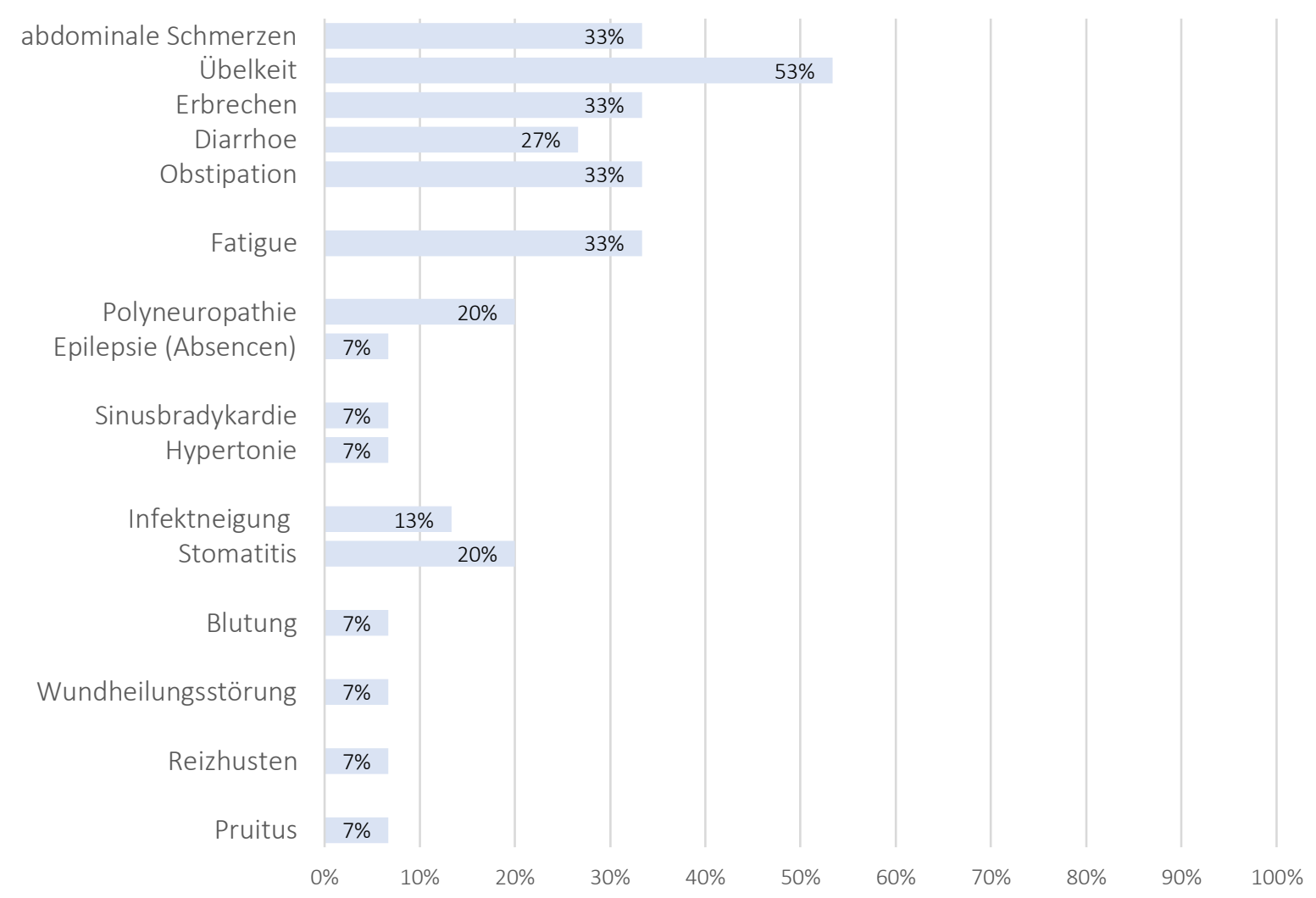

Abbildung 16: Unerwünschte Ereignisse.

Eine periphere Polyneuropathie war bei Diagnosestellung bei zwei der elf Patienten mit fortgeschrittenem Magenkarzinom vorbeschrieben. Bis zum Beginn der Therapie mit 
FOLFIRI und Ramucirumab waren insgesamt sieben der 15 auf unerwünschte Ereignisse hin untersuchten Patienten an einer peripheren Polyneuropathie erkrankt. Zumeist erkrankten die Patienten während vorangegangener Platin- und Taxan-haltigen Chemotherapien. In drei dieser sieben Fälle wurde ein neuer Aspekt oder eine Exazerbation der Polyneuropathie während der Therapie mit FOLFIRI und Ramucirumab verzeichnet. Insgesamt traten bei zwei Patienten kardiovaskuläre unerwünschte Ereignisse auf. Die Sinusbradykardie wird im Rahmen einer ausgeprägten cholinergen Reaktion auf Irinotecan gewertet. Hypertonien sind ein typisches unerwünschtes Ereignis bei der Therapie mit Ramucirumab.

Zur dauerhaften medikamentösen Therapie der unerwünschten Ereignisse konnten den schriftlichen Akten der elf Patienten mit fortgeschrittenem Magenkarzinom die Hinzunahme unterstützender Medikamente entnommen werden (Abbildung 17).

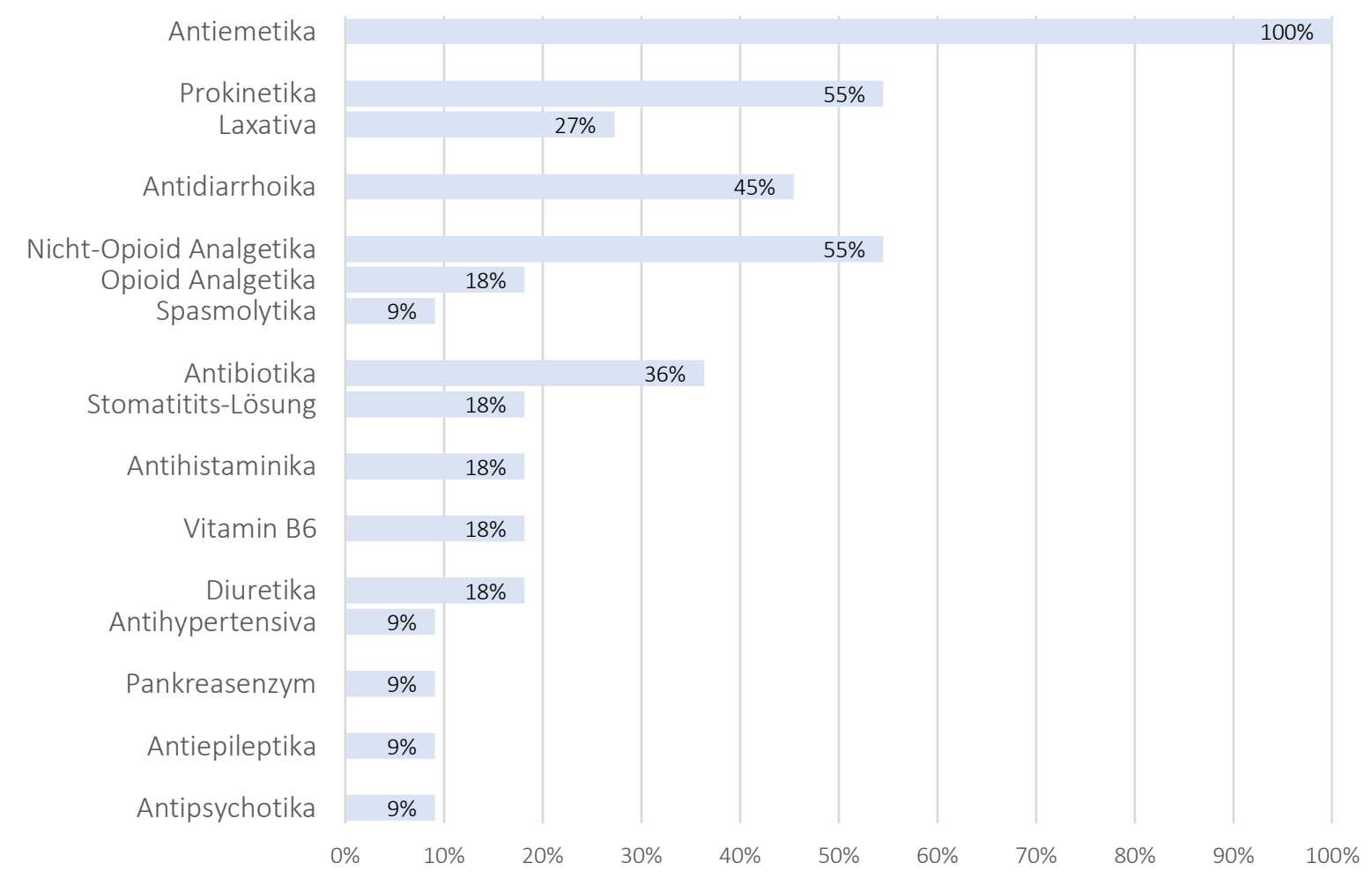

Abbildung 17: Hinzugenommene Dauermedikamente während Ramucirumab plus FOLFIRI-Therapie.

Alle Patienten erhielten zur antiemetischen Therapie 5-HT3-Rezeptor-Antagonisten, welche in manchen Fällen mit Dopamin-Antagonisten kombiniert wurden. Für die Therapie der abdominalen Schmerzen kamen Analgetika verschiedener WHO-Stufen bei mehr als der Hälfte der Patienten zum Einsatz. Ein Patient entwickelte unter der Therapie mit Ramucirumab und FOLFIRI eine Absenceepilepsie, welche in diesem Fall die Etablierung eines Antiepileptikums erforderte. Vitamin B6 wurde zur Therapie der Polyneuropathie 
sowohl im Rahmen der unterstützenden Medikation während der Verabreichung von Ramucirumab und FOLFIRI bei 36 Prozent der Patienten gegeben, als auch bei 18 Prozent der Patienten in die Dauermedikation aufgenommen.

In einem der 15 Fälle, die zur Untersuchung der unerwünschten Ereignisse einbezogen wurden, wurde ein Therapie-assoziierter Tod während der Behandlung mit Ramucirumab und FOLFIRI dokumentiert. Nach der ersten und einzigen Gabe der Kombinationstherapie präsentierte der Patient eine ausgeprägte Leukozytopenie und Thrombozytopenie und verstarb an einer Sepsis am zehnten Tage nach Therapiebeginn. 


\section{Diskussion}

\subsection{Datenerhebung}

Die Datenerhebung für die palliative Therapie mit Ramucirumab in Kombination mit FOLFIRI-Chemotherapie bei fortgeschrittenem Magenkarzinom und Adenokarzinomen des ösophagogastralen Überganges an der Universitätsmedizin Göttingen im Zeitraum vom 01.11.2015 bis zum 01.09.2017 erfolgte retrospektiv. Während des angegebenen Zeitraumes wurden elf Patienten mit fortgeschrittenen Adenokarzinomen des Magens oder ösophagogastralen Überganges und vier mit fortgeschrittenen kolorektalen Karzinomen mit der untersuchten Kombinationstherapie behandelt. Hieraus resultierte eine Patientenzahl von $\mathrm{n}=$ elf für die Analyse des Therapieansprechens und nach Hinzunahme der Patienten mit kolorektalen Karzinomen eine Anzahl von $n=15$ für die Auswertung der unerwünschten Ereignisse. Die elf Patienten mit Magenkarzinomen wiesen Unterschiede bezüglich Tumorcharakteristika, sowie Anzahl und Art vorangegangener Behandlungen auf. Aufgrund des kleinen Patientenumfanges erfolgte keine Analyse der Subgruppen.

Die unerwünschten Ereignisse wurden den handschriftlichen und elektronischen Patientenakten entnommen. Die Laborbestimmungen, Gewichtsmessungen und radiologischen Untersuchungen wurden nach standardisierten Schemata durchgeführt. Es erfolgte keine subjektive Einschätzung der Nebenwirkungen und Lebensqualität durch die Patienten selbst. Aus diesem Grund ergab sich eine unvollständige und in Teilen ungenaue Analyse der unerwünschten Ereignisse. Für die objektivierbaren Parameter, wie Laborwerte und Körpergewicht, erfolgte eine Schweregradeinteilung gemäß den CTCAE1.1Kriterien (CTCAE 2016). Das Auftreten der übrigen unerwünschten Ereignisse wurde qualitativ ausgewertet. Eine Nachverfolgung von Patienten, bei welchen die Therapie initial in Göttingen begonnen und im Verlauf heimatnah fortgeführt wurde, gelang beschränkt. Hieraus ergab sich eine unvollständige Erhebung, insbesondere der unerwünschten Ereignisse, und folglich gestaltete sich eine genaue Interpretation der Toxizitäten und ein Vergleich mit klinischen Studien erschwert. 


\subsection{Vergleich mit Phase-III-Studien}

Bisher wurden zwei klinische Phase-III-Studien zur Behandlung von Magenkarzinomen und Adenokarziomen des ösophagogastralen Überganges mit Ramucirumab in Mono- oder Kombinationstherapie im Rahmen einer Zweitlinientherapie abgeschlossen. Im Folgenden werden, nach Zusammenfassung dieser beiden Studien, die Resultate der REGARD-Studie und der RAINBOW-Studie mit der Analyse des Ramucirumab-plus-FOLFIRITherapieansatzes verglichen.

Im Rahmen der REGARD-Studie wurde im Zeitraum von Oktober 2009 bis Januar 2012 der Überlebensvorteil der Monotherapie mit Ramucirumab gegenüber einer Placebogabe bei 355 eingeschlossenen Patienten mit fortgeschrittenem und vorbehandeltem Magenkarzinom oder Adenokarzinomen des ösophagogastralen Überganges untersucht. In der RAINBOW-Studie erhielten 665 Patienten in 170 Zentren entweder Paclitaxel und Ramucirumab oder Paclitaxel und Placebo zwischen Dezember 2010 und September 2012. Eingeschlossen wurden Patienten mit fortgeschrittenem Adenokarzinom des Magens oder des ösophagogastralen Überganges, welche während oder innerhalb von vier Monaten nach Abschluss der first-line Chemotherapie einen Progress zeigten. Die Erstlinientherapie bestand bei allen Patienten aus einem Platinderivat und einem Fluoropyrimidin. In manchen Fällen wurde die Chemotherapie um ein Antracyclin, beispielsweise entsprechend des ECF- oder ECX-Schemas, erweitert.

Alle Patienten der jeweiligen Ramucirumab-Gruppen erhielten den Antikörper in gleicher Dosierung und nach demselben Schema mit acht Milligramm pro Kilogramm Körpergewicht alle 14 Tage. Es wurden Karzinome aller Laurén-Klassifikationen und Malignitätsgrade (Grading) eingeschlossen. Molekulare Biomarker waren für die Patientenselektion in keiner der Studien von Bedeutung. In beiden Phase-III-Studien war ein Progress unter einer vorangegangenen leitliniengerechten Erstlinientherapie gefordert. Für die Therapie mit Ramucirumab plus FOLFIRI wurden Patienten mit bis zu drei vorangegangenen systemischen Therapien eingeschlossen. Für die REGARD- und RAINBOW-Studien wurde als primärer Endpunkt das OS gewählt. Sekundär wurden unter anderem PFS, ORR und DCR, sowie das Auftreten von unerwünschten Ereignissen untersucht. 


\subsubsection{Therapieansprechen}

In der REGARD-Studie betrug das mediane OS 5,2 Monate für Patienten in der Ramucirumab Gruppe und 3,8 Monate in der Kontrollgruppe (Fuchs et al. 2014). Es ergab sich ein signifikanter Überlebensvorteil für die Antikörpertherapie bei einer hazard ratio von 0,776 mit einem Konfidenzintervall von 0,603 bis 0,998 und einem p-Wert von 0,047. Das PFS betrug 2,1 Monate mit Ramucirumabtherapie gegenüber 1,3 Monaten in der Placebogruppe. Die 1-Jahres-Überlebenswahrscheinlichkeit betrug 17,6 Prozent für die Patienten in der Ramucirumabgruppe. Für die Monotherapie mit Ramucirumab konnte nur eine niedrige ORR von vier Prozent nachgewiesen werden, jedoch konnte im Verglich zur Kontrollgruppe eine signifikant größere DCR von 45 Prozent gegenüber 23 Prozent, bei erheblich häufigerer SD als Best Overall Response, nachgewiesen werden.

In der RAINBOW-Studie war das OS im Ramucirumab-plus-Paclitaxel-Arm mit einem Median von 9,6 Monaten gegenüber dem Placebo-plus-Paclitaxel-Arm mit 7,4 Monaten, bei einer hazard ratio von 0,807 mit einem Konfidenzintervall von 0,678 bis 0,962 und einem p-Wert von 0,017, signifikant verlängert (Wilke et al. 2014). Weiterhin konnte ein verbessertes PFS von 4,4 Monaten gegenüber 2,9 Monaten für die antikörperhaltige Kombinationstherapie nachgewiesen werden. Die 1-Jahres-Überlebenswahrscheinlichkeit betrug 40 Prozent für die Patienten in der Ramucirumab-plus-Paclitaxel-Therapiegruppe. Im Vergleich zur Kontrollgruppe steigerte Ramucirumab die ORR um 28 Prozent entgegen 16 Prozent und die DCR auf 80 Prozent gegenüber 64 Prozent für Paclitaxel plus Placebo basierend auf dem besten Tumorassessment während der Therapie.

Zum Vergleich des Therapieansprechens auf die Kombinationstherapie mit Ramucirumab plus FOLFIRI-Chemotherapie gegenüber den Ergebnissen der REGARD- und RAINBOWStudien werden die Parameter OS, PFS und 1-Jahres-Überlebenswahrscheinlichkeit, sowie ORR und DCR nach Best Overall Response im Tumorassessment herangezogen. Hier zeigt sich für die Therapie mit Ramucirumab plus FOLFIRI gegenüber einer RamucirumabMonotherapie beim fortgeschrittenen und vorbehandelten Magenkarzinom ein deutlich längeres medianes OS von 9,3 Monaten gegenüber 5,2 Monaten (Abbildung 18). Hingegen ist das mediane OS von 9,6 Monaten der RAINBOW-Studie vergleichbar mit dem OS unter Ramucirumab und FOLFIRI. 


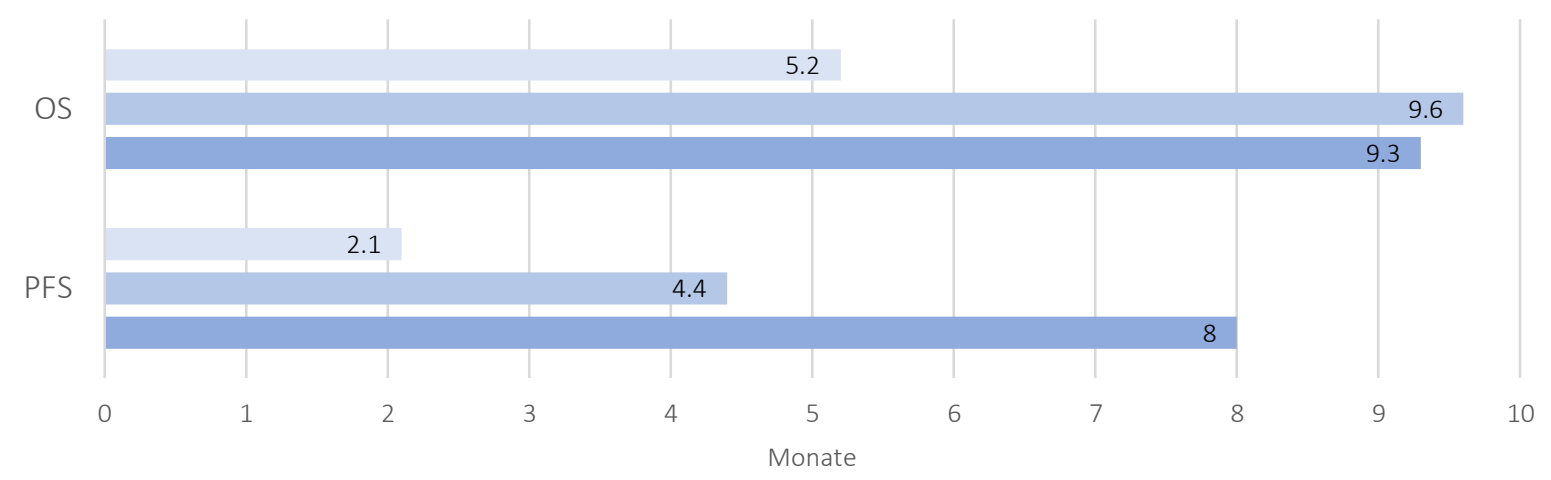

Ramucirumab (REGARD) ${ }^{1} \quad$ Ramucirumab + Paclitaxel (RAINBOW) ${ }^{2} \quad$ Ramucirumab + FOLFIRI $^{3}$

Abbildung 18: Medianes Overall Survival (OS) und medianes Progression Free Survival (PFS) in Monaten. ${ }^{1}$ REGARD-Studie (Fuchs et al. 2014) ${ }^{2}$ RAINBOW-Studie (Wilke et al. 2014) ${ }^{3}$ Ramucirumab und FOLFIRI (eigenes Ergebnis).

Das PFS zeigte sich mit 8 Monaten deutlich höher unter Ramucirumab plus FOLFIRI gegenüber den Ergebnissen der REGARD- und RAINBOW-Studien (Abbildung 19).

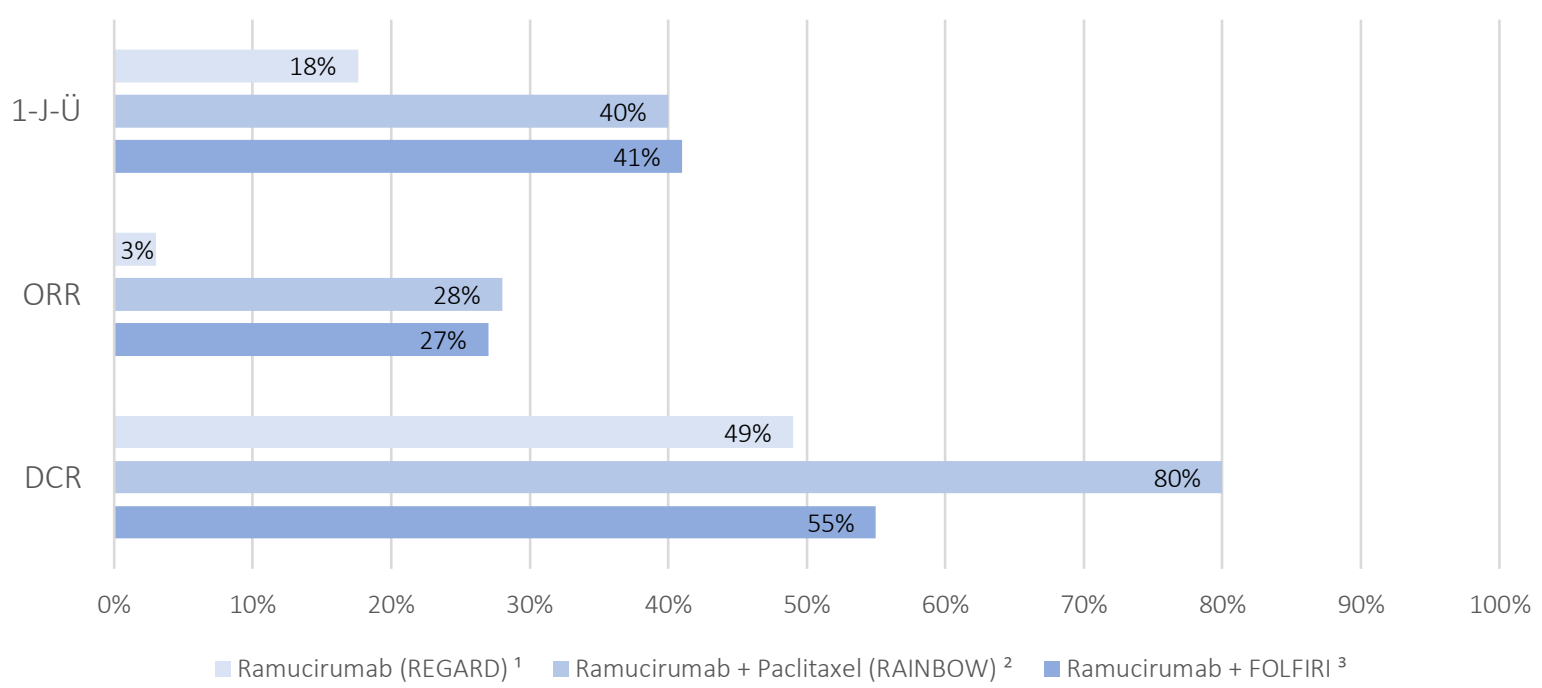

Abbildung 19: 1-Jahres-Überlebenswahrscheinlichkeit (1-J-Ü), Objective Response Rate (ORR) und Disease Control Rate (DCR) ${ }^{1}$ REGARD-Studie (Fuchs et al. 2014) ${ }^{2}$ RAINBOW-Studie (Wilke et al. 2014) ${ }^{3}$ Ramucirumab und FOLFIRI (eigenes Ergebnis).

Ein zu berücksichtigender Faktor ist hier, dass sowohl in der REGARD- als auch in der RAINBOW-Studie ein Tumorassessment nach jeweils sechs Wochen während der Therapie erfolgte. Während Ramucirumab plus FOLFIRI erfolgte alle zwölf Wochen eine Staginguntersuchung, sodass ein Progress möglicherweise erst später detektiert wurde und so ein längeres PFS berechnet wurde. Die 1-Jahres-Überlebenswahrscheinlichkeit für Ramucirumab plus FOLFIRI entspricht mit 41 Prozent in etwa der für Ramucirumab plus Paclitaxel. Auch für den Vergleich der ORR und DCR sind die unterschiedlichen Abstände des Tumorassessments von zwölf Wochen gegenüber sechs Wochen zu beachten. Die ORR entsprach mit 27 Prozent für Ramucirumab plus FOLFIRI ungefähr dem Ergebnis der 
RAINBOW-Studie. Die DCR für Ramucirumab und FOLFIRI zeigte sich hingegen mit 55 Prozent eher im Bereich der REGARD-Studie. In Zusammenschau dieser Ergebnisse konnte für Patienten mit fortgeschrittenem Magenkarzinom unter Ramucirumab plus FOLFIRI ein vergleichsweise gutes Therapieansprechen und verglichen mit einer RamucirumabMonotherapie ein potentieller Überlebensvorteil für die Kombinationstherapie gezeigt werden. Dieser Überlebensvorteil basiert möglicherweise auf einer additiven oder synergistischen Wirksamkeit von Ramucirumab und FOLFIRI, wie sie für Ramucirumab und FOLFOX angenommen wird (Yoon et al. 2016). Aufgrund des kleinen Patientenumfanges und einer fehlenden Kontrollgruppe kann jedoch keine Aussage über Signifikanzen getroffen werden.

\subsubsection{Toxizität und Lebensqualität}

Für die Chemotherapie nach dem FOLFIRI-Schema bei fortgeschrittenem Magenkarzinom wurde in mehreren Studien ein nebenwirkungsärmeres und damit günstigeres Toxizitätsprofil gegenüber beispielswiese Platin-haltigen Therapien beschrieben (Dank et al. 2008; Guimbaud et al. 2014). Die häufigsten schweren unerwünschten Ereignisse waren Leuko- und Neutrozytopenie, Anämie und Diarrhoe. Für den Antikörper Ramucirumab wurde die Hypertonie sowohl in der REGARD-Studie (16 Prozent) als auch in der RAINBOW-Studie (25 Prozent) als häufigstes Grad drei unerwünschtes Ereignis identifiziert (Fuchs et al. 2014; Wilke et al. 2014). Ihre Inzidenz war zweifach respektive vierfach im Vergleich zu den jeweiligen Placebo-Gruppen erhöht. In keiner der beiden Studien traten Grad vier oder fünf Hypertonien auf. Für zielgerichtete Therapien gegen VEGF-Rezeptoren, wie beispielsweise Ramucirumab, konnten in verschiedenen Arbeiten ein häufigeres Auftreten von Blutungen und Wundheilungsstörungen gezeigt werden (Chen und Cleck 2009). In der REGARD-Studie traten bei 13 Prozent der Patienten der RamucirumabGruppe gegenüber elf Prozent in der Placebo-Gruppe Blutungen auf. In der RAINBOWStudie hingegen war das Auftreten von Blutungen mehr als verzweifacht (42 Prozent gegenüber 18 Prozent). In beiden Studien war in jeweils beiden Gruppen die Inzidenz von drittgradigen oder schwereren Blutungskomplikationen kleiner als vier Prozent. Das Auftreten von anderen nicht-hämorrhagischen unerwünschten Ereignissen, wie Fatigue, abdominalen Schmerzen, verminderter Appetit, Erbrechen und Obstipation, war in der REGARD-Studie in beiden Gruppen ähnlich. Diese, bei Magenkarzinomen häufig auftretenden Symptome waren auch in der RAINBOW-Studie unter den häufigsten 
dokumentierten unerwünschten Ereignissen. In der REGARD-Studie konnte für die Ramucirumab-Monotherapie gegenüber der Placebogabe keine gesteigerte Hämatotoxizität nachgewiesen werden. Demgegenüber steht ein deutlich vermehrtes Auftreten von Neutrozytopenie und Leukozytopenie in der Ramucirumab-plus-Paclitaxel-Gruppe im Vergleich zur Kontrollgruppe der RAINBOW-Studie. Bezüglich des unerwünschten Ereignisses Leberfunktionsstörung und -versagen betrug die Inzidenz im Ramucirumabplus-Paclitaxel-Arm der RAINBOW-Studie 17 Prozent gegenüber zwölf Prozent im PlaceboArm.

Im Vergleich zu den oben beschriebenen unerwünschten Ereignissen aus den beiden Phase-III-Studien lässt sich für das Auftreten von unerwünschten Ereignissen unter Ramucirumab plus FOLFIRI ein ähnliches Profil abgrenzen. Auch hier ist zu berücksichtigen, dass die kleine Patientenkohorte der eigenen Untersuchung einen signifikanten Vergleich nicht erlaubt. Bei einem von 15 Patienten trat eine Hypertonie auf und erforderte die Hinzunahme eines Antihypertonikums (Grad drei). Weiterhin lag die Inzidenz von Blutungen bei 6,7 Prozent, entsprechend einem Patienten. Gastrointestinale Beschwerden wie Übelkeit und Erbrechen, Diarrhoen, Obstipation und abdominale Schmerzen waren die am häufigsten auftretenden unerwünschten Ereignisse und führten bei allen Patienten mit Magenkarzinom zu einer Eskalation der antiemetischen Therapie. Weiterhin wurde in mehr als der Hälfte der Fälle eine Schmerztherapie etabliert. Bezüglich der Hämatotoxizität zeichnete sich bei knapp 60 Prozent der Patienten eine Anämie ab, welche jedoch in keinem Fall den CTCAE-Schweregrad zwei überschritt. Dritt- und viertgradige unerwünschte Ereignisse traten mit jeweils 14 Prozent für Leukozytopenie und Thrombozytopenie auf. Vergleichsweise lag die Inzidenz für dritt- oder schwerergradige Leukozytopenien in der RAINBOW-Studie bei 17 Prozent. In zwei von elf Fällen wurde während der Behandlung mit Ramucirumab plus FOLFIRI eine Therapie mit dem Granulozyten-Kolonie-stimulierenden-Faktor durchgeführt. Als Ausdruck einer schwereren Leberfunktionsstörung, entsprechend Grad drei und größer, zeigten sich Transaminasenund Gamma-GT-Erhöhungen mit sieben und 21 Prozent.

Zur weiteren Einordnung der Toxizität und Verträglichkeit wurden die Anzahl und Gründe für stationäre Aufnahmen während der Therapie mit Ramucirumab plus FOLFIRI betrachtet. Insgesamt kam es bei knapp 67 Prozent, also zehn der 15 Patienten, zu einer oder mehreren stationären Aufnahmen. Drei Patienten erhielten alle Therapiegaben im 
stationären Rahmen. Gründe hierfür waren beispielsweise ein reduzierter Allgemeinzustand. Bei einem Patienten kam es während der Behandlung zu rezidivierenden Sinusbradykardien, welche stationäres Monitoring erforderten. Dieses unerwünschte Ereignis ist am ehesten auf die Irinotecanwirkung im Sinne eines cholinergen Syndroms zurückzuführen und bedurfte einer höheren Atropindosis im Vergleich zur durchschnittlichen unterstützenden Therapie. Bei drei weiteren Patienten wurden einzelne Gaben von Ramucirumab plus FOLFIRI stationär gegeben, in zwei Fällen war es die erste Gabe. Knapp 27 Prozent, entsprechend vier von 15 Patienten, wurden wegen unerwünschten Ereignissen und Reduktion des Allgemeinzustandes oder Progress stationär aufgenommen.

In einem Fall wurde ein Therapie-assoziierter Tod dokumentiert. Die ausgeprägte Leukozytopenie und konsekutive schwere Sepsis ist möglicherweise durch eine potenzierte Hämatotoxizität des Irinotecans während gleichzeitig bestehender Amiodarontherapie zu erklären. Bei diesem Patienten erfolgte keine Dosisreduktion des Irinotecans im FOLFIRI Schema. Die Medikamenteninteraktion wird bei gleichzeitiger Anwendung im Rahmen einer verzögerten Verstoffwechselung des aktiven Metabolit SN38 des Irinotecans und des Amiodarons aufgrund einer Konkurrenz um denselben zellulären Exporter und weiterhin durch eine für den SN38 Metabolismus relevanten Enzyminhibition durch Amiodaron erklärt (Wishart et al. 2006).

In den verbliebenen 14 Fällen wurde kein Therapieabbruch aufgrund von unerwünschten Ereignissen verzeichnet. Hieraus lässt sich schlussfolgern, dass sich mit Hilfe der unterstützenden Medikationen zeitgleich zur Verabreichung von Ramucirumab und FOLFIRI, gegebenenfalls Dosisreduktion von FOLFIRI und in seltenen Fällen auch von Ramucirumab, sowie der Anpassung der Bedarfs- und Dauermedikamente eine gute Symptom-kontrolle erreichen ließ.

Es erfolgte für die Patienten mit Ramucirumab plus FOLFIRI keine Umfrage bezüglich der subjektiv wahrgenommenen Nebenwirkungen und Lebensqualität. Aus der REGARD-Studie lässt sich entnehmen, dass die subjektive Lebensqualität unter der Ramucirumabtherapie im Vergleich zur Placebo-Gruppe in 24 Prozent gegenüber 13 Prozent als gleich oder verbessert empfunden wurde (Fuchs et al. 2014). Folglich kann die Durchführung einer Zweitlinientherapie neben dem Gesichtspunkt der Lebensverlängerung auch mit dem Aspekt der verbesserten Lebensqualität begründet werden. 
Insgesamt ergab sich die Therapie mit Ramucirumab und FOLFIRI in der eigenen Untersuchung als sichere Substanzkombination und zeigte im Rahmen einer zweitlinigen oder späteren Therapie ein akzeptables Toxizitätsprofil.

\subsection{Therapieoptionen}

Der Standard für die Erstlinientherapie bei fortgeschrittenem Magenkarzinom oder Adenokarzinomen des ösophagogastralen Überganges ist gemäß der deutschen S3Leitlinie eine zweifache Kombinationstherapie aus einem Platinderivat und einem Fluoropyrimidin, gegebenenfalls mit Erweiterung um ein Taxan im Sinne des FLOTProtokolls (Leitlinie Magenkarzinom 2012). Für die Untergruppe von Patienten mit HER2positiven Karzinomen hat die erfolgreiche ToGA-Studie zu einer Etablierung von Trastuzumab zusätzlich zu einem Platinderivat und Fluoropyrimidin in der Erstlinientherapie geführt (Bang et al. 2010). Durch die Hinzunahme von Trastuzumab resultierte in der Studie ein medianes OS von 16 Monaten für die Subgruppen mit IHC3+ oder IHC2+ und FISH+ Tumoren. Bis jetzt gibt es keine Empfehlung für molekular zielgerichtete Therapien bei HER2-negativen Karzinomen in der Erstlinientherapie.

Bezüglich der Zweitlinientherapie im Stadium IV gibt es weniger Konsens. In der aktuellen deutschen S3-Leitline sind Ramucirumab und Paclitaxel jeweils in Monotherapie und in Kombination, sowie Irinotecan und Docetaxel zugelassen (Leitlinie Magenkarzinom 2012). In einer Metaanalyse von Phase-III-Studien für Zweitlinientherapien variierte das OS für die Therapiegruppen zwischen vier und 9,6 Monaten (Abbildung 20, Studien 1-6) (Young et al. 2015). Dem gegenüberstehend betrug das OS für die Kontrollgruppen, welche alle BSC und in manchen Studien ein Placebo erhielten, 2,4 bis 3,8 Monate. Bei der Gegenüberstellung der Studien zu Zweitlinientherapien ist zu beachten, dass bei der Untersuchung von Paclitaxel gegenüber Irinotecan bei ungefähr 80 Prozent der Patienten eine Drittlinientherapie angeschlossen wurde (Hironaka et al. 2013). Der Überlebensvorteil ist so nicht unbedingt alleinig der Therapie mit Irinotecan oder Paclitaxel zuzurechnen.

In der RAINBOW-Studie wird konkludiert, dass die Kombinationstherapie mit Ramucirumab und Paclitaxel als neuer Standard in der Zweitlinientherapie des fortgeschrittenen Magenkarzinoms betrachtet werden könnte (Wilke et al. 2014). Allerdings wurden in dieser Studie nur Patienten inkludiert, welche in der Erstlinientherapie kein Taxan erhielten. Aufgrund der erfolgreichen FLOT4-Studie, in welcher die perioperative 
Chemotherapie nach dem FLOT-Schema mit dem ECF/ECX-Schema verglichen wurde, erhalten bereits viele Patienten ein Taxan in ihrem ersten Chemotherapieregime. In der aktuellen Leitlinie in Deutschland ist zum jetzigen Zeitpunkt noch eine Therapie nach ECFSchema der Standard, in der Zukunft ist jedoch eine Empfehlung des FLOT-Regimes mit jeweils vier prä- und postoperativen Zyklen gemäß der FLOT4-Studie zu erwarten (Leitlinie Magenkarzinom 2012).

1. Studie von Hironka et al. 2013

Paclitaxel

Irinotecan

2. COUGAR-02 Studie von Ford et al. 2014

Docetaxel

BSC

3. Studie von Kang et al. 2012

Docetaxel oder Irinotecan

BSC

4. Studie von Thuss-Patience et al. 2011

Irinotecan

BSC

5. REGARD Studie von Fuchs et al. 2014

Ramucirumab

Placebo und BSC

6. RAINBOW Studie von Wilke et al. 2014

Ramucirumab und Paclitaxel

Paclitaxel

7. Studie von Satake et al. 2018

Ramucirumab und Irinotecan

8. eigenes Ergebnis Ramucirumab und FOLFIRI

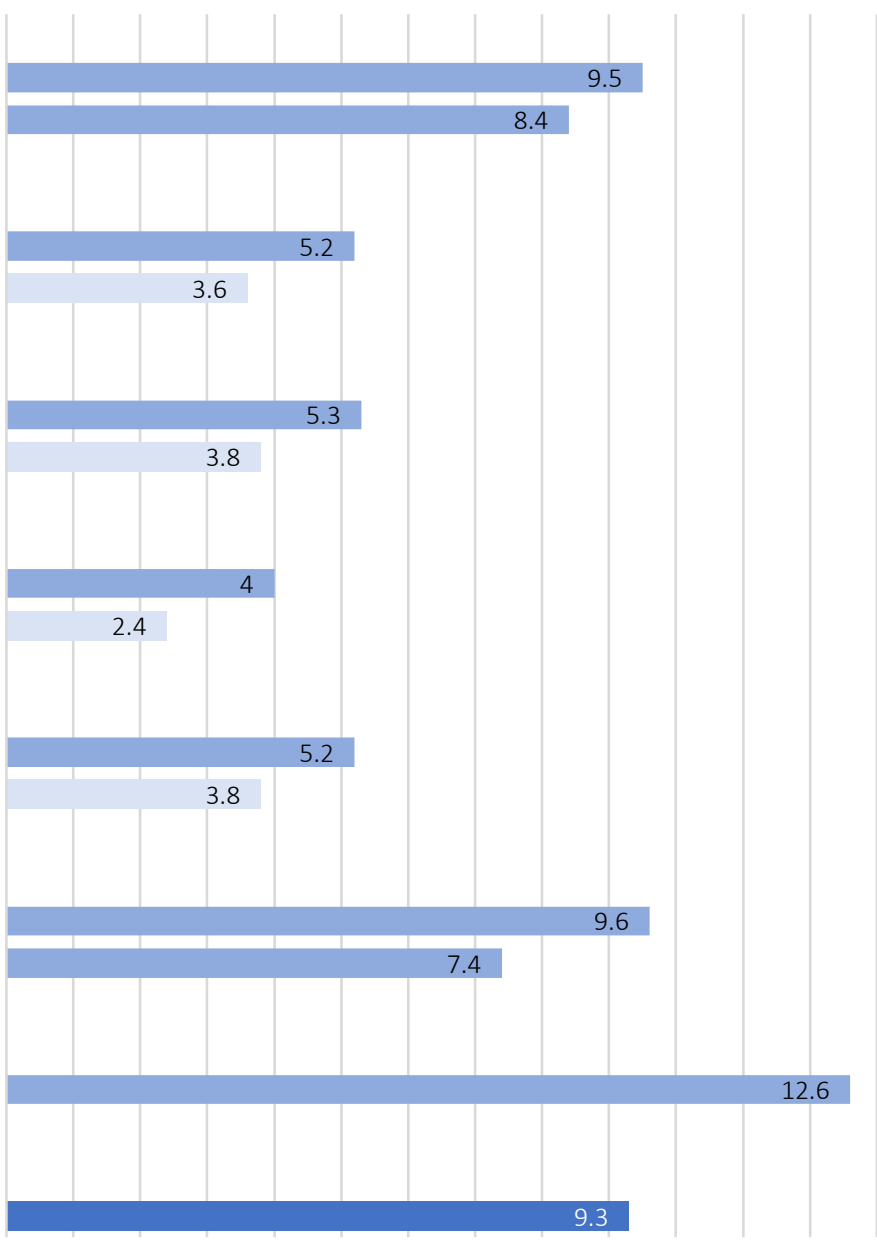

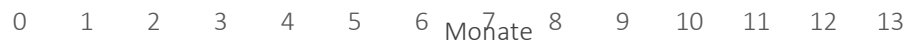

Abbildung 20: Medianes Overall Survival in Monaten in Studien zu Zweitlinientherapien bei fortgeschrittenem Magenkarzinom. 1. Paclitaxel versus Irinotecan (Hironaka et al. 2013), 2. Docetaxel versus Best Supportive Care (BSC) (Ford et al. 2014), 3. Docetaxel oder Irinotecan versus BSC (Kang et al. 2012), 4. Irinotecan versus BSC (Thuss-Patience et al. 2011), 5. Ramucirumab versus Placebo und BSC (Fuchs et al. 2014), 6. Ramucirumab und Paclitaxel versus Paclitaxel (Wilke et al. 2014), 7. Ramucirumab und Irinotecan (Satake et al. 2018), 8. Ramucirumab und FOLFIRI (eigenes Ergebnis).

Insbesondere aufgrund dieses Sachverhaltes ist es notwendig, weitere Zweitlinientherapieoptionen zu evaluieren. Für Patienten, die mit einer Taxan-haltigen Erstlinientherapie behandelt werden und hierunter einen Progress zeigen, ist der Nutzen einer Kombination von Ramucirumab und Paclitaxel als Zweitlinientherapie unklar. Das FOLFIRI-Schema beispielsweise beinhaltet mit Irinotecan ein Präparat, das in der Vortherapie dieser Patienten bisher nicht enthalten war. Im Rahmen einer Phase-Ib-Studie 
wurden sechs Patienten mit fortgeschrittenem und vortherapiertem Magenkarzinom mit Ramucirumab und Irinotecan behandelt (Satake et al. 2018). Ziel der Studie war die Bestimmung der maximalen verträglichen Dosierung durch schrittweise Reduktion der Startdosierung. Jedoch zeigten sich bereits mit der Startdosierung von Irinotecan (150 $\mathrm{mg} / \mathrm{m}^{2}$ ) und Ramucirumab (8 $\mathrm{mg} / \mathrm{kg}$ ) zweiwöchentlich keine dosislimitierenden Toxizitäten, sodass die maximale verträgliche Dosierung nicht erreicht wurde. Die Kombinationstherapie zeigte sich in der Studie aufgrund des milden Toxizitätsprofil gut verträglich. Drittgradige oder schwerere unerwünschte Ereignisse waren Neutropenie, Anämie und Hypertonie, welche mit je 17 Prozent Vorkommen ein Resultat vergleichbar mit der eigenen Untersuchung ergab. In Göttingen erhielten die Patienten Irinotecan im Rahmen von FOLFIRI in einer maximalen Dosis von $180 \mathrm{mg} / \mathrm{m}^{2}$ zweiwöchentlich. Das OS der kleinen Kohorte betrug 12,6 Monate (Abbildung 20, Studie 7) und vier von sechs Patienten erhielten im Anschluss eine weitere Chemotherapie.

In der aktuellen Studie RAMIRIS (EudraCT Nummer 2015-005171-24) werden die systemischen Kombinationstherapien Ramucirumab plus FOLFIRI und Ramucirumab plus Paclitaxel in einer zweitlinigen Behandlung nach Erstlinientherapie mit einem Platinderivat und Fluoropyrimidin, sowie gegebenenfalls einem Anthrazyclin oder Docetaxel, verglichen (Lorenzen et al. 2018). Als primärer Endpunkt wurde das OS nach sechs Monaten gewählt. Sekundär werden PFS, ORR und DCR, sowie die Inzidenz und Schwere von unerwünschten Ereignissen und subjektive Lebensqualität der Patienten betrachtet. Die Studie wurde im Mai 2017 begonnen und zum aktuellen Zeitpunkt wird als voraussichtlicher Endpunkt März 2021 angegeben. Eine Analyse der Subgruppen wird zeigen, ob die FOLFIRI-basierte Therapie mit Irinotecan als Medikament einer neuen Wirkstoffgruppe gegenüber der Paclitaxel-basierten Therapie bei Patienten mit einer Taxan-haltigen Erstlinienbehandlung, beispielsweise FLOT, einen signifikanten Überlebensvorteil bringt.

Diverse zielgerichtete Substanzen wurden in klinischen Phase-I- bis Phase-III-Studien beim fortgeschrittenen Magenkarzinom untersucht und bilden einen großen Fokus in der gegenwärtigen Forschung. Neben Trastuzumab sind in der Therapie von HER2-positiven Mammakarzinomen auch Pertuzumab und TDM-1 bereits zugelassen. In der Phase-IIIStudie JACOB wurde der Antikörper Pertuzumab, der an einer anderen Stelle als Trastuzumab an den HER2-Rezeptor bindet und die Dimerisation verhindert, bei HER2posititven Magenkarzinomen untersucht (Roviello und Generali 2018). Es konnte für die 
Kombinationstherapie Pertuzumab, Trastuzumab und Chemotherapie gegenüber Placebo, Trastuzumab und Chemotherapie kein signifikanter Überlebensvorteil nachgewiesen werden. TDM-1 ist ein Konjugat aus Trastuzumab und dem Zytostatikum DM-1. In der Therapie des Magenkarzinoms konnte in der GATSBY-Studie jedoch kein Vorteil gegenüber einer Taxantherapie gezeigt werden (Thuss-Patience et al. 2017). Der EGF-Rezeptor HER1 ist ein Mitglied derselben Tyrosinkinaserezeptor-Gruppe wie HER2 und kann die gleiche intrazelluläre Signalkaskade aktivieren. Allerdings konnte in Studien für die beiden EGFRAntikörper Cetuximab und Panitumumab kein Überlebensvorteil aufgezeigt werden (Lordick et al. 2013; Waddell et al. 2013).

Bevacizumab ist ein monoklonaler VEGF-a-Antikörper und ist bereits im Rahmen diverser Therapieregime für die Behandlung fortgeschrittener und metastasierter Tumorerkrankungen, unter anderem für Kolon-, Rektum- Mamma-, Bronchial- und Nierenzellkarzinome, zugelassen. In der AVAGST-Studie für Bevacizumab in Kombination mit Chemotherapie beim fortgeschrittenen Magenkarzinom konnte die Verlängerung der Gesamtüberlebenszeit als primärer Endpunkt nicht erreicht werden (Ohtsu et al. 2011). Allerdings waren das PFS und die ORR signifikant verlängert und in der Analyse der Subgruppen konnte für Patienten aus Nord- und Südamerika ein Überlebensvorteil nachgewiesen werden. Ein Erklärungsansatz für die insgesamt schwächere Wirksamkeit beim Magenkarzinom im Vergleich zu Ramucirumab wird im Rahmen der unterschiedlichen molekularen Ziele diskutiert. Während Bevacizumab nur an VEGF-a bindet verhindert Ramucirumab durch seine Bindung an den VEGFR-2 die Wirkung verschiedener VEGFs und unterbindet möglicherweise erfolgreicher die VEGF-rezeptorvermittelte Angiogenese (Hsieh und Tsai 2019).

Eine Phase-III-Studie hat den selektiven Inhibitor der Tyrosinkinase des VEGF-Rezeptors Apatinib als Drittlinientherapie bei fortgeschrittenem Magenkarzinom untersucht und eine signifikante Verlängerung der Gesamtüberlebenszeit gezeigt (Li et al. 2016).

Die intrazelluläre PI3K/Akt/mTOR Signalkaskade übermittelt Signale von Membranrezeptoren, zum Beispiel VEGFR, HER2 und EGFR, und reguliert so Proliferation und Apoptose der Zelle, sowie Differenzierung, Proteintranslation und Angiogenese. mTOR ist eine Serin/Threonin-Kinase und kann durch Everolimus gehemmt werden, welches zu einer Inhibition des PI3K/Akt/mTOR Signalweges führt. In Phase-III-Studien zur Gabe von Everolimus konnten für Patienten mit fortgeschrittenem Magenkarzinom weder im 
Vergleich zu BSC noch in Kombination mit Paclitaxel eine signifikante Verlängerung des Gesamtüberlebens als primärer Endpunkt erreicht werden (Ohtsu et al. 2013; Al-Batran et al. 2017a). Der Hepatozyten-Wachstumsfaktor bindet am Tyrosinkinaserezeptor c-MET und reguliert so über verschiedene intrazelluläre Signalwege unter anderem Zellproliferation, Invasion und Angiogenese (Catenacci et al. 2017; Shah et al. 2017). Eine hohe cMET-Expression wurde insbesondere bei Magenkarzinomen im fortgeschrittenen Stadium festgestellt und wird mit einer schlechteren Prognose assoziiert. Verschiedene zielgerichtete Substanzen, welche die c-MET Aktivität inhibieren, werden in Studien zur Behandlung des fortgeschrittenen Magenkarzinoms untersucht. Bisher konnte jedoch weder in Phase-III-Studien für Rilotumumab noch für Onartuzumab eine signifikante Verlängerung des Gesamtüberlebens durch eine c-MET-Inhibitortherapie gezeigt werden (Catenacci et al. 2017; Shah et al. 2017).

Ein vielversprechender Bestandteil gegenwärtiger Krebstherapieforschung ist die Immuntherapie mit Immun-Checkpoint-Inhibitoren. Das Immunsystem kann Tumorzellen erkennen und eliminieren, jedoch können Tumorzellen dem Immunsystem durch Entwicklung von Modulationsmechanismen entkommen (Pardoll 2012). Das Verständnis dieser Mechanismen führte zur Entwicklung neuer zielgerichteter Therapien, insbesondere Antikörper gegen das cytotoxic-T-lymphocyte-associated-Protein-4 (CTLA-4), das Programmed-cell-death-Protein 1 (PD-1) und den Programmed-cell-death-1-Ligand-1 (PDL1). Wenn der Ligand PD-L1 auf der Tumorzelle an PD-1 auf der Immunzelle bindet, wird die PD-1-Signalkaskade aktiviert und dadurch eine Immunantwort inhibiert. Durch das Unterbinden dieser Interaktion kann das Immunsystem Tumorzellen erkennen und angreifen. ATTRACTION-2, die erste Phase-III-Studie mit dem PD-1-Inhibitor Nivolumab, konnte für Patienten mit fortgeschrittenem Magenkarzinom oder Adenokarzinomen des gastroösophagealen Überganges im Rahmen einer Immuntherapie eine signifikante Verlängerung von PFS und OS zeigen (Kang et al. 2017). Pembrolizumab ist ein weiterer monoklonaler Antikörper gegen PD-1 und wurde bereits in den USA für die Drittlinientherapie von PD-L1 positiven fortgeschrittenen Magenkarzinomen zugelassen (Kim und Oh 2018). In einer der aktuellen klinischen Phase-III-Studie für diesen Antikörper wird die Erstlinientherapie mit Pembrolizumab für Patienten mit PD-L1-positiven und HER2negativen fortgeschrittenem Magenkarzinom oder Adenokarzinomen des gastro- 
ösophagealen Überganges in Monotherapie und in Kombination mit Cisplatin und einem Fluoropyrimidin untersucht (Tabernero et al. 2016).

\subsection{Zusammenfassung und Fazit}

Die Therapie des fortgeschrittenen Magenkarzinoms stellt insbesondere aufgrund der Heterogenität eine große Herausforderung dar. In den letzten Jahren konnten viele Fortschritte gemacht werden und erste molekular zielgerichtete Therapien etabliert werden.

Ramucirumab ist als VEGF-Rezeptor-2-Antikörper der einzige zugelassene, zielgerichtete Wirkstoff, welcher in Monotherapie und in Kombination im Rahmen einer Zweitlinientherapie einen Überlebensvorteil bei einer molekular unselektierten Population mit fortgeschrittenen Adenokarzinomen des Magens oder des ösophagogastralen Überganges zeigte. In der retrospektiven Studie an der Universitätsmedizin Göttingen zeigte sich die Kombination von Ramucirumab mit FOLFIRI als sichere Therapie mit einem akzeptablen Toxizitätsprofil und Wirksamkeit bei vorbehandelten Patienten. Bei standardmäßiger Erstlinientherapie mit dem Taxan-haltigen FLOT-Schema in Deutschland stellt die Kombination aus Ramucirumab und FOLFIRI eine sinnvolle Zweitlinientherapie dar, welche vermutlich wirksamer als eine Ramucirumab-Monotherapie ist. Eine Bestätigung der Ergebnisse wird durch die laufende RAMIRIS-Studie zu Ramucirumab plus FOLFIRI und Ramucirumab plus Paclitaxel erwartet.

Zusammenfassend lässt sich festhalten, dass zum aktuellen Zeitpunkt nach vielen klinischen Studien die VEGF-Rezeptor-Inhibition (Ramucirumab und Apatinib) beim fortgeschrittenen Magenkarzinoms, neben der PD-1/PD-L1-Inhibition (Nivolumab und Pembrolizumab) und für ausgewählte Patienten auch die HER2-Rezeptor-Inhibition (Trastuzumab), die einzige wirksame zielgerichtete Therapie ist und somit die Evaluation neuer Kombinationen aus diesen Substanzen gemeinsam mit Chemotherapeutika eine maßgebliche Rolle für die Erweiterung der Behandlungsmöglichkeiten fortgeschrittener Magenkarzinome und Adenokarzinome des ösophagogastralen Überganges spielt.

Für die zukünftige Therapie des fortgeschrittenen Magenkarzinoms gilt es, noch viele offene Fragen zu klären. Sollte zum Beispiel eine begonnene systemische Therapie bis zum Progress fortgeführt, auf eine Erhaltungsdosis umgestellt oder eine Therapiepause bei SD 
eingelegt werden? Inwiefern profitieren unterschiedliche ethnische Subgruppen von unterschiedlichen Therapien?

Weiterhin hat die Suche nach prädiktiven Biomarkern einen hohen Stellenwert und die Identifikation von molekularen Subtypen trägt zur Weiterentwicklung zielgerichteter Therapien bei. Idealerweise können Patienten in Zukunft individualisierter und entsprechend ihrer molekularen Tumoreigenschaften behandelt werden, sodass ein verlängertes Überleben und eine bessere Lebensqualität erreicht wird. 


\section{Zusammenfassung}

Das fortgeschrittene Magenkarzinom stellt eine epitheliale Neoplasie des Gastrointestinaltraktes dar, bei welcher zum Zeitpunkt der Diagnosestellung oft bereits eine Metastasierung stattgefunden hat. Die Behandlungsoptionen in dieser palliativen Situation sind meist medikamentöser Art und auf eine Symptomkontrolle, sowie in günstigen Fällen auf eine passagere Begrenzung des Tumorwachstums, ausgerichtet. Hierzu standen bislang verschiedene Chemotherapieprotokolle zur Verfügung, welche ungerichtet zytostatisch wirksam sind und in Abhängigkeit des Gesamtzustandes und der Komorbiditäten prinzipiell bei jedem Patienten mit Magenkarzinom eingesetzt werden können. Neue Entwicklungen identifizieren onkogene Signalwege, welche in der Progression des Magenkarzinoms von Bedeutung und die einer spezifischen Behandlung zugänglich sind. Die Evaluation von Kombinationen aus zielgerichteten Substanzen gemeinsam mit Chemotherapeutika spielt eine maßgebliche Rolle für die Erweiterung der Behandlungsmöglichkeiten fortgeschrittener Magenkarzinome und Adenokarzinome des ösophagogastralen Überganges.

Ramucirumab ist als VEGF-Rezeptor-2-Antikörper der einzige zugelassene, zielgerichtete Wirkstoff, welcher in Monotherapie und in Kombination im Rahmen einer Zweitlinientherapie einen Überlebensvorteil bei einer molekular unselektierten Population mit fortgeschrittenen Adenokarzinomen des Magens oder des ösophagogastralen Überganges zeigte. Im Rahmen dieser Promotionsarbeit wurde der Einsatz von Ramucirumab und FOLFIRI im Sinne einer molekular zielgerichteten Therapie beim fortgeschrittenen Magenkarzinom retrospektiv evaluiert. Es wurde ein Patientenkollektiv untersucht, dass im Zeitraum von 01.11.2015 bis zum 01.09.2017 an der Universitätsmedizin Göttingen mindestens eine Gabe des Antikörpers Ramucirumab in Kombination mit dem Chemotherapieregime FOLFIRI erhalten hat. Neben Daten zur Wirksamkeit dieser Kombinationstherapie wurden insbesondere auch unerwünschte Ereignisse und das Toxizitätsprofil dieser neuen, bisher nicht zugelassen Medikamentenkombination untersucht. Die Kombination von Ramucirumab mit FOLFIRI zeigte sich als sichere Therapie mit einem akzeptablen Toxizitätsprofil und Wirksamkeit bei vorbehandelten Patienten. Die Ergebnisse wurden mit klinischen Phase-III-Studien zum Einsatz von Ramucirumab beim fortgeschrittenen Magenkarzinom verglichen und interpretiert. Bei standardmäßiger Erstlinientherapie mit dem Taxan-haltigen FLOTSchema in Deutschland stellt die Kombination aus Ramucirumab und FOLFIRI eine sinnvolle 
Zweitlinientherapie dar, welche vermutlich wirksamer als eine RamucirumabMonotherapie ist. Eine Bestätigung der Ergebnisse wird durch die laufende RAMIRIS-Studie zu Ramucirumab plus FOLFIRI und Ramucirumab plus Paclitaxel erwartet. 


\section{Literaturverzeichnis}

Al-Batran SE, Hartmann JT, Probst S, Schmalenberg H, Hollerbach S, Hofheinz R, Rethwisch V, Seipelt G, Homann N, Wilhelm G et al. (2008): Phase III trial in metastatic gastroesophageal adenocarcinoma with fluorouracil, leucovorin plus either oxaliplatin or cisplatin: a study of the Arbeitsgemeinschaft Internistische Onkologie. J Clin Oncol Off J Am Soc Clin Oncol 26, 1435-1442

Al-Batran SE, Riera-Knorrenschild J, Pauligk C, Goetze TO, Hegewisch-Becker S, Seraphin J, Thuss-Patience PC, Kopp H-G, Dechow TN, Vogel A et al. (2017a): A randomized, double-blind, multicenter phase III study evaluating paclitaxel with and without RAD001 in patients with gastric cancer who have progressed after therapy with a fluoropyrimidine/platinum-containing regimen (RADPAC). J Clin Oncol 35, 4-4

Al-Batran SE, Pauligk C, Homann N, Schmalenberg H, Kopp HG, Haag GM, Luley Kim B, Schmiegel Wolff H, Folprecht G, Probst S et al. (2017b): LBA-008Docetaxel, oxaliplatin, and fluorouracil/leucovorin (FLOT) versus epirubicin, cisplatin, and fluorouracil or capecitabine (ECF/ECX) as perioperative treatment of resectable gastric or gastro-esophageal junction adenocarcinoma: The multicenter, randomized phase 3 FLOT4 trial (German Gastric Group at AIO). Ann Oncol 28

Allgemeine Terminologie und Merkmale unerwünschter Ereignisse v4.03 (CTCAE) Common Terminology Criteria for Adverse Events (CTCAE) Version 4.031 Deutsche Version 05/2016, DKFZ Heidelberg (2016)

Bang YJ, Cutsem EV, Feyereislova A, Chung HC, Shen L, Sawaki A, Lordick F, Ohtsu A, Omuro Y, Satoh T et al. (2010): Trastuzumab in combination with chemotherapy versus chemotherapy alone for treatment of HER2-positive advanced gastric or gastro-oesophageal junction cancer (ToGA): a phase 3, open-label, randomised controlled trial. The Lancet 376, 687-697

Brierley J, Gospodarowicz MK, Wittekind C (Hrsg.): TNM classification of malignant tumours. 8. Auflage; John Wiley \& Sons, Hoboken 2017

Catenacci DVT, Tebbutt NC, Davidenko I, Murad AM, Al-Batran SE, Ilson DH, Tjulandin S, Gotovkin E, Karaszewska B, Bondarenko I et al. (2017): Rilotumumab plus epirubicin, cisplatin, and capecitabine as first-line therapy in advanced METpositive gastric or gastro-oesophageal junction cancer (RILOMET-1): a randomised, double-blind, placebo-controlled, phase 3 trial. Lancet Oncol 18, 1467-1482

Chen HX, Cleck JN (2009): Adverse effects of anticancer agents that target the VEGF pathway. Nat Rev Clin Oncol $\underline{6}$, 465-477

Claesson-Welsh L, Welsh M (2013): VEGFA and tumour angiogenesis. J Intern Med 273, 114-127

Corso G, Seruca R, Roviello F (2012): Gastric cancer carcinogenesis and tumor progression. Ann Ital Chir 83, 172-176 
Dank M, Zaluski J, Barone C, Valvere V, Yalcin S, Peschel C, Wenczl M, Goker E, Cisar L, Wang K, Bugat R (2008): Randomized phase III study comparing irinotecan combined with 5-fluorouracil and folinic acid to cisplatin combined with 5fluorouracil in chemotherapy naive patients with advanced adenocarcinoma of the stomach or esophagogastric junction. Ann Oncol $\underline{19}, 1450-1457$

DKG S3-Leitlinie zur Diagnostik und Therapie der Adenokarzinome des Magens und ösophagogastralen Übergangs. (2012)

Eisenhauer EA, Therasse P, Bogaerts J, Schwartz LH, Sargent D, Ford R, Dancey J, Arbuck S, Gwyther S, Mooney M et al. (2009): New response evaluation criteria in solid tumours: revised RECIST guideline (version 1.1). Eur J Cancer Oxf Engl 1990 45, 228-247

Ford HER, Marshall A, Bridgewater JA, Janowitz T, Coxon FY, Wadsley J, Mansoor W, Fyfe D, Madhusudan S, Middleton GW et al. (2014): Docetaxel versus active symptom control for refractory oesophagogastric adenocarcinoma (COUGAR-02): an openlabel, phase 3 randomised controlled trial. Lancet Oncol 15, 78-86

Fuchs CS, Tomasek J, Yong CJ, Dumitru F, Passalacqua R, Goswami C, Safran H, Santos LV dos, Aprile G, Ferry DR et al. (2014): Ramucirumab monotherapy for previously treated advanced gastric or gastro-oesophageal junction adenocarcinoma (REGARD): an international, randomised, multicentre, placebo-controlled, phase 3 trial. The Lancet $\underline{383}, 31-39$

Gravalos C, Jimeno A (2008): HER2 in gastric cancer: a new prognostic factor and a novel therapeutic target. Ann Oncol 19, 1523-1529

Guimbaud R, Louvet C, Ries P, Ychou M, Maillard E, André T, Gornet JM, Aparicio T, Nguyen S, Azzedine A et al. (2014): Prospective, randomized, multicenter, phase III study of fluorouracil, leucovorin, and irinotecan versus epirubicin, cisplatin, and capecitabine in advanced gastric adenocarcinoma: A French Intergroup (Fédération Francophone de Cancérologie Digestive, Fédération Nationale des Centres de Lutte Contre le Cancer, and Groupe Coopérateur Multidisciplinaire en Oncologie) Study. J Clin Oncol 32, 3520-3526

Hironaka S, Ueda S, Yasui H, Nishina T, Tsuda M, Tsumura T, Sugimoto N, Shimodaira H, Tokunaga S, Moriwaki T et al. (2013): Randomized, open-label, phase III study comparing irinotecan with paclitaxel in patients with advanced gastric cancer without severe peritoneal metastasis after failure of prior combination chemotherapy using fluoropyrimidine plus platinum: WJOG 4007 Trial. J Clin Oncol 31, 4438-4444

Holmes DI, Zachary I (2005): The vascular endothelial growth factor (VEGF) family: angiogenic factors in health and disease. Genome Biol $\underline{6}, 209$

Hsieh AC, Moasser MM (2007): Targeting HER proteins in cancer therapy and the role of the non-target HER3. Br J Cancer 97, 453-457 
Hsieh HL, Tsai M-M (2019): Tumor progression-dependent angiogenesis in gastric cancer and its potential application. World J Gastrointest Oncol 11, 686-704

Kang JH, Lee SI, Lim DH, Park KW, Oh SY, Kwon HC, Hwang IG, Lee SC, Nam E, Shin DB et al. (2012): Salvage chemotherapy for pretreated gastric cancer: A randomized phase III trial comparing chemotherapy plus best supportive care with best supportive care alone. J Clin Oncol $\underline{30}$, 1513-1518

Kang YK, Kang WK, Shin DB, Chen J, Xiong J, Wang J, Lichinitser M, Guan Z, Khasanov R, Zheng L et al. (2009): Capecitabine/cisplatin versus 5 -fluorouracil/cisplatin as firstline therapy in patients with advanced gastric cancer: a randomised phase III noninferiority trial. Ann Oncol 20, 666-673

Kang YK, Satoh T, Ryu MH, Chao Y, Kato K, Chung HC, Chen JS, Muro K, Kang WK, Yoshikawa T et al. (2017): Nivolumab (ONO-4538/BMS-936558) as salvage treatment after second or later-line chemotherapy for advanced gastric or gastroesophageal junction cancer (AGC): A double-blinded, randomized, phase III trial. J Clin Oncol 35, 2-2

Kaplan EL, Meier P (1958): Nonparametric estimation from incomplete observations. J Am Stat Assoc 53, 457-481

Kim HJ, Oh SC (2018): Novel systemic therapies for advanced gastric cancer. J Gastric Cancer $\underline{18}, 1-19$

Lauren P (1965): The two histological main types of gastric carcinoma: Diffuse and socalled intestinal-type carcinoma. An attempt at a histo-clinical classification. Acta Pathol Microbiol Scand 64, 31-49

Li J, Qin S, Xu J, Xiong J, Wu C, Bai Y, Liu W, Tong J, Liu Y, Xu R et al. (2016): Randomized, double-blind, placebo-controlled phase III trial of apatinib in patients with chemotherapy-refractory advanced or metastatic adenocarcinoma of the stomach or gastroesophageal junction. J Clin Oncol Off J Am Soc Clin Oncol 34, 1448-1454

Lordick F, Kang YK, Chung HC, Salman P, Oh SC, Bodoky G, Kurteva G, Volovat C, Moiseyenko VM, Gorbunova V et al. (2013): Capecitabine and cisplatin with or without cetuximab for patients with previously untreated advanced gastric cancer (EXPAND): a randomised, open-label phase 3 trial. Lancet Oncol 14, 490-499

Lorenzen S, Thuss-Patience PC, Pauligk C, Goekkurt E, Ettrich TJ, Lordick F, Reichardt P, Stahl M, Kopp HG, Hegewisch-Becker S et al. (2018): FOLFIRI plus ramucirumab versus paclitaxel plus ramucirumab for patients with advanced or metastatic adenocarcinoma of the stomach or gastroesophageal junction as second-line therapy: The RAMIRIS study. J Clin Oncol 36, TPS4132

Lu D, Shen J, Vil MD, Zhang H, Jimenez X, Bohlen P, Witte L, Zhu Z (2003): Tailoring in vitro selection for a picomolar affinity human antibody directed against vascular endothelial growth factor receptor 2 for enhanced neutralizing activity. J Biol Chem 278, 43496-43507 
Nagini S (2012): Carcinoma of the stomach: A review of epidemiology, pathogenesis, molecular genetics and chemoprevention. World J Gastrointest Oncol 4, 156-169

Ohtsu A, Shah MA, Van Cutsem E, Rha SY, Sawaki A, Park SR, Lim HY, Yamada Y, Wu J, Langer B et al. (2011): Bevacizumab in combination with chemotherapy as first-line therapy in advanced gastric cancer: A randomized, double-blind, placebocontrolled phase III study. J Clin Oncol 29, 3968-3976

Ohtsu A, Ajani JA, Bai YX, Bang YJ, Chung HC, Pan HM, Sahmoud T, Shen L, Yeh KH, Chin K et al. (2013): Everolimus for previously treated advanced gastric cancer: results of the randomized, double-blind, phase III GRANITE-1 study. J Clin Oncol Off J Am Soc Clin Oncol 31, 3935-3943

Okines AFC, Asghar U, Cunningham D, Ashley S, Ashton J, Jackson K, Hawkes E, Chau I (2010): Rechallenge with platinum plus fluoropyrimidine + /- epirubicin in patients with oesophagogastric Cancer. Oncology 79, 150-158

Pardoll DM (2012): The blockade of immune checkpoints in cancer immunotherapy. Nat Rev Cancer 12, 252-264

Pennathur A, Gibson MK, Jobe BA, Luketich JD (2013): Oesophageal carcinoma. The Lancet 381, 400-412

Plosker GL, Faulds D (1993): Epirubicin. Drugs 45, 788-856

Prins MJD, Verhage RJJ, ten Kate FJW, van Hillegersberg R (2012): Cyclooxygenase isoenzyme-2 and vascular endothelial growth factor are associated with poor prognosis in esophageal adenocarcinoma. J Gastrointest Surg 16, 956-966

Robert Koch-Institut, Gesellschaft der epidemiologischen Krebsregister in Deutschland e.V. (Hrsg): Krebs in Deutschland für 2013/2014. 11. Ausgabe; Berlin 2017

Roviello G, Generali D (2018): Pertuzumab therapy for HER2-positive metastatic gastric or gastro-oesophageal junction cancer. Lancet Oncol 19, 1270-1272

Sakamoto J, Chin K, Kondo K, Kojima H, Terashima M, Yamamura Y, Tsujinaka T, Hyodo I, Koizumi W, Clinical Study Group of Capecitabine (2006): Phase II study of a 4-week capecitabine regimen in advanced or recurrent gastric cancer. Anticancer Drugs $\underline{17}$, 231-236

Satake H, Sagawa T, Fujikawa K, Hatachi Y, Yasui H, Kotaka M, Kato T, Tsuji A (2018): Phase Ib study of irinotecan and ramucirumab for advanced gastric cancer previously treated with fluoropyrimidine with/without platinum and taxane. Cancer Chemother Pharmacol 82, 839-845

Schulte N, Ebert MP, Härtel N (2015): Gastric cancer: New drugs - New strategies. Gastrointest Tumors 1, 180-194

Schütte J, Barth J: Zytostatische Chemotherapie. In: Hiddemann W, Bartram CR (Hrsg.): Die Onkologie. Springer, Berlin 2010, 401-436 
Shah MA, Bang YJ, Lordick F, Alsina M, Chen M, Hack SP, Bruey JM, Smith D, McCaffery I, Shames DS et al. (2017): Effect of fluorouracil, leucovorin, and oxaliplatin with or without onartuzumab in HER2-negative, MET-positive gastroesophageal adenocarcinoma. JAMA Oncol 3 , 620-627

Spechler SJ (2013): Barrett esophagus and risk of esophageal cancer: a clinical review. JAMA $\underline{310}, 627-636$

Tabernero J, Yoshino T, Cohn AL, Obermannova R, Bodoky G, Garcia-Carbonero R, Ciuleanu T-E, Portnoy DC, Cutsem EV, Grothey A et al. (2015): Ramucirumab versus placebo in combination with second-line FOLFIRI in patients with metastatic colorectal carcinoma that progressed during or after first-line therapy with bevacizumab, oxaliplatin, and a fluoropyrimidine (RAISE): a randomised, double-blind, multicentre, phase 3 study. Lancet Oncol 16, 499-508

Tabernero J, Bang YJ, Fuchs CS, Ohtsu A, Kher U, Lam B, Koshiji M, Van Cutsem E (2016): KEYNOTE-062: Phase III study of pembrolizumab (MK-3475) alone or in combination with chemotherapy versus chemotherapy alone as first-line therapy for advanced gastric or gastroesophageal junction (GEJ) adenocarcinoma. J Clin Oncol 34, TPS185

The Cancer Genome Atlas Research Network (2014): Comprehensive molecular characterization of gastric adenocarcinoma. Nature 513, 202-209

Thuss-Patience PC, Kretzschmar A, Bichev D, Deist T, Hinke A, Breithaupt K, Dogan Y, Gebauer B, Schumacher G, Reichardt P (2011): Survival advantage for irinotecan versus best supportive care as second-line chemotherapy in gastric cancer - A randomised phase III study of the Arbeitsgemeinschaft Internistische Onkologie (AIO). Eur J Cancer 47, 2306-2314

Thuss-Patience PC, Shah MA, Ohtsu A, Van Cutsem E, Ajani JA, Castro H, Mansoor W, Chung HC, Bodoky G, Shitara K et al. (2017): Trastuzumab emtansine versus taxane use for previously treated HER2-positive locally advanced or metastatic gastric or gastro-oesophageal junction adenocarcinoma (GATSBY): an international randomised, open-label, adaptive, phase 2/3 study. Lancet Oncol 18, 640-653

Torre LA, Bray F, Siegel RL, Ferlay J, Lortet-Tieulent J, Jemal A (2015): Global cancer statistics, 2012. CA Cancer J Clin 65, 87-108

Van Cutsem E, Moiseyenko VM, Tjulandin S, Majlis A, Constenla M, Boni C, Rodrigues A, Fodor M, Chao Y, Voznyi E et al. (2006): Phase III study of docetaxel and cisplatin plus fluorouracil compared with cisplatin and fluorouracil as first-line therapy for advanced gastric cancer: A report of the V325 study group. J Clin Oncol 24, 49914997

ter Veer E, Haj Mohammad N, van Valkenhoef G, Ngai LL, Mali RMA, van Oijen MGH, van Laarhoven HWM (2016): Second- and third-line systemic therapy in patients with advanced esophagogastric cancer: a systematic review of the literature. Cancer Metastasis Rev $\underline{35}$, 439-456 
Waddell T, Chau I, Cunningham D, Gonzalez D, Okines AFC, Frances A, Okines C, Wotherspoon A, Saffery C, Middleton G et al. (2013): Epirubicin, oxaliplatin, and capecitabine with or without panitumumab for patients with previously untreated advanced oesophagogastric cancer (REAL3): a randomised, open-label phase 3 trial. Lancet Oncol 14, 481-489

Wagner AD, Unverzagt S, Grothe W, Kleber G, Grothey A, Haerting J, Fleig WE (2010): Chemotherapy for advanced gastric cancer. The Cochrane database of systematic reviews 3 , CD004064

Wilke H, Muro K, Cutsem EV, Oh SC, Bodoky G, Shimada Y, Hironaka S, Sugimoto N, Lipatov O, Kim TY et al. (2014): Ramucirumab plus paclitaxel versus placebo plus paclitaxel in patients with previously treated advanced gastric or gastro-oesophageal junction adenocarcinoma (RAINBOW): a double-blind, randomised phase 3 trial. Lancet Oncol 15, 1224-1235

Wishart DS, Knox C, Guo AC, Shrivastava S, Hassanali M, Stothard P, Chang Z, Woolsey J (2006): DrugBank: a comprehensive resource for in silico drug discovery and exploration. Nucleic Acids Res 34, D668-D672

Yoon HH, Bendell JC, Braiteh FS, Firdaus I, Philip PA, Cohn AL, Lewis N, Anderson DM, Arrowsmith E, Schwartz JD et al. (2016): Ramucirumab combined with FOLFOX as front-line therapy for advanced esophageal, gastroesophageal junction, or gastric adenocarcinoma: a randomized, double-blind, multicenter Phase II trial. Ann Oncol Off J Eur Soc Med Oncol 27, 2196-2203

Young K, Smyth E, Chau I (2015): Ramucirumab for advanced gastric cancer or gastrooesophageal junction adenocarcinoma. Ther Adv Gastroenterol $\underline{8}$, 373-383 